\title{
ALO-85 \\ SAI-124-79-PGH \\ REVIEW OF LITERATURE ON THE \\ TMI ACCIDENT AND CORRELATION TO THE LWR SAFETY TECHNOLOGY PROGRAM
}

\author{
W. J. Miller \\ Prepared by \\ Science Applications, Inc. \\ 4328 Old William Penn Highway \\ Monroeville, Pennsylvania 15146 \\ Prepared for \\ U. S. Department of Energy \\ Sandia National Laboratories \\ Albuquerque, New Mexico 87185 \\ Sponsored by \\ U. S. Department of Energy \\ Division of Nuclear Power Development \\ Washington, D.C. 20545
}

Light Water Reactor Safety Technology Management Center

Work performed under Sandia Contract No. 13-6458

Submitted: September 1979

Printed: May 1980 


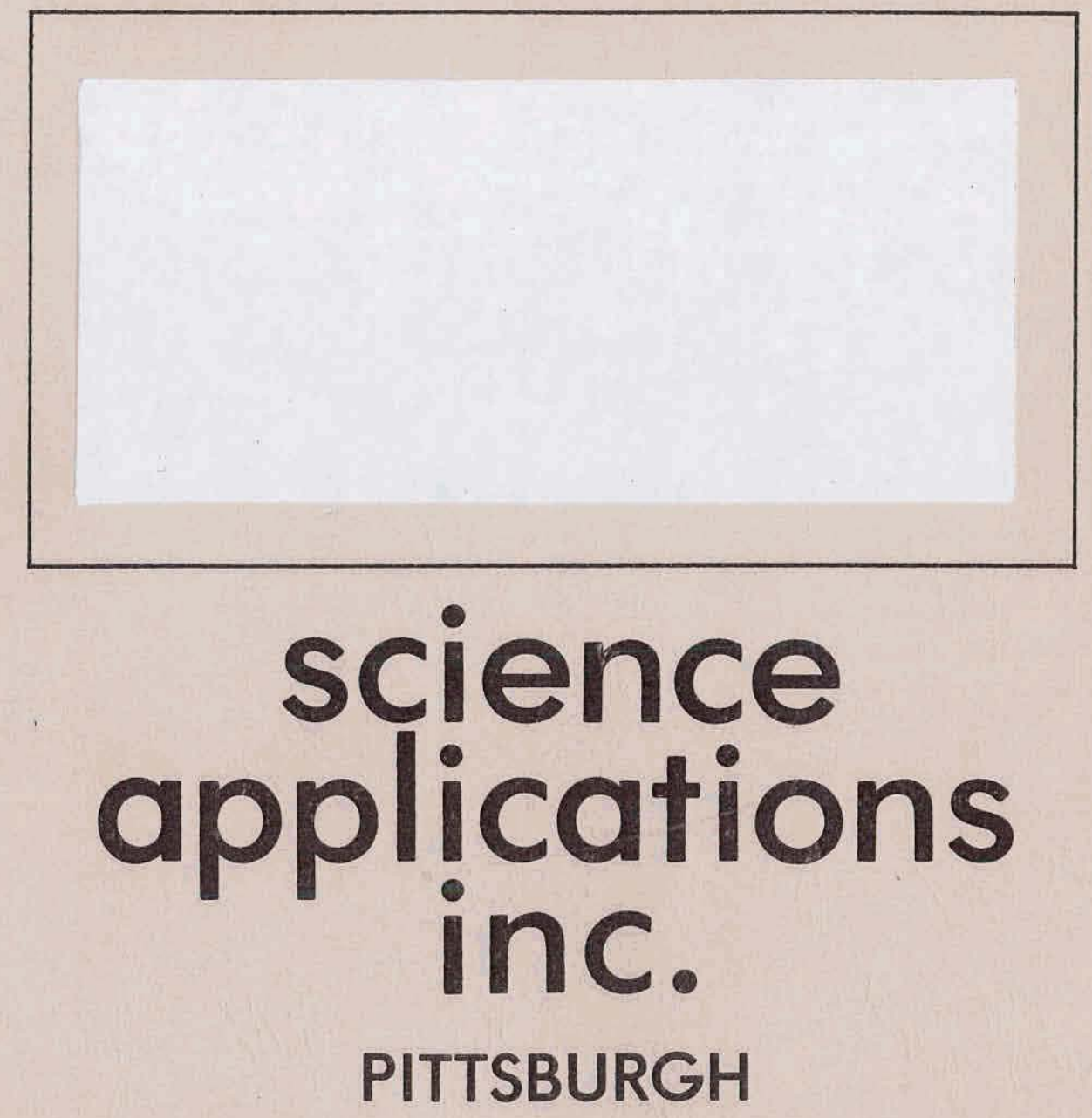




\section{DISCLAIMER}

This report was prepared as an account of work sponsored by an agency of the United States Government. Neither the United States Government nor any agency Thereof, nor any of their employees, makes any warranty, express or implied, or assumes any legal liability or responsibility for the accuracy, completeness, or usefulness of any information, apparatus, product, or process disclosed, or represents that its use would not infringe privately owned rights. Reference herein to any specific commercial product, process, or service by trade name, trademark, manufacturer, or otherwise does not necessarily constitute or imply its endorsement, recommendation, or favoring by the United States Government or any agency thereof. The views and opinions of authors expressed herein do not necessarily state or reflect those of the United States Government or any agency thereof. 


\section{DISCLAIMER}

Portions of this document may be illegible in electronic image products. Images are produced from the best available original document. 
NOTICE

This report was prepared as an account of work sponsored by an agency of the United States Government. Neither the United States nor any agency thereof, nor any of their employees, makes any warranty, expressed or implied, or assumes any legal liability or responsibility for any third party's use or the results of such use of any information, apparatus, product or process disclosed in this report, or represents that its use by such third party would not infringe privately owned rights.

Printed in the United States of America

Available from

National Technical Information Service

$\mathrm{U}$. S. Department of Commerce

5285 Port Royal Road

Springfield, VA 22161

Price: Printed Copy $\$ 9.25$; Microfiche $\$ 3.00$ 
TABLE OF CONTENTS

SECTION

PAGE

1.0 INTRODUTION

1.1 Summary Conclusions

1.2 Specific Conclusions and Recommendations

$1-0$

$1-1$

$1-2$

2.0 MAJOR REPORTS ISSUED IN RELATION TO TMI-2 ACCIDENT

2.1 NUREG-0600

$2-1$

2.1.1 Purpose and Scope

2-1

2.1.2 Summary of Content

$2-2$

2.1.3 Current Status

$2-3$

$2-4$

2.2.1 Purpose and Scope

2.2.2 Summary of Content

2.3 NUREG-0558

2.3.1 Purpose and Scope

2.3.2 Summary of Content

$2-4$

$2-4$

$2-6$

$2-6$

2.3.3 Current Status

$2-6$

$2-6$

$2-8$

$2-8$

2.4.1 Purpose and Scope

2-9

2.4.2 Summary of Content

$2-9$

2.4.3 Current Status

2.5 NUREG-0557

$2-11$

2.5.1 Purpose and Scope

$2-11$

2.5.2 Summary of Content

$2-11$

2.5.3 Current Status

$2-11$

2.6 NUREG-0560

$2-12$

2.6.1 Purpose and Scope

$2-12$

2.6.2 Summary of Content

$2-13$

2.6.3 Current Status

$2-14$

2.7. NUREG-0625

$2-15$

2.7.1 Purpose and Scope

$2-15$

2.7.2 Summary of Content

$2-16$

3.0 DETAILED CORRELATIONS

3.1/2 Valves and Relief Valves

3.1.1 Summary of Research Project

$3-1$

3.1.2 Relevant TMI Events and Actions

$3-1$

3.1.3 Required or Suggested Action

$3-9$

3.1.4 Relation to Sandia Research Program

3-13 
3.3 Pumps

3.3.1 Summary of Research Project

3.3.2 Relevant TMI Events and Actions

$3-14$

3.3.3 Required or Suggested Corrective Action

$3-14$

3.3 .4

Relation to Sandia Research Program

$3-20$

$3-21$

3.4 Steam Generators

3.4.1 Summary of Research Project:

3.4.2 Related TMI Events and Actions

3.4.3 Required or Suggested Corrective Action

3.4 .4

Relation to Sandia Research Programs

$3-24$

$3-28$

$3-29$

$3-31$

$3-31$

3.5.1 Summary of Sandia Research Program

$3-31$

3.5.2 Relevant TMI Events and Actions

$3-32$

3.5.3 Required or Suggested Corrective Action

$3-33$

3.5.4 Relationship to Sandia Research Program

3.6 Unresolved NRC Safety Issues

3.7 Fuel Performance
3.7.1 Summary of Sandia Research Program

3.7.2 Relevant TMI Events and Actions

3.7.3 Required or Suggested Corrective Action

$3-34$

$3-35$

$3-35$

$3-35$

3.7.4 Relationship to Sandia Research Program

$3-38$

$3-41$

$3-43$

3.8 Shutdown Cooling System Performance

3.8.1 Summary of Sandia Research Program

$3-43$

3.8.2 Relevant TMI Events and Actions

$3-55$

3.8.3 Required or Suggested Corrective Action

$3-58$

3.8.4 Relationship to Sandia Research Program

$3-59$

3.9 Containment Function and Systems

$3-59$

3.9.1 Summary of Research Program

3.9.2 Relevant TMI Events and Actions

$3-59$

3.9.3 Required or Suggested Corrective Action

$3-62$

3.9.4 Relationship to Sandia Research Program

3.10 Test and Maintenance

$3-64$

$3-66$

3.10.1 Summary of Sandia Research Program

$3-66$

3.10.2 Relevant TMI Events and Actions

$3-66$

3.10.3 Required or Suggested Action

$3-68$

3.10.4 Relationship to Sandia Research Program

3.11/ Emergency and Disturbance Control

$3.11 /$ Summary of Research Program

12.1

3.11/ Relevant TMI-2 Events and Actions

3-72 $12.2^{\circ}$ 
3.11/ Required or Corrective Action

12.3

3.13 Design Guidance

$3-79$

3.14 Emergency Response

$3-81$

3.14.1 Summary of Sandia Research Program

$3-81$

3.14.2 Relevant TMI Events and Actions

$3-81$

3.14.3 Required or Suggested Corrective Action

$3-86$

3.14.4 Relationship to Sandia Research Program

$3-91$

3.15 Siting

3.15.1 Summary of Sandia Research Program

$3-92$

3.15.2 TMI-Related Studies and Findings

$3-92$

3.15.3 Relationship to Sandia Research Program

$3-92$

3.16 Risk Method Utilization

$3-94$

3.16.1 Summary of Sandia Research Program

$3-96$

3.16.2 Post-TMI REcommendations

$3-96$

3.16.3 Relationship to Sandia Research Program

$3-96$

$3-100$

4.0 REFERENCES AND SELECTED RELEVANT MATERIAL

4-1

References

Additional Relevant Material

$4-1$

$4-3$

4.1/2 Material

$4-5$

4.3 Material

$4-76$

4.4 Material

$4-18$

4.8 Material

$4-35$

4.9 Material

$4-38$

4.11/12 Material

$4-43$

4.14 Material

$4-51$

Appendix A 


\section{I.0 INTRODUCTION}

This report is the result of approximately two man-months of effort devoted to assimilating ard comprehending significant publicly available material related to Three Mile Island Unit 2 and events during and subsequent to the accident experienced on March 28, 1979. Those events were then correlated with the Preliminary LWR Safety Technology Program Plan (Preliminary Prograil Plan) prepared for the U.S. Department of Energy by Sandia National Lab. This report is being submitted simultaneously with the SAI report entitled "Preliminary Prioritization of Tasks in the Draft LWR Safety Technology Program Plan".

The Preliminary Program Plan tasks have been organized into sixteen research programs as explained in the above mentioned Preliminary Prioritization Report. Similarly, the TMI -2 materials presented herein are correlated to these sixteen research programs.

In the six months since the TMI-2 accident, thousands of man-years of effort have been devoted to understanding, evaluating, directing, publishing and speculating on TMI -2 related areas. It is not the intent of this report to be complete in reporting a 11 activities, opinions and studies that are in process or completed, nor is it intended to introduce additional opinions and speculation. It is the intent of this report to relate TMI-2 documentation and subsequent actions to the Sandia program plan. Therefore, the specific purpose of this correlation is to assist structuring and prioritizing the individual research programs.

This report is organized into four major sections and one appendix. Section $l^{\prime}$ includes this Introduction, Summary Conclusions and Specific , Conclusions. Section 2 presents a synopsis of each major report of study relied upon in preparation of this report. Section 3 presents the details 
of TMI events directly applicable to each of the 16 research programs and correlates findings, results and recommendations issued to date to each program. Section 4 provides copies of major findings and recommendations from reports referenced in the Section 3 discussions, provides references used throughout this report, and identifies additional relevant background material.

In addition, an Appendix $A$ is provided which identifies entities involved in TMI related activities in a very general fashion.

1.1 SUMMARY CONCLUSIONS

It is apparent that the TMI-2 accident has initiated a thorough evaluation of all aspects of the safety of commercial nuclear reactors in the United States. In general, major areas of this evaluation include:

1. Specific structure, system, and component design

2. Design philosophies

3. Construction and maintenance practices

4. Operational responsibilities from those of maintenance to senior management

5. Regulatory involvement in the process

6. Emergency roles and responsibilities of individuals and organizations

7. The ability of these entities to fulfill those responsibilities 
8. Financial questions dealing with liability, insurance and the structure of a regulated industry

9. The maturity of the technology

10. The circumstances and criteria under which commercial reactors can and should be operated

11. The advisability of a continued commercial nuclear program.

Minor and major changes are expected to continue for an extended period of time as a result of this evaluation process. A spectrum of activities that need to be pursued, studies that need to be performed, and techniques and technology that need to be expanded have and will emerge. Many of these are not new, rather the present circumstances are renewing emphas is and urgency. The Sandia program plan provides a means to answer questions, develop technology and techniques and pursue studies in response to many of these needs.

Although the program plan is preliminary, the conclusion of this study is that it is comprehensive. Indeed, rather few recommendations in this report relate to additional areas of emphasis. In some instances, recommendations are presented for modification or expansion of subject areas or topics currently included in the Preliminary Program Plan. In general, however, comments are not offered on the extent or depth of discussion of subject areas or topics within the Plan in recognition of its preliminary nature.

\subsection{SPECIFIC CONCLUSIONS AND RECOMMENDATIONS}

The attached Tabies 3.1 through 3.17 present a correlation of TMI-2 events and related actions to the Sandia Research Program. These Tables indicate if TMI events and actions support the summarized Sandia objectives or if TMI support is inconclusive. The suggested Sandia Program modifications re- . lated to TMI are identified in Table 3.18. Subjects and topics which suggested themselves during this review, aside from TMI-2 events and actions, have also been included in Table 3.18 . 
TABLE 3.1

Research Program - 1. Valves \& 2. Safety/Relief Valves

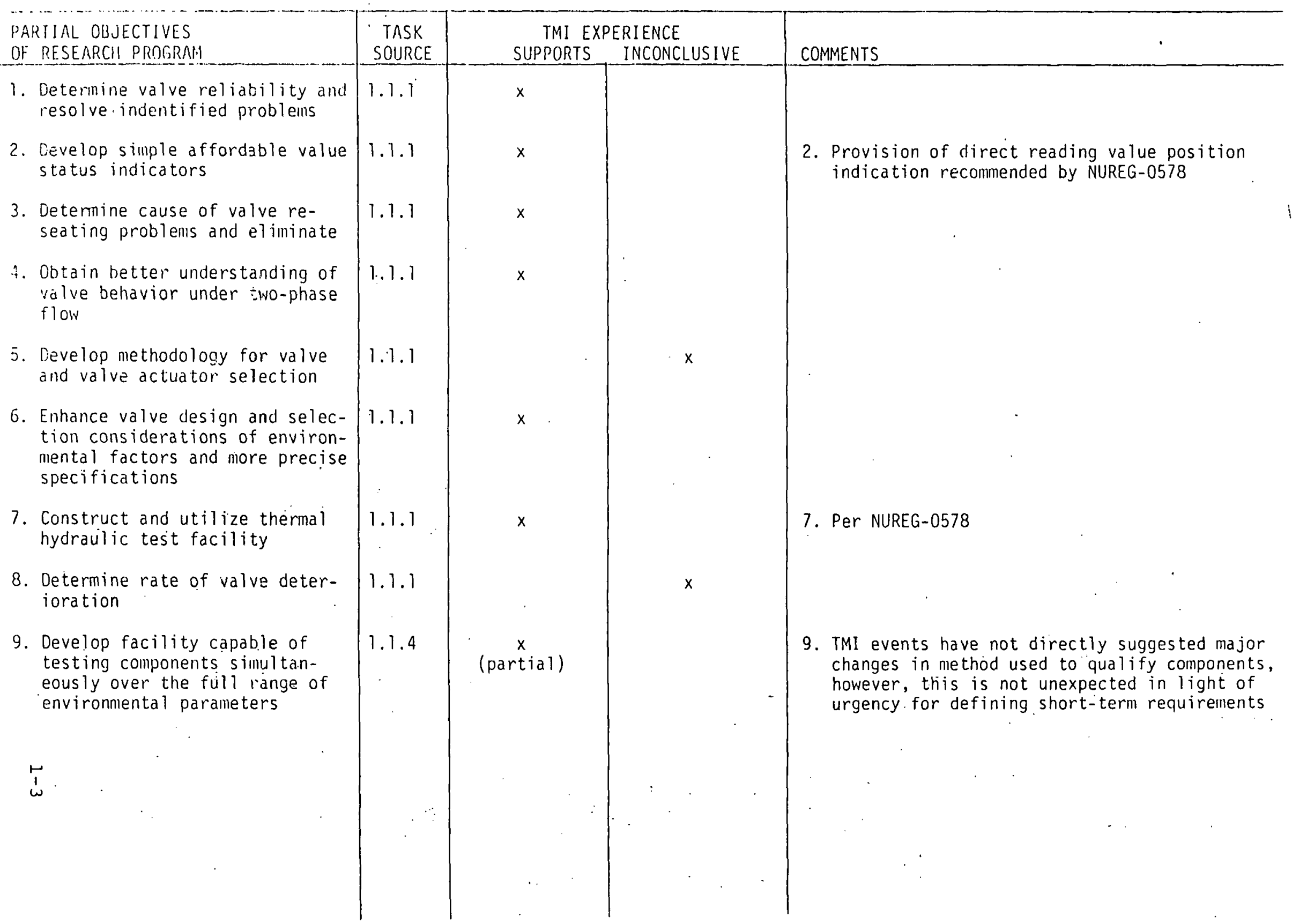


TABLE $3: 3$

Research Program - 3. Pumps

1. Develop variable speed reactor coolant pumps

2. Improve understanding of hydrodynamic instabilities and improve pump rotor design

3. Determine advisability of leak collection systems for pump seals

4. Determine and improve performance under accident conditions

5. Environmental qualification in suitable test facility

\section{TMI EXPERIENCE}

SUPPORTS INCONCLUSIVE

$x$

1.1 .2

1.1 .2

1.1 .2

1.1 .4

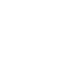

$x$

$x$
COMMENTS

1/2. Indirect support for these objectives is apparent in the problems encountered with TMI reactor coolant pumps, al though the fact remains that insufficient coolant inventory was the problem leading to core damage

3. Seal leakage contributed to radioactive releases as noted in Section 3.3

5. See Valves, Item 9 
TABLE 3.4

Resear.ch Program - 4. Steam Generators

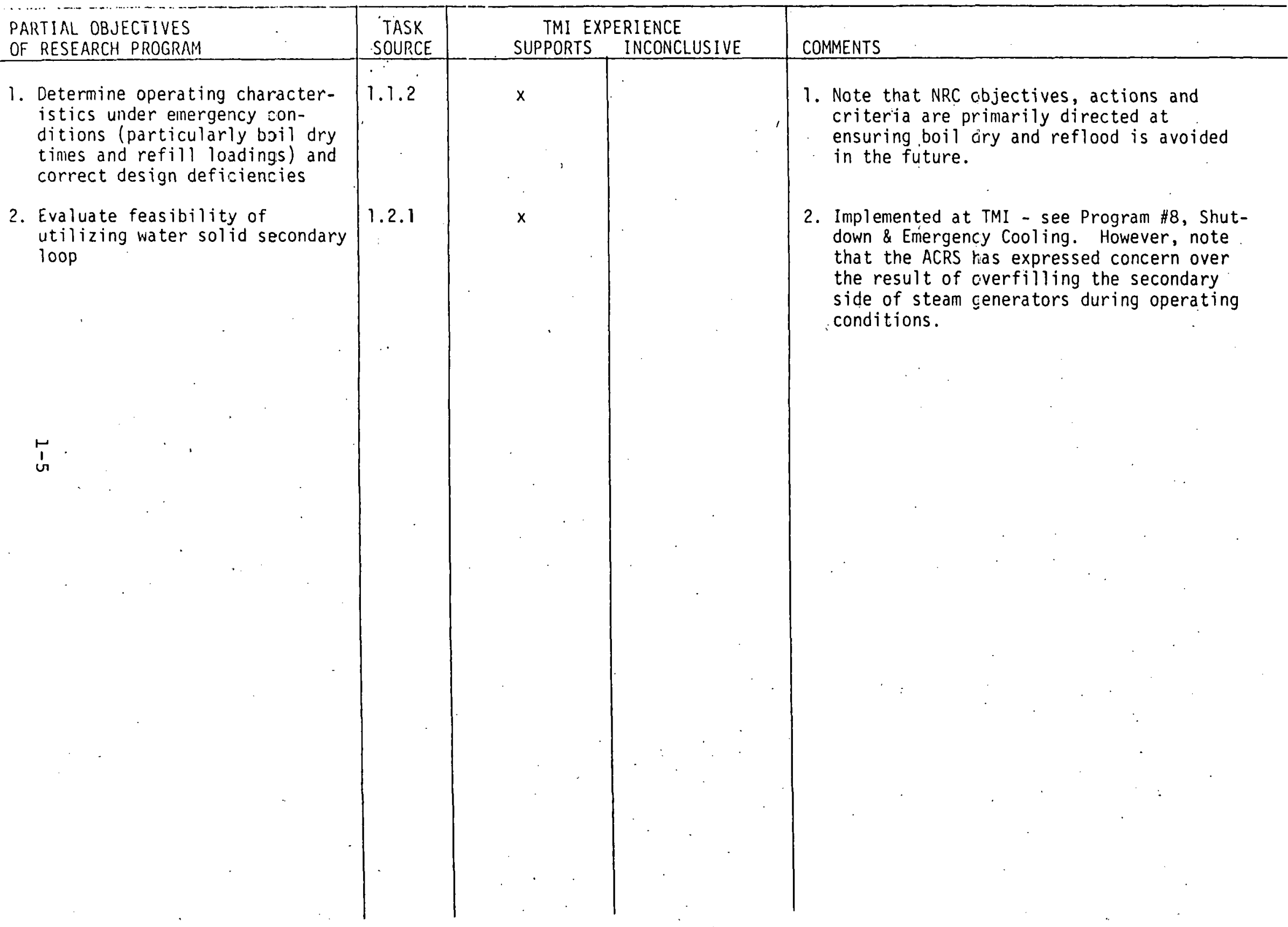


TABLE 3.5

Research Program - 5. Piping

PARTIAL OBJECTIVES

OF RESEARCH PROGRAM

1. Improve definition and control of operating environments

2. Environmental qualification in suitable multi-parameter test facility

3. Develop advanced fracture mechanics, understanding and prediction techniques. Study subcritical crack growth and propagation:

4. Develop improved techniques for modeling and analyzing fluid structure interaction

5. Develop and verify improved ISI $1.3 .2(6)$ TMI EXPERIENCE SUPPORTS INCONCLUSIVE

COMMENTS techniques

ตั 
TABLE 3.6

Research Program - 6. NRC Unresolved Safety Issues

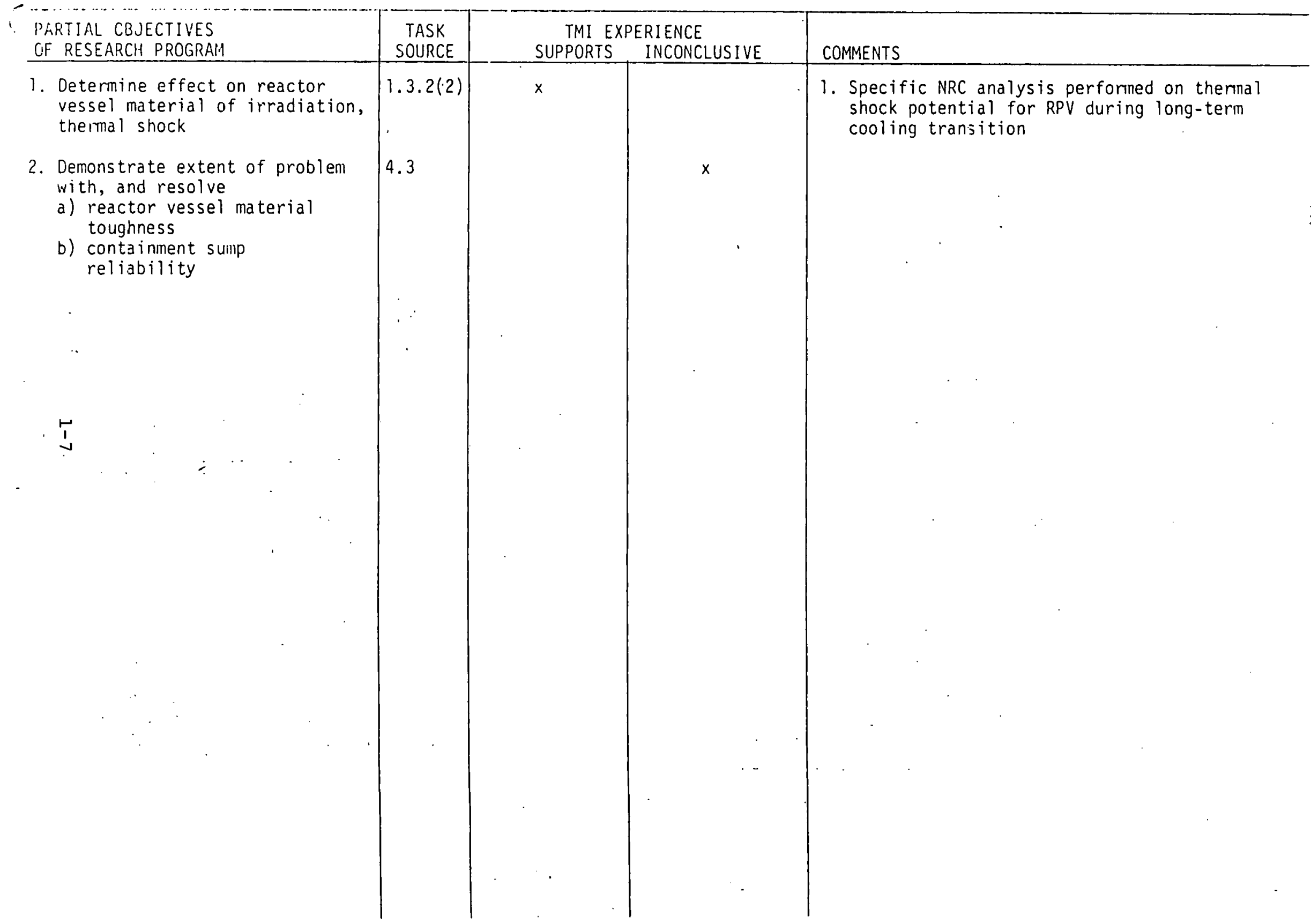


TABLE 3.7

Research Program - 7. Fuel

PARTIAL OBJECTIVES
OF RESEARCH PROGRAM

1. Resolve problems with fuel behavior due to stress corrosion cracking, PCI.

2. Develop design methodology for creep collapse fuel-clad therma ratcheting strain cycling, long term irradiation effects and in-service flaws.

3. Evaluate core cooling and heat transfer during partial core coverage, flow blockage, void generation, etc. Develop submodels for core damage events.

4. Understand DNB phenomena and utilize knowledge to evaluate necessary fuel operating constraints.

•
TMI EXPERIENCE

SUPPORTS INCONCLUSIVE

$x$

1.3
1
4

3. Development of models is an important activity and is worthy of expanded discussion.

4. Indirect relationship to TMI. The knowledge gained may alter operational characteristics or cooling system design, hence is pertinent. 
TABLE 3.8

Research Program - 8. Shutdown and Emergency Cooling

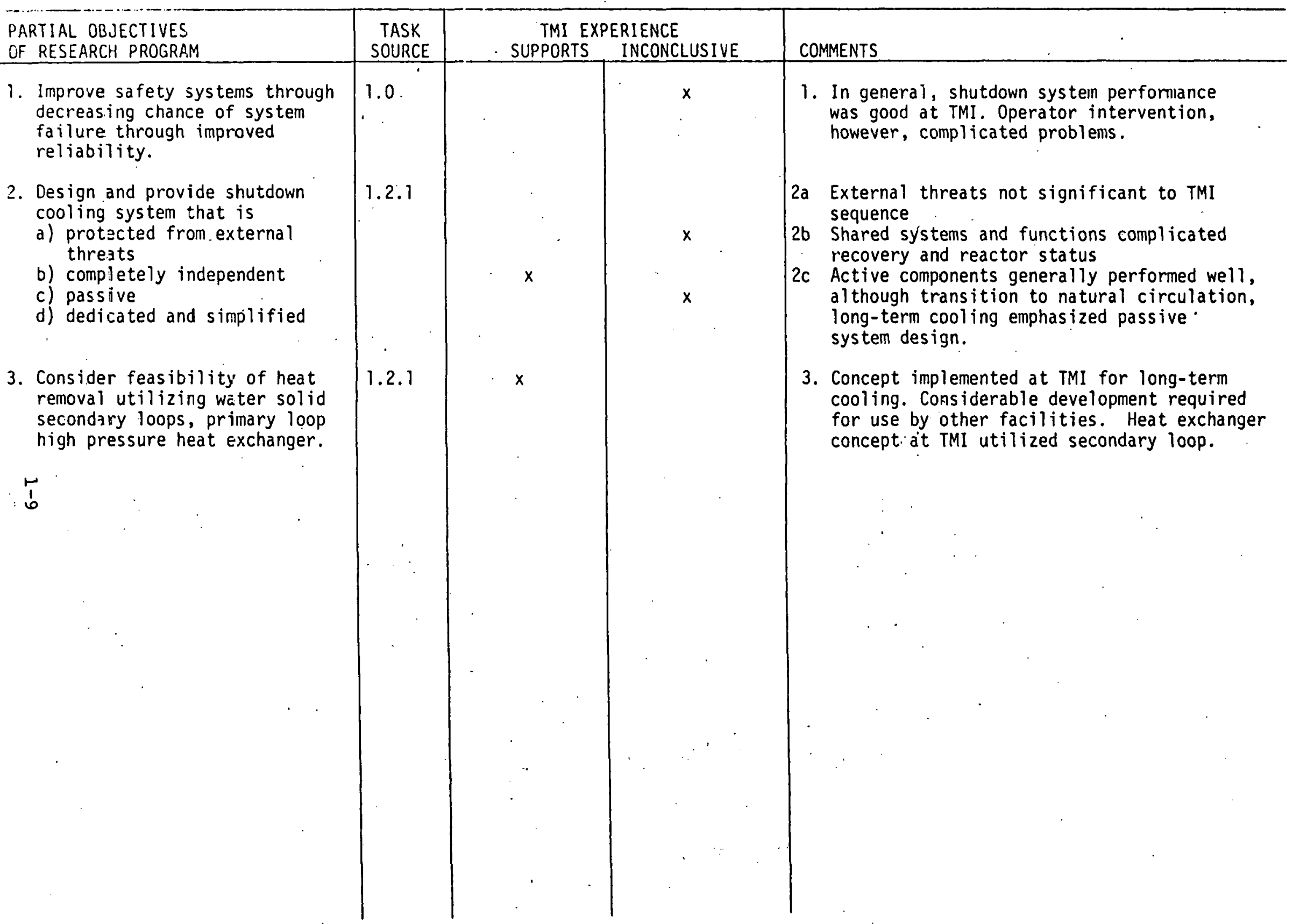


TABLE 3.9

esearch Program - 9. Containment Functions and Systems

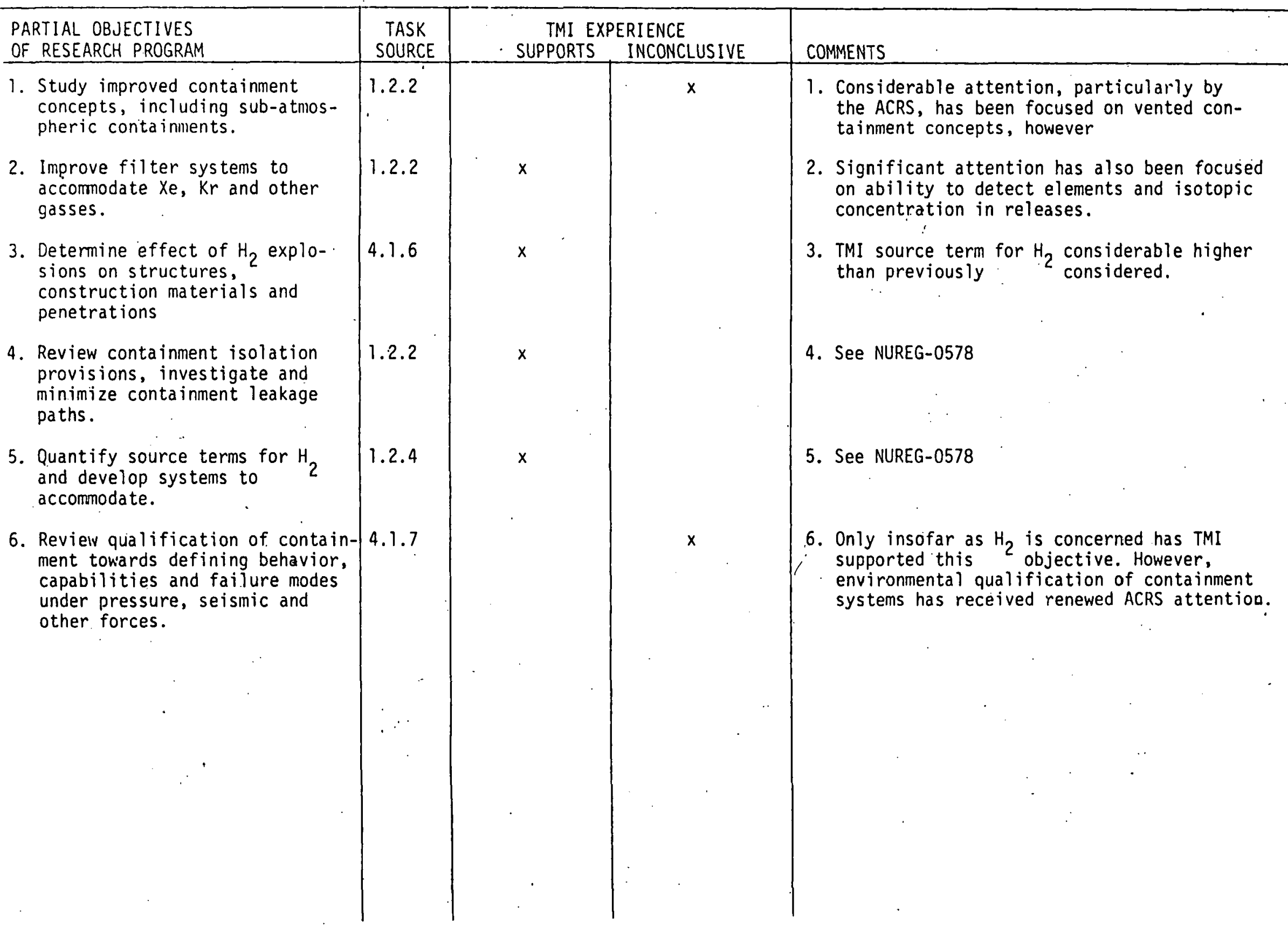


TABLE 3.10

Research Program - 10. Test and Maintenance

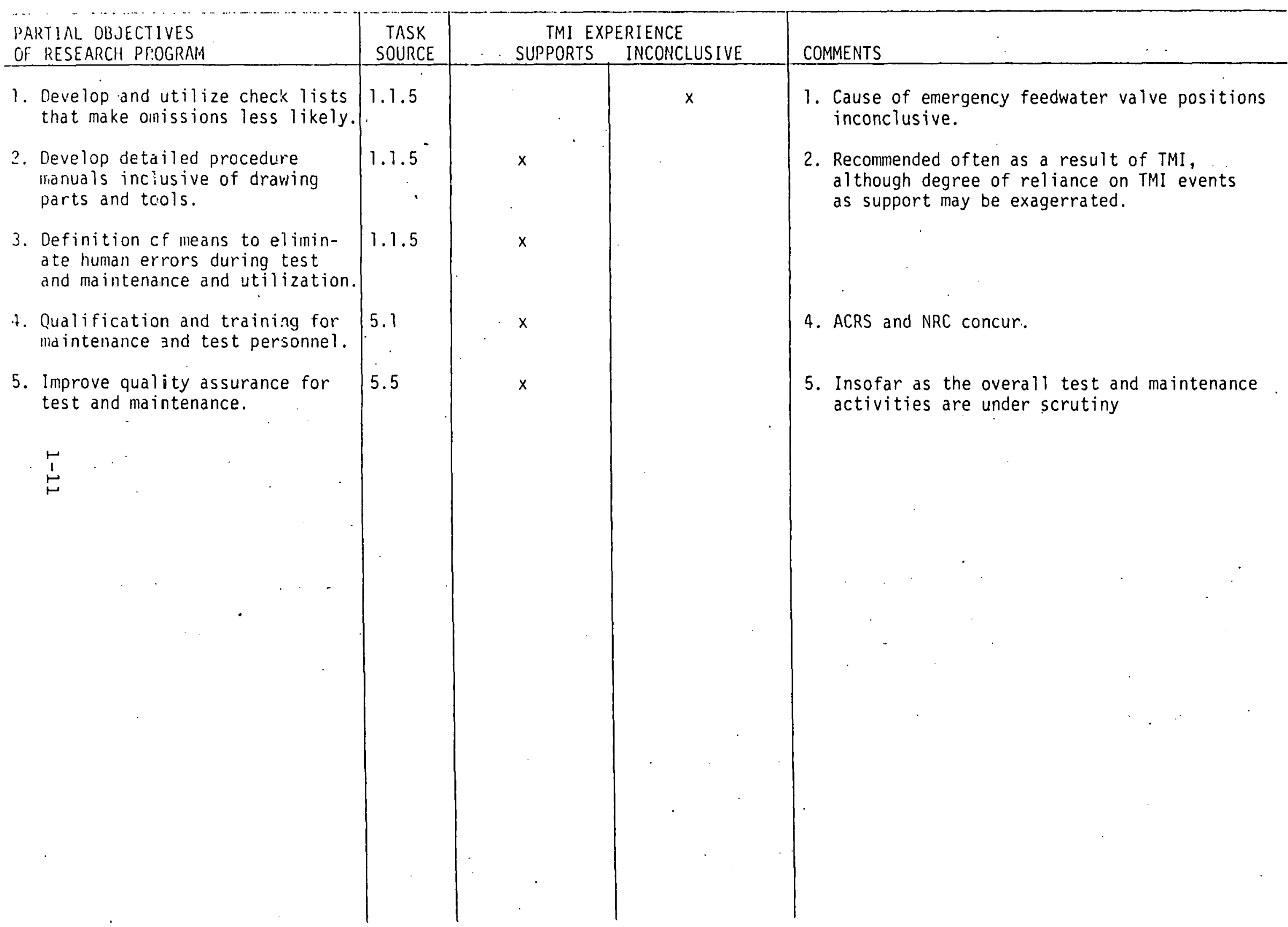


TABLE 3.11

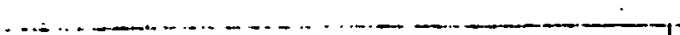

PARTIAL OBJECTIVES

OF RESEARCH PROGRAM

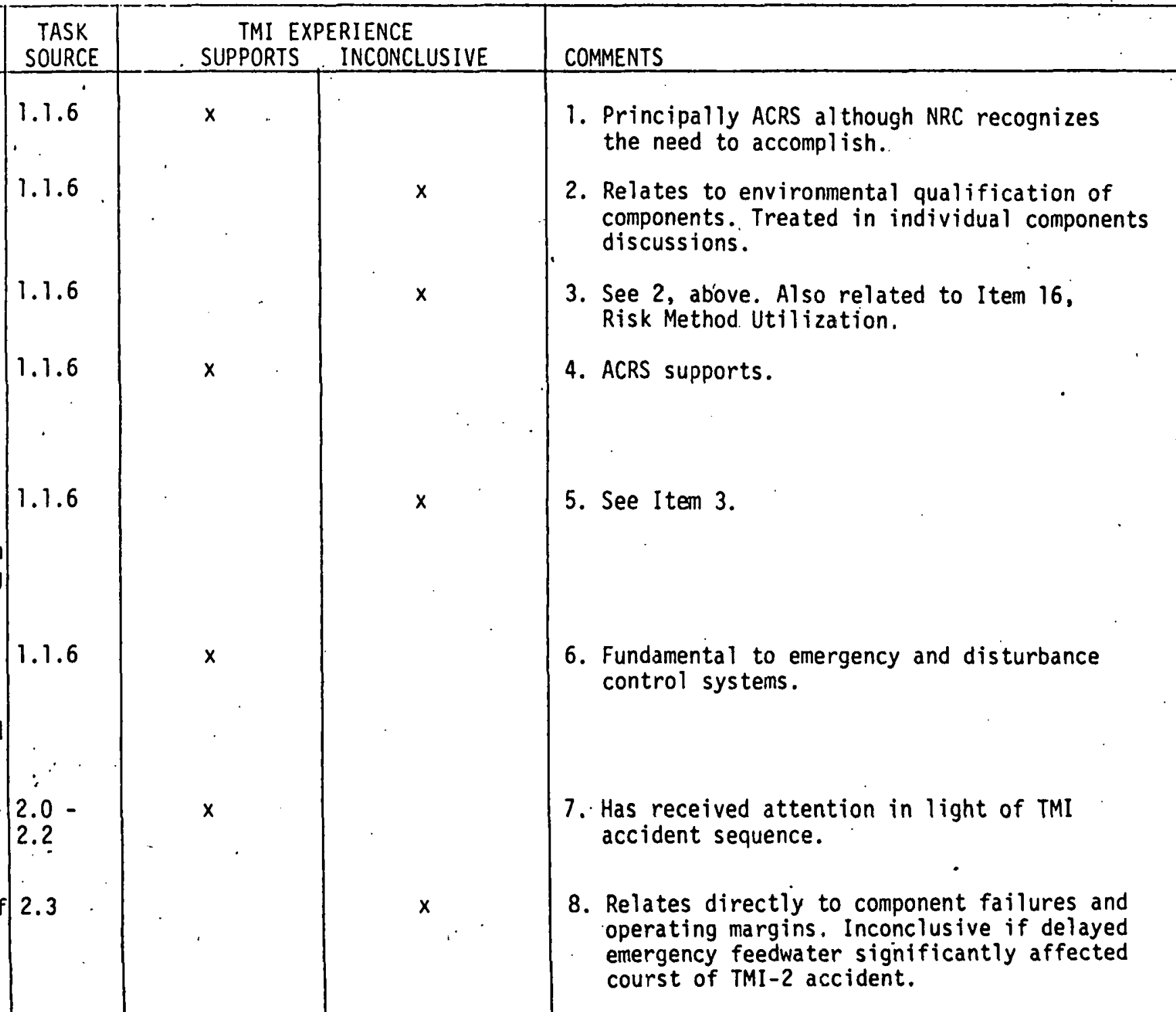


Research Program $11 / 12$ (continued)

\begin{tabular}{|c|c|c|c|c|}
\hline $\begin{array}{l}\text { PrRTIAL OB.JECTIVES } \\
\text { FESEARCA PROGRAM }\end{array}$ & $\begin{array}{l}\text { TASK } \\
\text { SOUURCE }\end{array}$ & $\begin{array}{r}\text { TMI E } \\
\text { SUPPORTS } \\
\end{array}$ & $\begin{array}{l}\text { RIENCE } \\
\text { INCONCLUSIVE }\end{array}$ & COMMENTS \\
\hline $\begin{array}{l}\text { 9. Frovide operator information on } \\
\text { lilargins in safety systems } \\
\text { parameters during various } \\
\text { operating conditions. }\end{array}$ & 2.5 & & $x$ & $\begin{array}{l}\text { 9. In general, the TMI experience does support } \\
\text { need, but literature reviewed to date does } \\
\text { not specifically state this objective. }\end{array}$ \\
\hline $\begin{array}{l}\text { 3. Iimprove control room efficiency } \\
\text { through evaluation of annuncia- } \\
\text { tors, controls (sizing, loca- } \\
\text { tion) and instrumentation and } \\
\text { improving design in these areas. }\end{array}$ & 5.2 & $x$ & & $\begin{array}{l}\text { 10. Many examples have been identified for } \\
\text { needed improvements. }\end{array}$ \\
\hline $\begin{array}{l}\text { 1. Improve modeling techniques and } \\
\text { utilize in understariding and } \\
\text { respond ing to accident sequences } \\
\text { and tramsients. }\end{array}$ & $\begin{array}{l}4.1 .1 \\
4.1 .2 \\
4.2\end{array}$ & $x$ & & $\begin{array}{l}\text { 11. Necessary for development of systems which } \\
\text { predict or recommend actions and consequences } \\
\text { ACRA and NRC require more modeling. }\end{array}$ \\
\hline $\begin{array}{l}\text { 2. Upgrade operator training and } \\
\text { certification utilizing psyco- } \\
\text { logical profiles, aptitudes } \\
\text { and qualifications. }\end{array}$ & 5.1 & $x$ & & $\begin{array}{l}\text { 12. Operator training, like some other areas, is } \\
\text { an area amenable to non-technical individ- } \\
\text { ual's criticism. }\end{array}$ \\
\hline $\begin{array}{l}\text { 3. Utilization of seasoned individ- } \\
\text { uals in each plant shift. }\end{array}$ & 5.1 & $x$ & & 13. Per NUREG-0578 \\
\hline $\begin{array}{l}\text { - Improve operating procedures and } \\
\text { diagnostics. Quantify human } \\
\text { failure rates under stress and } \\
\text { factor into design process. }\end{array}$ & $\begin{array}{l}5.3 \\
5.4\end{array}$ & $x$ & . & $\begin{array}{l}\text { 14. Procedural review and improvement recognized } \\
\text { required for all reactors. (See ACRS } \\
\text { comments). }\end{array}$ \\
\hline $\begin{array}{l}\text { 5. Utilization of non-safety sys- } \\
\text { tems during emergencies. } \\
\text { 岕 }\end{array}$ & 6.7 & $x$ & & $\begin{array}{l}\text { 15. Should be done in conjunction with Risk } \\
\text { Methodol.ogy tasks as well. }\end{array}$ \\
\hline
\end{tabular}


TABLE 3.13

Research Program - 13. Design Guidance

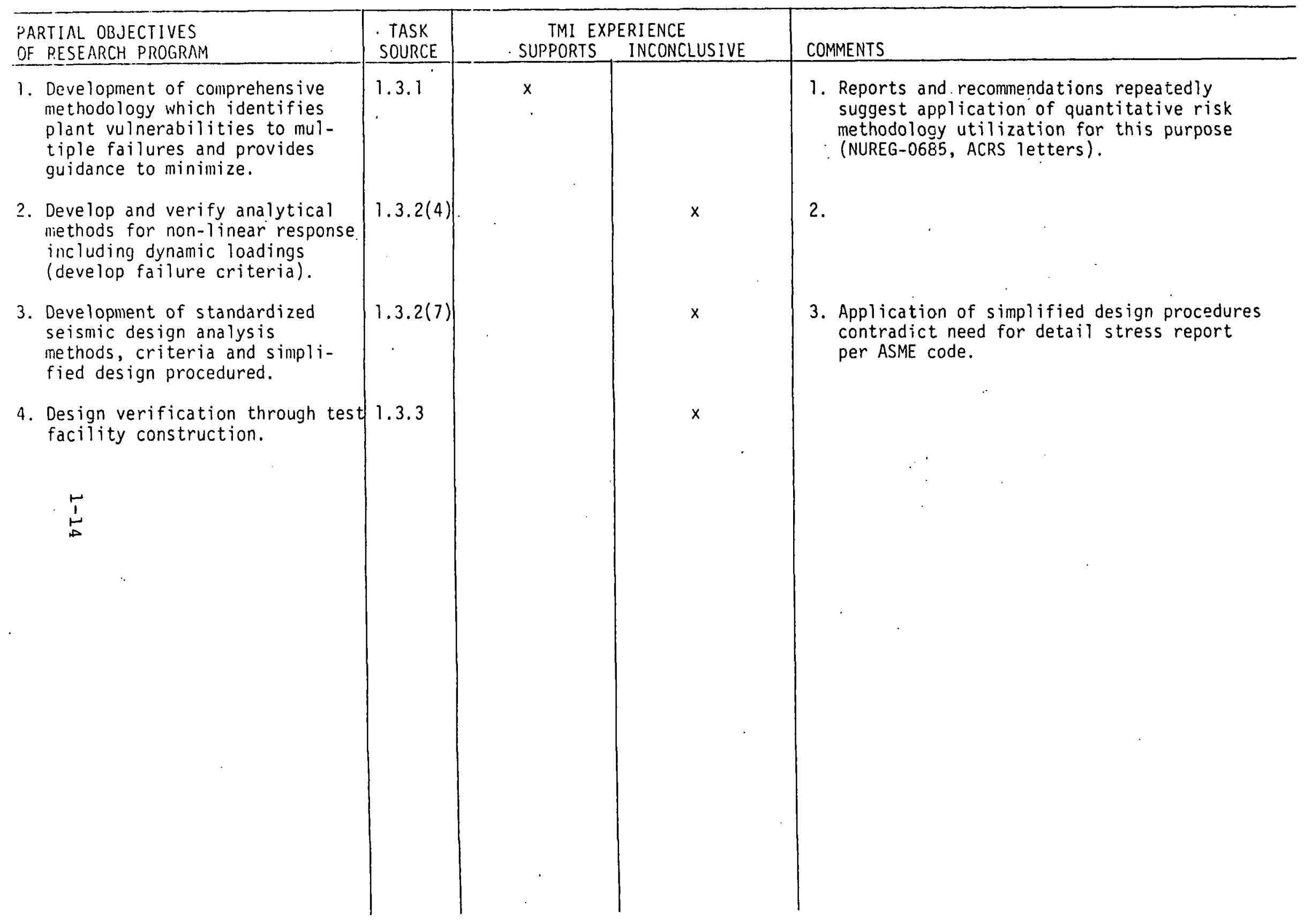


TABLE 3.14

Research Program - 14. Emergency Response

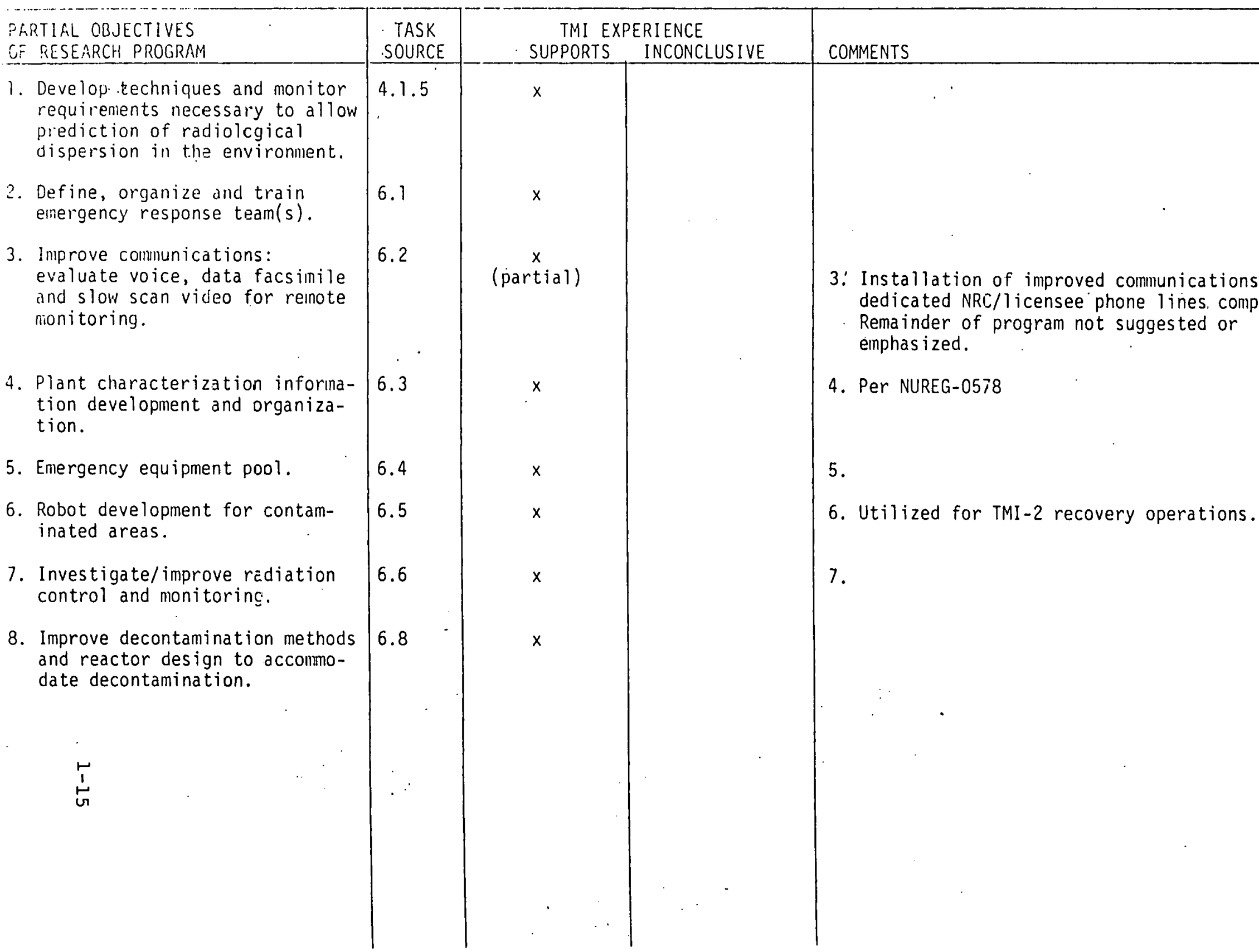


TABLE 3:15

Research Program -15 . Siting

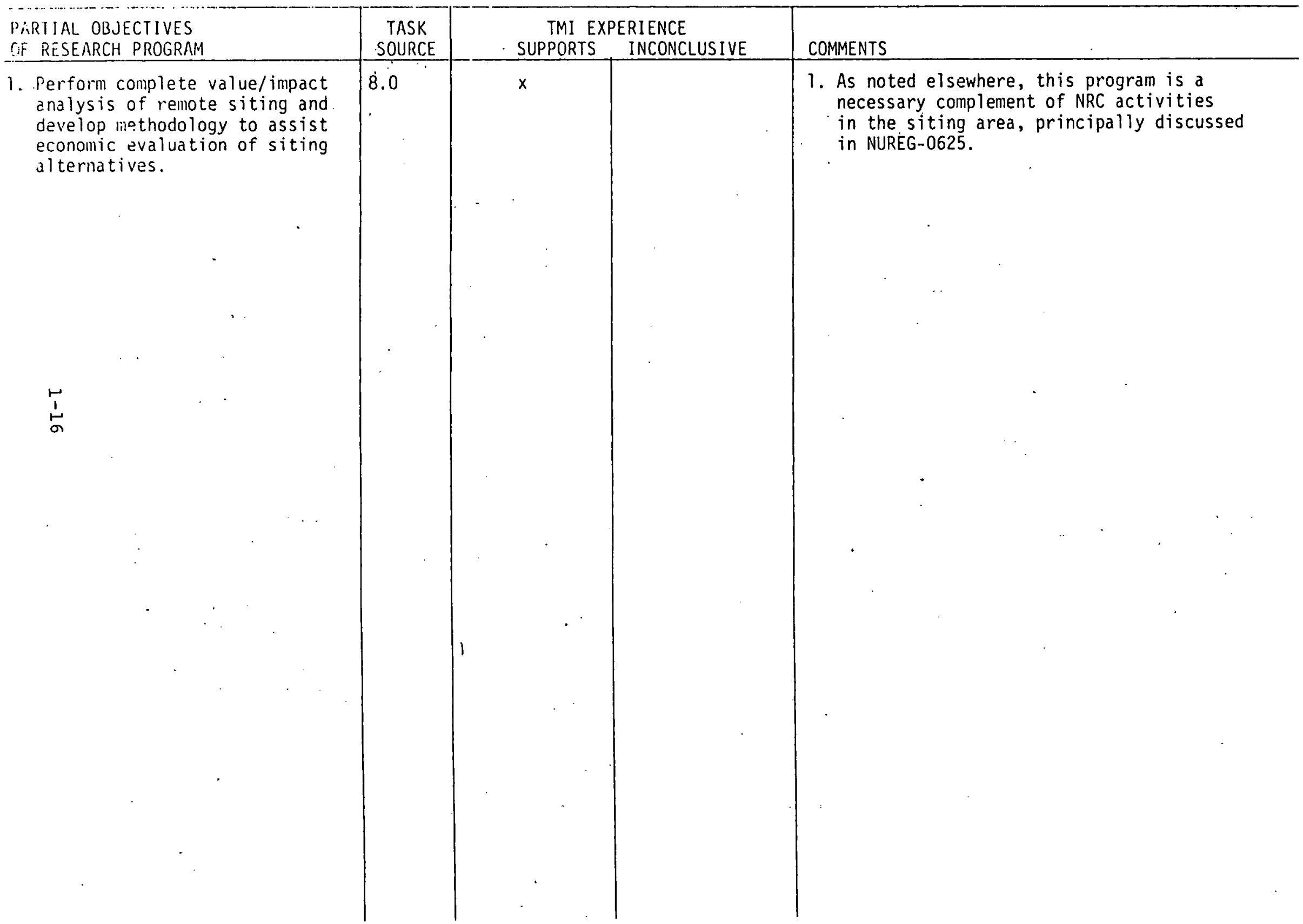

PRRIIAL OBJECTIVES

IF RESEARCH PROGRAM

economic evaluation of siting

セே necessary complement of NRC activities

in the siting area, principally discussed in NUREG-0625. 
TABLE 3.16

Research Program - 16. Risk Method Utilization

\section{PARTIAL OBJECTIVES \\ OF RESEARCH PROGRAN}

1. Evaluation, by fault and event tree analysis, effect of changes in component degradation rates on reactor safety.

2. Continue development of probabilistic risk methodology for LWR safety in areas of

a) human error

b) partial failures

c) multiple failures

d) non-independent failures

e) R\&D selection methodology

3. Develop analytical methods for application to design decision.

4. Review accident sequences toward grouping significant causes and consequences for non-catastrophic conseiuences feedback into design.

5. Develop data base and statistics for inproved application of methodology.

6. Develop toals necessary to allow 3.5 determination of acceptable risk objectives or accptance criteria.

$\stackrel{\sim}{1}$

\begin{tabular}{|l|c|c|c}
\hline $\begin{array}{c}\text { TASK } \\
\text { SOURCE }\end{array}$ & \multicolumn{2}{|c|}{ TMI EXPERIENCE } & \\
\hline 1.1 .6 & SUPPORTS & INCONCLUSIVE & COMMENTS \\
\hline & $\times$ & $\begin{array}{l}1 . \text { Post-TMI }: 1 \text { iterature supports more extensive } \\
\text { use of quantitative risk methodology. }\end{array}$
\end{tabular}

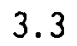

3.3
3. Implicit in ACRS encouragement for increased risk method utilization.

4. Although often suggested as a proper course of action, little evidence exists that such is being pursued.

5. A necessary ellement of methodology utilization.

6. TMI-related studies:(NUREG-0625) further. recommend definition of acceptable risk objectives for various critical siting parameters utilizing risk methodology as its basis. 
TABLE 3.17

Research Program - Miscellaneous

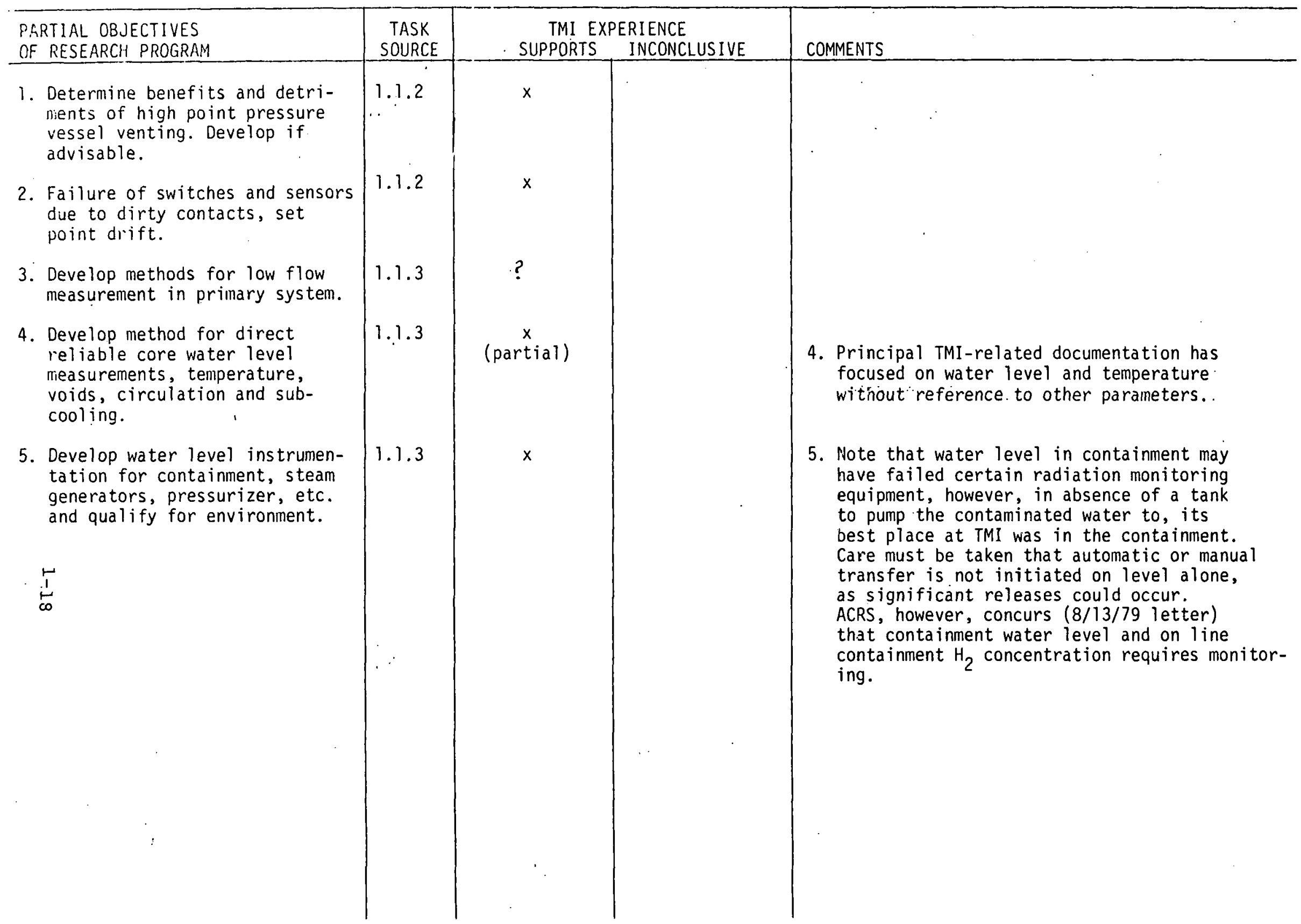


Research Program - Miscellaneous (continued)

\begin{tabular}{|c|c|c|c|c|}
\hline $\begin{array}{l}\text { PARTIAL OBJECTIVES } \\
\text { OF RESEARCI PROGRAM }\end{array}$ & $\begin{array}{l}\text { TASK } \\
\text { SOURCE }\end{array}$ & $\begin{array}{r}\text { TMI EX } \\
\text { SUPPORTS } \\
\end{array}$ & $\begin{array}{l}\text { ERIENCE } \\
\text { INCONCLUSIVE }\end{array}$ & COMMENTS \\
\hline $\begin{array}{l}\text { 6. Improve ma intenance and problems } \\
\text { associated with fuel handling } \\
\text { and transfer. }\end{array}$ & 2.1 .1 & & $x$ & . \\
\hline $\begin{array}{l}\text { 7. Cevelop analytical methods to } \\
\text { characterize coolant chemistry } \\
\text { fission product behavior in } \\
\text { primary and other systems, } \\
\text { transport, plateout and inter- } \\
\text { action. }\end{array}$ & 4.1 .4 & $x$ & & $\begin{array}{l}\text { 7. Indeed, NUREG-0578, if implenented, would } \\
\text { require detailed piant specific analysis } \\
\text { in this area. }\end{array}$ \\
\hline 8. TMI analysis & $\therefore$ & $x$ & . & $\begin{array}{l}\text { 8. Although several of the } 16 \text { research programs } \\
\text { contain elements of Sandia Program Plan } \\
\text { tasks, this material is listed here for } \\
\text { clarity in presentation. At this writing, } \\
\text { minimum information is available to allow } \\
\text { detailed comparison with completed ongoing } \\
\text { or planned TMI cleanup and analysis } \\
\text { operations. However, it is our under- } \\
\text { standing that a controlled Bechtel report } \\
\text { does contain details of recovery operations. }\end{array}$ \\
\hline
\end{tabular}


TABLE 3.18 SUGGESTED PROGRAM

ADDITIONS AND MODIFICATIONS

\section{Steam Generators}

1. Leaking steam generator tubes have caused numerous plant outages and constitute a pathway for radioactive material from the reactor coolant pressure boundary. Greater emphasis on understanding failure mechanisms, development of improved techniques for determining quantity and source of leaks, improving design and operating environments is warranted for availability and safety reasons.

2. In accordance with ACRS recommendations, the consequences and implications of overfilling the secondary side of steam generators requires evaluation in addition to feasibility studies of utilizing water solid secondary loops for decay heat removal.

\section{Piping}

1. Sandia research programs currently address loading and reaction forces on reactor internals from major pipe ruptures; however, the state-of-the art for determining jet impingement, pipe whip and environmental (pressure, temperature) effects on adjacent piping structures and equipment needs improvement. For example, the simplistic assumption that a whipping pipe will rupture smaller adjacent piping but not equal or larger piping is utilized in accident analysis. Research and model development would assist in plant design and layout, equipment sizing and protective feature design towards improving or at least understanding reactor safety vulnerability.

Fuel

1. Program does not currently address fuel design and optimizing such design to minimize $\mathrm{H}_{2}$ generation. 
2. Program should address methodology development for prediction of core deformation due to variable cooling/pressure/temperature conditions for sustained periods of time in a more detailed manner than Task 4.1.3.

3. Techniques and instrumentation to detect or predict fuel failures while in service would have assisted TMI-2 operators in realizing when core damage was occurring, where and to what extent. Sandia may wish to devote some research in this area to at least determine feasibility of providing such a system.

\section{Containment Functions \& Systems}

1. Following an accident such as occurred at TMI, access to containment required considerable time delay to allow radiation levels to subside. Although fixed radiation detectors were installed, the ability to transverse containment with devices capable of independent motive power would aid in determining specifically the extent of radiation fields and location, as well as serve to verify fixed instrument readings. Development of such a system, similar to Sandia's Robot development program, would be of assistance in localizing radiation sources and leaks during operation (particularly in those containments not designed for access during operation) and minimizing "trial and error" during attempted reentry as information would be available in advance of attempted reentries or maintenance and repair operations.

\section{Test and Maintenance}

1. Test and maintenance activities rely heavily upon a system for identifying needed maintenance, tracking, status of completion, prioritizing for schedulings and documenting completion. It is difficult for operators to be aware of what test and maintenance activities are in progress, planned, or completed. To aid in scheduling and prioritizing 
T\&M activities and recognition of the status of equipment and systems potentialiy affected by T\&M activities, development of a computer assisted system that tracks, schedules, and correlates T\&M activities and provide immediate indication of plant system or component tests or maintenance status and even diagnose and. recommend test and maintenance activities would be desirable. Such a system could be integrated with the disturbance and emergency control systems discussed elsewhere.

\section{Emergency Response}

1. Emergency response is an area easily amenable to non-technical evaluation following TMI. As such, it has received emphasis by the news media, legislators, regulators, as well as the technical community. A comprehensive evaluation of ongoing activities by the multitude of agencies and organizations would assist in definition of specific, necessary resarch that would avoid duplication and would be meaningful to other programs in progress.

\section{Risk Method Utilization}

1. TMI experience demonstrated the need for additional risk method developmental work to model system and component reliability as a function of duration of demand. Such development will serve to identify particularly crucial systems and components and provide feedback into the design process to ensure proper component qualification or redundancy.

\section{Miscellaneous}

1. "The Task Force concludes that sampling of plant gaseous effluents, with laboratory analysis of samples subsequent to release, is the only valid technique for monitoring accidental releases of radioiodines 
and particulates. In the absence of valid on-line monitoring capability for accident-levei releases of radioiodines and particulates, we strongly urge that research be undertaken promptly to develop such capability." (NUREG 0578 A-38)

Valves

1. TMI events indicate that valve location and whether valves require local manipulation were significant from a health physics standpoint.

$\underline{\text { Pumps }}$

1. Some pump problems in the short term at TMI were the result of control circuitry as opposed to pump failure suggesting a need to concentrate some attention in this area.

2. The loss of power to the oil pumps delayed attempts to restart RCPs. In cases where failure of pumps can affect operation of essential equipment, design attention should be focused.

\section{Design Guidance}

1. In the past, plant protective feasutes in these areas have been approved toward assuring adequate protection over the plant lifetime. With all systems operable, this has resulted in indirectly determining what constitutes an acceptable risk. At TMI it was necessary to ensure certain critical functions remained even though some of the equipment and systems were degraded or inoperable. Although the probability of failure of these systems may have been less due to fire, earthquake or sabotage for the short time periods (days or weeks) involved, the consequence of failure would probably have been more severe. The TMI experience suggests that Sandia may wish to include evaluation and 
quantification of risk and resultant design quidance evolved for situations in which degraded protection (either diversity, redundancy or separation) is present but the required duration of performance is relatively short. 
Section 2 of this report presents a summary of major reports issued on or as a result of the TMI-2 accident. These reports are organized into three basic types and include the reports noted.

I Studies and findings aimed principally at fact finding

2. T NUPEG-0600

2.2 NSAC- 1

2.3 NUREG-0558

II Studies and findings aimed principally at initiating shortterm actions at commercial facilities

2.4 NUREG-0578

2.5 NUREG-0557

2.6 NUREG-0550

II Studies and findings aimed at evaluating and modifying policy and major criteria

2.7 NUREG-0625 
2.1 NUCLEAR REGULATORY COMMISSION REPORT - NUREG-0600: INVESTIGATION INTO THE MARCH 28, 1979 THREE MILE ISLAND ACCIDENT BY OFFICE OF INSPECTION AND ENFORCEMENT, INVESTIGATIVE REPORT NO. 50-320/79, AUGUST 1979.

2.1.1 Purpose and Scope

The investigation by the Office of Inspection and Enforcement had two basic goals:

- To establish, in a comprehensive manner, the facts concerning the events of the Three Mile Island accident during the period investigated.

- To evaluate the performance of the Licensee in association with the Three Mile Island accident as a basis for corrective action or enforcement action as appropriate.

The NRC contends that this report contains a factual recounting, to the extent it has been possible to establish at the time of publication, of the significant operational and radiological events that transpired during the early hours and days of this accident. The report further provides an analysis of the actions of the licensee staff in light of those facts when compared to the NRC requirements to which they are subject.

This report is not a definitive study of every facet of the Three Mile Island accident. Nor is it an engineering evaluation of the accident. The I \& E investigation was limited to two aspects of the accident:. 
1. Those related operational actions by the licensee during the period from before the initiating event until approximately 8:00 p.m., March 28, when primary coolant flow was re-established by starting a reactor coolant pump, and

2. Those steps taken by the licensee to control the release of radioactive material to the off-site environs, and to implement his emergency plan during the period from the initiation of the event to midnight, March 30 .

\subsubsection{Summary of Content}

This report summarizes the investigation conducted by the NRC Office of Inspection and Enforcement. The Operational Sequence of Events is reported in detail for the period of time between the feedwater transient and 16 hours into the event. The Radiological Sequence of Events is reported out to three days after initiation of the event.

The determination of the sequence of events was a necessary prerequisite to determination of the cause of the event. This report presents an evaluation of licensee (and others) actions during the aforementioned time periods and attempts to identify those actions which caused or contributed to the sequence of events. The report then identifies 36 potential items of noncompliance that are under evaluation by the NRC for action against the licensee. Those findings of direct significance to the Sandia LWR. Safety Technology Program Plan are organized according to the related research program and itemized in Section 3. 


\subsubsection{Current Status}

Licensee actions that are under consideration by the NRC as potential items of noncompliance will be evaluated by the NRC and, where appropriate: formally provided to the licensee as a Notice of Violation. Regulations require the licensee to respond to the Notice of Violation with in 30 days. Ultimately, this process normally concludes by imposition of civil penalties and implementation by the licensee of any necessary corrective action.' The potential magnitude of the TMI violations and the potential severity of the accident, however, will probably require Atomic Safety and Licensing Board hearings on both the violations and continued operation of this facility, in addition to those currently being held on TMI Unit $?$. 
2.2. EPRI, NUCLEAR SAFETY ANALYSIS CENTER - NSAC-1; ANALYSIS OF THREE MILE ISLAND-UNIT 2 ACCIDENT - JULY 1979

2.2.1 Purpose and Scope

NSAC- 1 represents a partial report on many aspects of TMI-related activities. It, therefore, has a much broader scope that other documents being referenced in this section. NSAC's mission as an organization has been broadly defined (reference 1) to include six major tasks as follows:

1. Carry out a detailed technical analysis of the events at TMI-Unit 2;

2. Interpret lessons to be learned from TMI events;

3. Develop strategies to minimize the possibility of future accidents;

4. Address generic questions on reactor safety;

5. Act as clearing house for technical information on safety issues that emerge as a result of TMI;

6. Make recommendations on changes in safety systems or modifications of operating procedures that would further improve safety.

The major areas addressed in NSAC-1 are summarized below.

\subsubsection{Summary of Content}

The Nuclear Safety Analysis Center (NSAC) of the Electric Power Research Institute is analyzing the Three Mile Island-2 accident. An early result of this analysis was a brief narrative summary, issued in mid-May 1979. The NSAC- 1 report contains a revised version of that narrative summary, a highly detailed sequence of events, a standard reference list, a list of abbreviations and acronyms, and several appendices. 
The appendices serve either to describe plant features which are pertinent to the understanding of the sequence of events, or indicate how certain inferences and conclusions in the report were reached. Additional appendices are in preparation. These will be issued when available (e.g., the appendices Hydrogen Phenomena and Operator Actions during Initial Transient will follow later). Also in preparation is a matrix of equipment and system responses during the accident.

This report, together with future supplements and a separate core Damage Assessment report, will embody the principal results of the initial investigative phase of NSAC's work. Subsequent phases will concentrate on causes, lessons learned and generic remedial or preventive measures which may be appropriate. 
2.3 NUCLEAR REGULATORY COMMISSION - NUREG-0558 POPULATION DOSE AND HEALTH IMPACT OF THE ACCIDENT AT THE THREE MILE ISLAND NUCLEAR STATION, MAY 1979.

2.3.1 Purpose and Scope

An interagency team comprised of representatives from NRC, 'HEW and EPA were chartered to estimate the collective radiation dose received by the population within 50 miles of the reactor site and to determine the possible and probable health impact of that release. The investigation assimilated information on radioactive material released, demographic data and meteorological conditions between March 28 and April 7, 1979.

\subsubsection{Summary of Content}

This report is basically a factual report of the radioactive material released, the population and individual doses and the potential health impact from releases between March 28, and April 7. As such, there is very little of the report that identifies actions or equipment during the event that are directly relevant to the Sandia LWR Safety Technology Program Plan. However, this report does identify data limitations and inconsistencies. Inadequacies in the state of the art tools are also identified. The implications of this report are discussed in Section 3 where relevant to the specific research programs.

\subsubsection{Current Status}

Since the TMI accident, several studies have been initiated to gather data over the long term on health impacts on the general population. 
The most comprehensive study of this nature is that being jointly funded by the State of Pennsylvania, the Electric Power Research Institute, and others. In the future, the findings and observations of this study will be frequently compared with NUREG-0558, and the knowledge gained used to revise techniques applied in the NUREG analysis. 
2.4 NUCLEAR REGULATORY COMMISSION REPORT - NIREG-0578: TMI-2 LESSONS LEARNED TASK FORCE - STATUS AND SHORT-TERM RECOMMENDATIONS, JULY 1979

2.4.1 Purpose and Scope

The purpose of this Task Force was to identify and evaluate those safety concerns originating with the TMI-2 accident that required 1 icensing actions (beyond those already specified in Inspection and Enforcement. (IE) Bulletins and Commission Orders) for presently operating reactors as well as for applicants with pending operating licenses (OL) and construction permits (CP). This includes the review and evaluation of investigative information, staff evaluations of responses to IE Bulletins and Orders, Commissioners' recommendations, ACRS recommendations, recommendations from NUREG-0560 ("Staff Report on the Generic Assessment of Feedwater Transients in Pressurized Water Reactors Designed by the Babcock \& Wilcox Company") and recommendations from outside of the NRC. In addition, the Task Force was charged to identify, analyze and recommend changes to licensing requirements and the licensing process for nuclear power plants based on the lessons learned. The scope of the Task Force included the following general technical areas:

1. Reactor operations, including operator training and licensing;

2. Licensee technical qualifications;

3. Reactor transient and accident:analysis;

4. Licensing requirements for safety and process equipment, instrumentation and controls;

5. Onsite emergency preparations and procedures;

6. NRR accident response role, capability and management; :

7. Feedback, evaluation, and utilization of reactor operating experience. 


\subsubsection{Summary of Content}

The Lessons Learned Task Force identified 23 specific short-term requirements in 12 areas ( 9 in the area of design and analysis and 3 in the operations area) whose implementation was judged by the NRC to provide substantial additional protection required for the public health and safety. Each requirement and the time scale for promulgation and implementation is described. Discussions particularly pertinent to Sandia Research Programs are reproduced in Section 4.

Except as discussed below, the recomended requirements were considered consistent with existing NRC regulations by the NRC. Three requirements were identified, however, which relate to the revision of present regulations:

1. Inerting all BWR containments;

2. Capability to install a recombiner at each LWR facility;

3. Revision of limiting conditions for operation based on safety system availability.

The Lessons Learned Task Force recommended that, upon approval by the Director of NRR, rulemaking proceedings be initiated on an immediately effective basis.

\subsubsection{Current Status}

The licensing requirements discussed in NUREG-0587 address those issues where the Task Force believes short-term improvements in safety can 
and need to be made. These requirements are narrow in scope and, with a few exceptions, are believed by the NRC to be consistent with existing regulations, Regulatory Guides and the staff's Standard Review Plan. The accident at Three Mile Island has raised a number of other significant questions and policy issues. The intent of the Task Force is to continue its evaluation of the accident by considering broader and more fundamental questions in the design and operation of nuclear power plants and in the licensing process.

The NRC believes that the accident at Three Mile Island was not the result of easily identified or isolated design deficiencies or operator errors, but was the consequence of many factors in the design, operation and licensing of the plant. The Task Force believes that an orderly, comprehensive evaluation of the accident - considering the many factors and their interrelationship - is required. Further evaluation will start with the broad, fundamental questions before further specific changes to current requirements are recommended. For convenience of organization, the Task Force has grouped the issues to be considered into four areas: general safety criteria, system design requirements, nuclear power plant operations and nuclear power plant licensing.

Subsequent to release of NUREG-0578, NRC management has concurred with many of the recommendations, extended some implementation schedules, sought and obtained licensee and applicant commitments to the recommendations and deferred implementation in cases where rulemaking or policy decisions are necessary. 
2.5 NUCLEAR REGULATORY COMMISSION - NUREG-0557: EVALUATION OF LONGIERM POST-ACCIDENT CORE COOLING OF THREE MILE ISLAND UNIT 2,

MAY 1979

\subsubsection{Purpose and Scope}

This document summarizes a safety evaluation of alternatives and timing for placing TMI-2 into long-term (natural circulation) cooling. . of necessity, the safety evaluation investigated the range of core geometries and states as well as systems and equipment required to function in this mode of operation.

\subsubsection{Summary of Content}

As noted above, this report is a safety evaluation of putting TMI-2 into natural circulation. The report provides a detailed assessment of options available to accomplish long-term cooling and identifies systems and components necessary to ensure establishment and maintenance of long-term cooling. This document further reports on critical parameters and conditions that must be maintained and monitored during transition to natural circulation. Portions of Appendix B to this report dealing with "TMI-2 Plant Modifications for Achieving Cold Shutdown" are reproduced in Section 4 .

\subsubsection{Current Status}

Subsequent to report publication, TMI-2 successfully established natural circulation for long-term cooling. 
2.6 NUCLEAR REGULATORY COMMISSION REPORT - NUREG-0560: STAFF REPORT ON THE GENERIC ASSESSMENT OF FEEDWATER TRANSIENTS IN PRESSURIZED WATER REACTORS DESIGNED BY THE BABCOCK \& WILCOX COMPANY, MAY 1979.

\subsubsection{Purpose and Scope}

The purpose of Task Force authoring this report was:

Given the operating experience with feedwater transients in operating $B$ \& $W$ designed reactors, assess whether reactor and plant systems at these plants provide adequate protection from design basis feedwater transients. This assessment should re-confirm whether these plant designs meet the requirements of NRC regulations, using appropriate staff guidelines for acceptable means of meeting these regulations. This should include an evaluation of the safety margins of these plant designs to assure that specified acceptable fuel design limits are not exceeded as a result of feedwater transients.

This broad purpose was divided into three objectives. The first objective was to make an early assessment concerning those measures that might be necessary to prevent a recurrence of the TMII-2 event at $B$ \& $W$ facilities In particular, consideration was given to the directives transmitted in Inspection and Enforcement Bulletins to utilities holding operating Ticenses for $B$ \& W plants to assure that implementation of the immediate measures required by the staff in those bulletins provide adequate protection pending completion of more intensive reviews. A second objective was to make an assessment concerning additional remedial measures of a short- and long-term nature that might be necessary to correct design and operational deficiencies in $B \& W$ 
plants, including those not yet licensed to operate. A third objective was to identify weaknesses in the regulatory review process that contributed to the failure to anticipate the sequence of events that led to degradation of core cooling in the earlv phases of the TMI-2 accident.

The assessment in NUREG-0560 deals mainly with the generic implications of the initiating event at TMI-2; that is, the feedwater types of transients that could lead to an overpressure condition that opens a power-operated relief vaive and could potentially result in a loss-of-coolant accident. The report presents a set of findings and recommendations for further action in each of the principal areas investigated. These findings and recommendations were intended to form the basis for more specific review by the staff, the reactor designers, and licensed utilities.

\subsubsection{Summary of Content}

NUREG-0560 presents the results of the Task Force assessment. in six major sections following the introduction.

Section 2 is a comparison of the general design features including configurations, sizes, and safety and control systems of $B$ \& $W$ operating plants to determine areas of uniformity and difference. These are in turn related to plant characteristics that govern systems behavior under transient conditions.

Section 3 deals with $B \& W$ operational event reports that have been reviewed in which certain events of some similarity to those involved in the TMI-2 accident are discussed in the interest of determining whether the TMI-2 event should have been anticipated.

Section 4 deals with operating procedures and operator training in light of the TMI-2 event. 
Section 5 treats the analyses presented in the Safety Analys is Reports and in response to specific licensing review questions. The Standard Review Plan is discussed to assess whether current licensing requirements would have required analysis of a TMI-2 type event. The General Design Criteria and Technical Specifications are also considered relative to the event.

Section 6 summarizes briefly the considerations given to plant design features for feedwater transients in other pressurized water reactor (PWR) designs. This action provides some insight into the generic applicability of the preliminary findings made on $B \& W$ plants, as a result of the TMI-2 incident, to PWR plants designed by Westinghouse (W) and Combustion Engineering $(C-E)$.

Section 7 relates to the IE Bulletin 79-05A. This bulletin provides a chronology of the event and identifies areas for immediate action by 1 icensees to avoid a recurrence of this incident. Near-term action is focused in this area.

The evaluation by the task group is presented as a set of findings and recommendations for further action in each of the principal areas investigated.

\section{6:3 Current Status}

The major impact of this report was to identify specific actions necessary to allow $B$ \& $W$ reactors to return to operation. Such actions have been taken, and with the exception of TMI-1, all 1icensed $B \& W$ reactors have received NRC permission to resume operation. 
2.7 IUUCLEAR PEGULATORY COMMISSION - NUREG-0625: REPORT OF THE SITING POLICY TASK FORCE, AUGUST 1979

\subsubsection{Purpose and Scope}

The purpose of the NRC task force whose reports comprise this document was to develop a general policy statement on nuclear power reactor siting. The stated goals of this work are contained in the "Abstract Prefacing NUREG$0625^{\prime \prime}$ and are incorporated into this review as stated.

1. "To strengthen siting as a factor in defense in depth by establishing requirements for site approval that are independent of plant

- design consideration. The present policy of permitting plant design features to compensate for unfavorable site characteristics has resulted in improved designs but has tended to deemphasize site isolation.

2. "To take into consideration in siting the risk associated with accidents beyond the design basis (Class 9) by establishing population density and distribution criteria. Plant design improvements have reduced the probability and consequences of design basis accidents, but there remains the residual risk from accidents not considered in the design basis. Although this risk cannot be completely reduced to zero, it can be significantly reduced by selective siting.

3. "To require that sites selected will minimize the risk from energy generation. The selected sites should be among the best available in the region where new generating capacity is needed. Siting requirements should be stringent enough to limit the residual risk of reactor operation but not so stringent as to eliminate the nuclear option from large regions of the country. This is because energy generation from any source has its associated risk, with risks from some energy sources being greater than that of the nuclear option." 
The ultimate object of formulating a general siting policy statement, as stated in Section 1.1, is to (1) improve siting, (2) improve predictability of siting decisions, and (3) improve efficiency of regulatory process with regard to siting.

\subsubsection{Summary of Content}

NUREG-0625 is comprised of two basic parts. Part 1 (contained in chapter 2 of NUREG) describes the current siting policy and practices of the Nuclear Regulatory Commission. This detailed treatment discusses the safety considerations that contribute to siting, including demography, off-site hazards, natural phenomena, and environmental aspects. This report does not discuss the economic aspects of site selection that are included within the Sandia Program Plan. Part 2 of the report presents the study results in the form of nine recommendations as discussed below. Additional pertinent sections are devoted to discussion of other opinions and points of view differing from the majority and a discussion of regulatory agency application of risk assessment in development of safety criteria. Major conclusions and recommendations reached in NUREG-0625 are presented in appropriate section 3 discussions (principally siting and risk method utilization). 


\subsection{VALVES AND 3.2 RELIEF VALVES}

\subsubsection{Summary of Research Project}

Sandia research programs related to valves have the following general objectives:

1. Determine reliability and resolve identified problems associated with power and air operated valves

2. Develop valve status indicators

3. Determine cause and resolve reseating problems

4. Develop better understanding of valve behavior under two phase flow

5. Develop methodology for improved valve selection

These programs encompass comprehensive aspects of valve design, selection, qualification and maintenance of valves. The following sections correlate specific valve problems at TMI-2 and subsequent events to the Sandia research programs.

\subsubsection{Relevant TMI Events and Actions}

\section{Valve Status Indicator}

Two major problems occurred at TMI-2 concerning valve_status indication. The approximately 8 minute delay in delivering emergency feedwater to the steam generators was caused by the two closed feedwater header isolation valves. 
"The operator stated that he had looked at the panel valve lineup twice before discovering the valves to be closed. The first scan of the panel was made standing close to the panel and leaning over the console, possibly obstructing his view of the lower valve $(E F-V 12 B)$. The upper valve (EF-V12A) indicator light (green for closed) was covered by a caution tag hanging from the main feedwater pump IB miniflow valve (VI6B) control station.

"NOTE: The caution tag indicated that the control for the main feedpump IB miniflow valve (V16B) should remain in MANUAL due to a flow instrument problem. The tag was issued on March 20, 1979, for the transmitter valve (COv530) repair.

"A review of Administrative Procedure 1037, Revision 1, August 23, 1978, Caution and Do-Not-Operate (DNO) Tags, revealed that no formal guidance is given concerning the method of hanging tags to prevent inadvertent covering of other information devices (lights, identification tags, etc.) or impeding the operation of other equipment or controls." (NUREG-0600, I-2-5)

The second involved the electromagnetic relief valive (EMOV), the source of primary coolant inventory loss for the initial period of the accident (two hours, nineteen minutes). Several indirect means were available to enable TMI operators to infer valve position. Primarily, these were thermocouple in the discharge pipe (as well as the reactor coolant system and reactor coolant drain tank, RCDT) (NSAC-1, Appendix ERV), solenoid actuator demand, and flow from the RCDT. 
"The electromatic relief valve has a labelled keylock switch in the control roon to indicate the mode of operation of the valve. A light on the control room console is on when the valve solenoid coil is energized, but this light does not necessarily indicate valve status. In the accident, the electromatic relief valve stuck open when the solenoid deenergized, but the indicating light went out, which would normally mean the value was closed. (NSAC-I, Appendix RCPS)

"One chromel constantan thermocouple $(T / C)$ is strapped to each relief valve exhaust line. The $T / C$ on the EMOV line is located about 3 feet downstream of the valve. (Plant Training Photograph No. 443; Ref. 74). The $T / C S$ on the code safety exhaust lines are located about one pipe diameter from these valves. (Plant Training Photograph No. 81 ; Ref. 75 ) Thus, about 40 feet of piping separate any one $T / C$ from the other two.

"NOTE: This location is based on discussions with plant staff and disagrees with plant drawings which show the $T / C$ located several feet further downstream of the vaives.

"These temperatures are normally recorded on a multipoint temperature recorder in the control room. However, this data is unavailable for the period of the incident. The chart drive stopped before the accident and entries were printing over each other during the accident. No information has been obtained to explain the cause of this recorder behavior. Operation of the chart drive resumed 
after the accident. No chart paper is missing. These three $T / C s$ are also connected to alarms that are printed out by the Computer Alarm Printer. "High temperature" is printed when one of these points exceeds about $200^{\circ} \mathrm{F}$. The alarm clearing is printed when the temperature decreases below about $193^{\circ} \mathrm{F}$. In addition, these temperatures can be called up by the operators through the computer and printed by the Utility Typer. This was done several times during: the accident." (NUREG-0600, I-4-35)

"The operators were operating the RCDT transfer pump with flow through the RCDT cooler continuously to maintain the RCDT temperature at ambient conditions with the apparent valve leakage into the tank. The continuous operation of the drain pump in order to maintain the tank temperature at ambient conditions indicated an abnormal condition existed." (NUREG-0600, I-1-5)

The normaliy slow recovery time for thermocouples on the exhaust line, complicated by the history of normal leakage through the EMOV, have been attributed to be the primary causes for delayed operator diagnosis of the EMOV being stuck open.

\section{Reseating and Leakage Problems}

The previous section discussed TMI-2 experience with regard to EMOV failure to reseat and leakage history.

In summary, the EMOV failed to reseat following actuation and the history of leakage was a contributing factor to delayed operator recognition 
of primary coolant inventory loss through this path.

"The pressurizer electromatic relief valve upstream block valve, RC-V2, had maintenance work performed on it on September 14, 1977. The motor operator was removed to allow repacking the valves. The valve was cycled. Discussions with licensee personnel indicate that there has been a concern that the block valve could stick shut or open if used too often." (NUREG-0600, I-1-52)

"The TMI machine history file on the electrical emergency feedwater pumps, EF-P-2A and 2B, did not indicate a problem relative to the event of March 28 , 1979. The most recent history indicated that motor windings and connecting electrical cables were checked after an event involving steam leakage in the pump area. The steam leakage was due to the atomospheric dump valves (MS-V $3 A$ and $B$ ) bellows (MS-U7A and $B$ ) failing during turbine trip testing on January 15, 1979, and subsequent reactor trip and loss of condenser vacuum. The steam was reported to have filled the $M-20$ area where the pressurizer breaker, silicon controlled rectifier (SCR) panels are located as wel] as the steam-driven emergency feedwater pump, EF-P-1. The adjacent area where EF-P-2A and $2 \mathrm{~B}$ are located also contained a steam environment." (NUREG-0600, I-1-53) 
With regard to the gaseous radwaste system, a control room operator "stated that a makeup tank vent valve (MU-V-12) was suspected to be leaking. Some of these problems may have caused releases to be larger than they would have otherwise been". (II-1-28)

"From maintenance records and discussions with licensee personnel, investigators determined that there were small liquid leaks from valves and instruments in the makeup and purification system. The contribution from these sources to the activity released to the auxiliary building sump could not be determined." (1I-3-14)

Other Valve Problems Encountered at TMI-2

As mentioned in the Sandia Program Plan, valve problems associated with the instrument air system have been attributed by some individuals to be the cause of the initial transient. The NRC's investigation concluded that the specific initiating cause which led to the turbine trip could not be idenfitied. The discussion contained in NUREG is included in its entirety in section 4. 
The NRC investigation (NUREG-0600) reviewed plant records of TMI operational history prior to the March 28 accident. This investigation identified an incident in December, 1978 in which "reactor trip [occurred] at power and ES actuation due to overfeeding of OTSGs during transfer from the statrup to main feedwater valves. The main feedwater regulating valve was found full open and disabled in that position". Documentation of this event has not been reviewed for purposes of this correlation.

Immediately following the turbine trip on March 28, 1979,

"The operator noted that the turbine trip was normal with the exception of one turbune stop valve which did not indicate closed. The associated control valve was verified closed and, additionally, the turbine was tripped manually." (NUREG-0600, I-2-3)

"At approximately 5 minutes into the turbine trip transient, the operator noted that the emergency feedwater level control valves were continuing to travel to the open position. The valves were not supplied adequate air to operate. The valves fail 'as is' and only respond if air pressure is available. It can be reasonably postulated that the failure of the condensate polisher outlet valves to the closed position (loss of instrument air pressure) and the failure of the emergency feedwater valves to respond normally (loss of instrument air pressure) were related. Operator intervievs revealed that the valves did not appear to operate properly. The valves were expected to open fully shortly after the OTSG levels decreased below 30 inches and the valves were continuing to travel at about 0404 hours." (I-2-5) 
"The steaming to the main condenser via the turbine bypass valves (MS-V25A, V25B, V26A and V26B) to maintain steam header pressure at 1010 psig apparently caused the hotwell level control valve controlier to fail (low level) and the hotwell was flooded from the condensate storage tank. The hotwell level increased from 21.82 inches to the completely flooded condition (greater than 50" indicated level) within 1 minute and the hotwell level was not recovered until 0653 hours.

Interviews, record reviews, and analysis indicate that attempts were made to reestablish the condensate system at $0405 \mathrm{hrs}$ as indicated by the start of the 1A condensate pump through $0653 \mathrm{hrs}$, when the hotwell level reject valve was finally recovered and the hotwell pumped down to normal. This was done to provide normal feedwater system flow to the generators and to prevent losing condenser vacuum. The loss of condenser vacuum (approximately 18 inches) terminates the release of decay heat steam to the condenser and automatically shifts the decay heat steam to the atmosphere." (I-2-27)

Radiation levels in various plant locations required evacuation and protective measures from several hours into the accident on. Personnel access into contaminated areas was occasionally required for valve manipulation purposes as documented in NUREG-0600, Section II-3. Although no significant 
valve problems cause these exposures, the observation is included here to alert the reader to the significance of valve location and whether valves require remote or local actuation from a health physics standpoint.

\subsubsection{Required or Suggested Action}

With regard to valve status indication, the following observations, requirements and suggestions have emerged following the TMI-2 accident:

1. NUREG-0578 recommendations regarding valve position indication is included in its entirety in Section 4. In summary,

"Although the pressurizer, power-operated relief valve was stuck open, control panel lights indicated that the valve was closed because the signal was derived from a sensor of solenoid actuation rather than a sensor of the valve position itself. The purpose of this position is to provide the operator a more positive indication of valve position and, therefore, provide additional assurance that the integrity of the reactor coolant pressure boundary can be maintained or a loss of integrity directly diagnosed." (NUREG-0578, A-9)

2. NUREG-0578 recommendations regarding performance testing of relief and safety valves is also included in its entirety in Section 4. In summary, 
"To date, there have been a number of instances of improper operation of relief and safety valves. These examples include valves opening below set pressure, valves opening above set pressure or failure to open; and valves failing to reseat when open. The failure of the power-operated relief valve to reseat was a significant contributor to the TMI-2 sequence of events. The purpose of this recommendation is to require qualification of relief and safety valves under expected operating conditions, which would include solid-water and two-phase flow conditions." (NUREG-0578, A-6, 7)

3. The ACRS has concurred that valve status monitoring is important (see Section 3.17/12).

4. Valve status indication problems have been identified in other areas as a result of TMI- 2 related activities. These items are treated by example below.

"No direct indication of pressurizer code safety value position is available in the control room. Valve position may be inferred from the rate of change of reactor coolant system pressure, reactor coolant drain tank pressure, temperature and level, and safety valve discharge temperatures. Reactor coolant system pressure is displayed on a front control console. Indications of reactor coolant drain tank pressure, 
level and temperature, with alarm of these parameters when off-normal, is provided on a back panel in the control room. The computer is used to monitor thermocouples which are clamped to the tailpipes of the electromatic relief valve and the safety valves. An alarm is indicated if the thermocouple temperatures exceed $200^{\circ} \mathrm{F}$." (NSAC-1, App. RCPCS)

5. NRC IE Bulletins (reference 1) issued shortly after the TMI-2 accident required PWRs to prepare and immediately implement procedures which

a. Identify those plant indications (such as valve discharge piping temperature, valve position indication, or valve discharge relief tank temperature or pressure indication). which plant operators may utilize to determine that pressurizer power operated relief valve(s) are open, and

b. Direct the plant operators to manually. close the power operated relief block valve(s) when reactor coolant system pressure is reduced to the set point for normal automatic closure of the power operated relief valve(s) and the valve(s) fail to close.

These Bulletins also required verification of proper emergency feedwater and ESF valve positioning. 
6. NUREG-0579 recommendations issued in May 1979 suggest:

Improved means for detecting a stuck-open power-operated relief valve (PORV) should be provided. In addition, consideration should be given to upgrading the PORV classification to safety grade and the associated controls and instruments to new standards for control systems; or, as an alternate, consideration should be given to closing the relief valve and block valve during power operation if resetting of the set point is not effective in reducing actuation of the PORV. 
3.1.4 Relation to Sandia Research Program

The relevance of Sandia objectives (related to valves) to TMI events and literature is presented in table 3.1 
TABLE 3.1

Research Program - 1. Valves \& 2. Safety/Relief.Valves

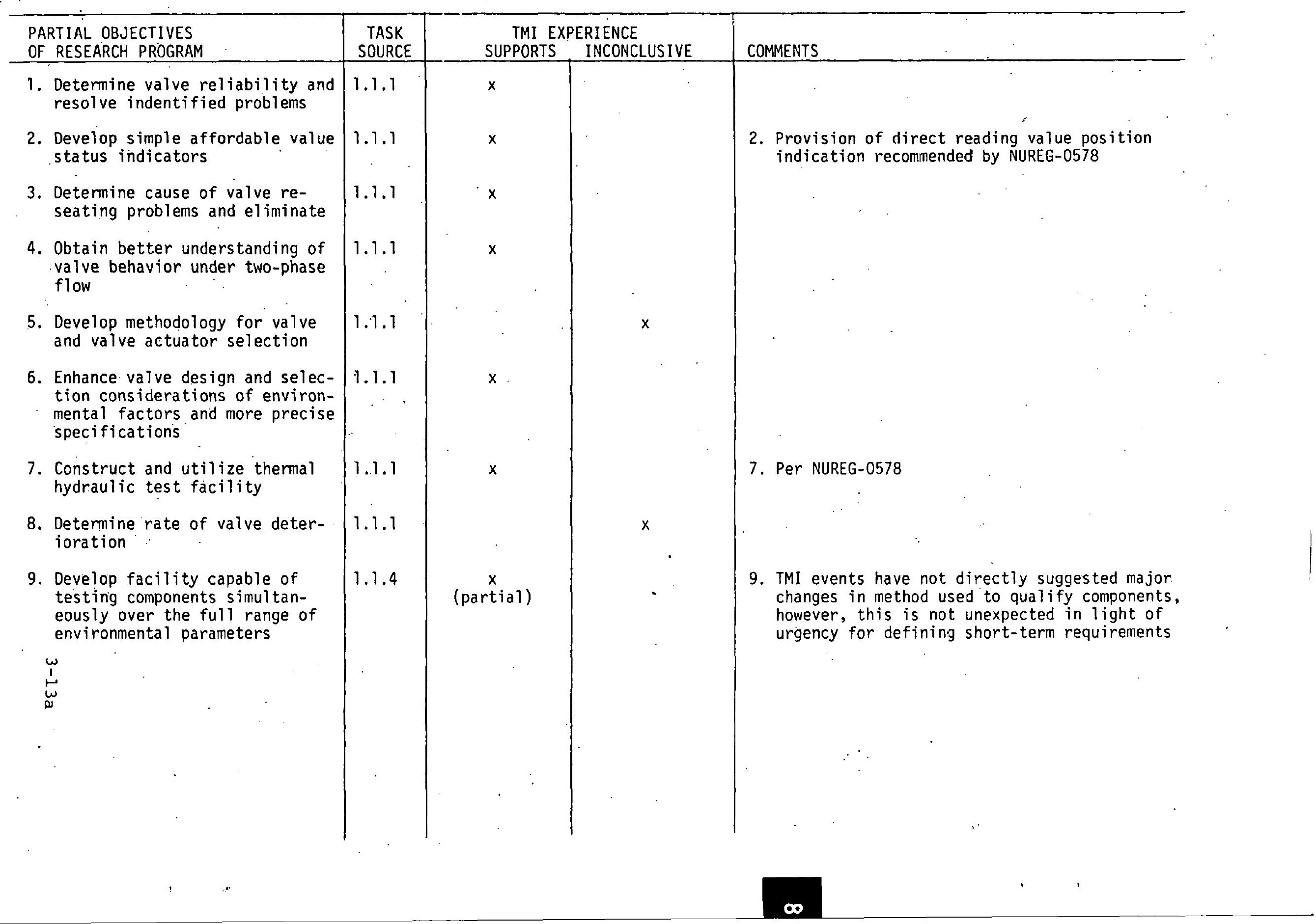




\subsection{PUMPS}

3.3.1 Summary of Research Project

Sandia Research Programs related to pumps have the following general objectives:

1. Pump operational characteristics and failure causes need to be better understọod

2. Pump design. and selection must be improved to ensure operation when required under all practical conditions

TMI-2 events have highlighted these needs as discussed in the following sections:

\subsubsection{Relevant TMI Events and.Actions}

Pump and pump operation played a significant role in several aspects of the TMI-2 accident. To date, available TMI literature has indicated performance problems associated with the Reactor Coolant Pumps, Reactor Coolant Makeup Pumps (including HPI mode) and Feedwater and Condensate Pumps (initiating event) affected the course of the TMI-2 accident.

\section{Reactor Coolant Pumps}

The operational history of the Reactor Coolant Pumps (RCPS) is well documented during the initial 16 hours of the accident (NUREG-0600, I-424 through 29, NSAC-1 Sum. Descrip., p. 5-7). Following the reactor trip at 0400 , the RCPs initially continued to operate in $100 \mathrm{P} B$ 
until 0514 and loop A until 0541 although the primary system was saturated at approximately 0406. The decreased coolant flow and increased pump and pump motor vibration were reported reasons for the operator action to trip the pumps. Although operator procedures for tripping the RCPs are inconsistent with regard to amplitude of vibration requiring action, the NRC evaluation has concluded that operator action should have been taken very early into the event to trip the RCPs (NUREG-0600, I-4-24). At 0654, the interlocks were. "jumped" in an attempt to start RCPs - successful only on RCP 2B which ran for 19 minutes (IA-43) at which time operators tripped 2B due to vibration and low motor current. At 0805, operators attempted a restart of RCPs by jumping interlocks; RCP-IA started, ran 37 seconds and was tripped by operators due to low motor current and caviation. At 1445, RCP restart preparations began; disabled oil pumps under repair (loss of power, inability to gain access due to high radiation). At 1533, RCP-1A ran 10 seconds. At 1550, $1 A$ started and was running under good conditions with indication of successful forced circulation (NUREG-0600, I-4-27).

\section{Reactor Coolant Makeup Pumps*}

The following excerpts from NUREG-0600 describe the performance of this equipment:

"During the course of this accident, the operators reportedly experienced multiple problems with starting reactor coolant makeup pumps (MUPS).

\footnotetext{
*In addition to serving normal operation functions, these three MUPs are used for HPI system operation. "During HPI, two pumps are on and the throttling valves for the pumps automatically go to full open, at which position each pump puts at least $500 \mathrm{gpm}$ into the RCS. When a pump is on, but HPI is not actuated, the flow can be throttled back by the operators. According to operator statements (Int. 15) the minimum flow that can be adequately controlled is about $100 \mathrm{gpm}$ per pump". (NUREG0600, I-4-14)
} 
"At 13 seconds into the event, the computer alarm status printout indicates an operator unsuccessfully attempted a start of MUP-IA. At 39 seconds into the event, the alarm status printout indicates an operator again tried to start MUP-IA and was successful. This sequence of events is confirmed by operator interviews, which further indicate that more than one unsuccessful attempt to start MUP-1A was experienced. A review of the computer generated sequence of events for the period of interest appears to show a condition of contact bounce related to the control switch disagreement relay. Assuming that the Burns \& Roe Drawings for this pump and its related components represent actual wiring, that computer indications of changes in electrical contact position are good, and that the memory of two separate operators is correct; focuses attention on the control room switch for MUP-1A, whose malfunction alone could defeat a manual or automatic start, fail to indicate additional operator start attempts, and provide the apparent anomalous indications to the sequence of event program.

"At 12 minutes into the event, the alarm status printout and the sequence of events review present similar indications of a start failure followed by a start success. Operator interviews confirm an event like this occurred, but their momory of timing does not agree with the computer listing.

"At 4 hours 18 minutes into the event, the alarm status printout and the sequence of events review present an additional example of these indications; with the exception that, at these times, the pump does not start. Operator interviews confirm these events and indicate the control room switch was then placed in the pull-to-lock 
position, thereby defeating MUP-IA capability to start automatically and enabling MUP-IB to take its place. The alarm status printout and sequence of event review indications on the following automatic ES actuation, 20 seconds later, supports that testimony.

"MUP-1A was left in pull-to-lock for the rest of the 16 hours reviewed by the investigation team. MUP-IA has reportedly been run. since the event, indicating the problem may be intermittent.

"At 15 hours 33 minutes into the event, the alarm status printout indicates an operator was attempting to start MUP-1C as an automatic ES actuation occurred. The pump did not start; but the alarm status printout indicates it was manually started by an operator 6 seconds later. The failure of MUP-IC to start during this ES actuation may be indicative of an example of a similar malfunction of the same type switch on another pump; but could also be related to the malfunction of several other components, such as a low lube oil pressure switch or one of several relays, which are not bypassed by the ES actuation signal.

"These switches are replacements for switches of the same type and manufacturer, of earlier vintage, that had experienced contactcam-follower failures. These switches are standard items used throughout the plant, but which are uniquely modified for the MUP application above." (NUREG I-4-76 through 78) 
"The information developed by the investigation team relative to this problem has been passed to the licensee and NRC management to ensure the ultimate resolution of the problem.

"During discussion with the licensee, the licensee indicated the problems with starting MUP-1A had been determined. The licensee investigation indicates the ammeter for MUP-IA was found s.tuck downscale and that the MUP had, in fact, started. The operator had seen the ammeter downscale and had secured the MUP.

"Analysis results of computer Alarm Typer records from March 28, 1979, challenge the credibility of the licensee's determination. The Alarm Typer record indicates the MUP-1A power supply breaker did not close at 04:00:05 and 08:18:53 during operator attemtps to start the MUP. Clearly, if the breaker does not close, the ammeter will not register current flow. It appears the licensee has not completed an adequate investigation of this matter." (NUREG-0600, I-4-78)

\section{Normal Feedwater Pumps}

An initiating event for the TMI-2 accident was the tripping of feedwater pumps $I A$ and IB on low feedwater pump suction. Low pump suction is related to operator actions in attempts to transfer resins from an isolated condensate polisher to the receiving tanks (NSAC-1, Sequence of Events, pages 2-3) and pump interlocks and wiring errors on the condensate pumps (NUREG-0600 I-4-4). In addition, "normal operating conditions of the condensate/feedwater systems were very near the design limits at full power." (NUREG$0600,(-1-7)$ 


\section{Other Pumps}

Auxiliary-Feedwater Pumps - started and performed as designed (NUREG-0600, 3, I-53).

Condenser Vacuum Pumps - 1702 unsuccessful start of condenser vacuum pump IA (for 11 minutes) - IC start successful.

Reactor Building Sump Pump - performed as designed. The high RB sump level was attributed to the blown rupture disc on the RCDT after opening of the EMOV.

\section{Radwaste System Pumps}

"Another potentially significant pathway developed at approximately 1352 on March 28 when seal water to various radwaste system pumps was lost. Seal water was lost because motor control centers (MCC) 2-32A and 2-42A became inoperable (Ref. 126). MCC 2-32A was made operable again at 0700 on March 29. Loss of seal water resulted in significant leakage from pumps WDL-P-5A \& B, which take suction on the reactor coolant bleed tanks (Ref. 127). Because of letdown relief valve (MR-R-3) discharges and because of their use in the letdown flow path, these tanks contained high levels of radioactivity. A sample of RCBHT-C on March 30 showed an iodine-131. concentration of $109 \mu \mathrm{Ci} /$ $\mathrm{ml}$ (Ref. 128). Other radwaste pumps were of less significance since the pumps were taking suction on tanks containing pre-accident water." (NUREG-0600, II-3-13) 


\subsubsection{Required or Suggested Corrective Action}

The following items are currently under evaluation by the NRC as possible items of noncompliance with regard to TMI-2 pumps:

1. "Based on the records review of the RCS/temperature relationships and discussions with licensee personnel, the low pressure RCP trip criteria was exceeded early in the event. Also, the discussion indicated that the pump vibration indicators had increased to their full scale indicating condition. Section 2.5 of Details I describes an item being considered as a possible item of noncompliance related to the failure to follow procedure and trip the RCPs." (Failure to take operator action NUREG-0600, I-4-26)

2. "The failure to maintain the operation of the high pressure injection system delivering the design injection flow to the reactor core of 250 gPm per HPI flow leg (4), during the accident, in accordance with the requirements of emergency procedure 2202-1.3, Rev. 8, Section B, step 2.2.3 and 3.5 resulted in apparent serious core damage and onsite and offsite exposures to radioactive materials. This failure to maintain the HPI system in accordance with procedure 2202-1.3 is under consideration as a potential item of noncompliance pursuant to Technical Specification 6.8.1.a." (Improper operator action NUREG-0600, I-2-21)

3. (Make up pumps) "High pressure safety injection was initiated at $0720 \mathrm{hrs}$ and MU-PIA started and operated until $0737 \mathrm{hrs}$, when the operator, having reset the ES signal at $0727 \mathrm{hrs}$, stopped the IC MUP. The MUP-1A continued to operate until $0756 \mathrm{hrs}$, when the building isolation occurred and the MUP-IC started. The MUP $-1 A$ and MUP-IC pumps operated in the (HPI) mode 
until about $0817 \mathrm{hrs,}$, when the operator stopped both $1 \mathrm{~A}$ and $1 \mathrm{C}$ pumps. The operator immediately attempted unsuccessfully to start the MUP-IA to reestablish RCP seal water injection. The MUP-1A control switch was placed in the PULL-TO-LOCK position and apparently remained in that position until after 2000 hrs due to the failure of the pump to start manually and the belief the pump had a mechanical problem. The investigation of this area indicates that the pump breaker, could not have closed, which led the operator to misunderstand indications." (Bypassed ability to initiate)

\subsubsection{Relation to Sandia Research Program}

Significant problems with pumps at TMI can apparently be simplified as follows:

\begin{tabular}{|c|c|c|}
\hline Feedwater & $\rightarrow$ & $\begin{array}{l}\text { operate close to design limits } \\
\text { maintenance activities caused low } \\
\text { suction and trip }\end{array}$ \\
\hline $\begin{array}{l}\text { Reactor Coolant } \\
\text { Pumps }\end{array}$ & $\rightarrow$ & $\begin{array}{l}\text { primary system saturation caused } \\
\text { vibration caviation }\end{array}$ \\
\hline HPI & $\rightarrow$ & $\begin{array}{l}\text { operator action throttled pump flow } \\
\text { when full flow required }\end{array}$ \\
\hline Makeup Pumps & $\rightarrow$ & $\begin{array}{l}\text { interlocks and control positions } \\
\text { defeated ability to start }\end{array}$ \\
\hline $\begin{array}{l}\text { 0i1 Pumps } \\
\text { for RCP }\end{array}$ & $\rightarrow$ & lack of power \\
\hline $\begin{array}{l}\text { Condenser Vacuum } \\
\text { Pump Delay }\end{array}$ & $\rightarrow$ & cause unknown \\
\hline
\end{tabular}

The relevance of Sandia objectives (relative to pumps). to TMI events and literature is presented in table 3.3 . 
TABLE $3: 3$

Research Program - 3. Pumps

PARTIAL OBJECTIVES

OF RESEARCH PF.OGRAM

1. Develop variable speed reactor coolant pumps

2. Improve understanding of hydrodynamic instabilities and improve pump rotor design

3. Determine advisability of leak collection systems for pump seals

4. Determine and improve performance under accident conditions

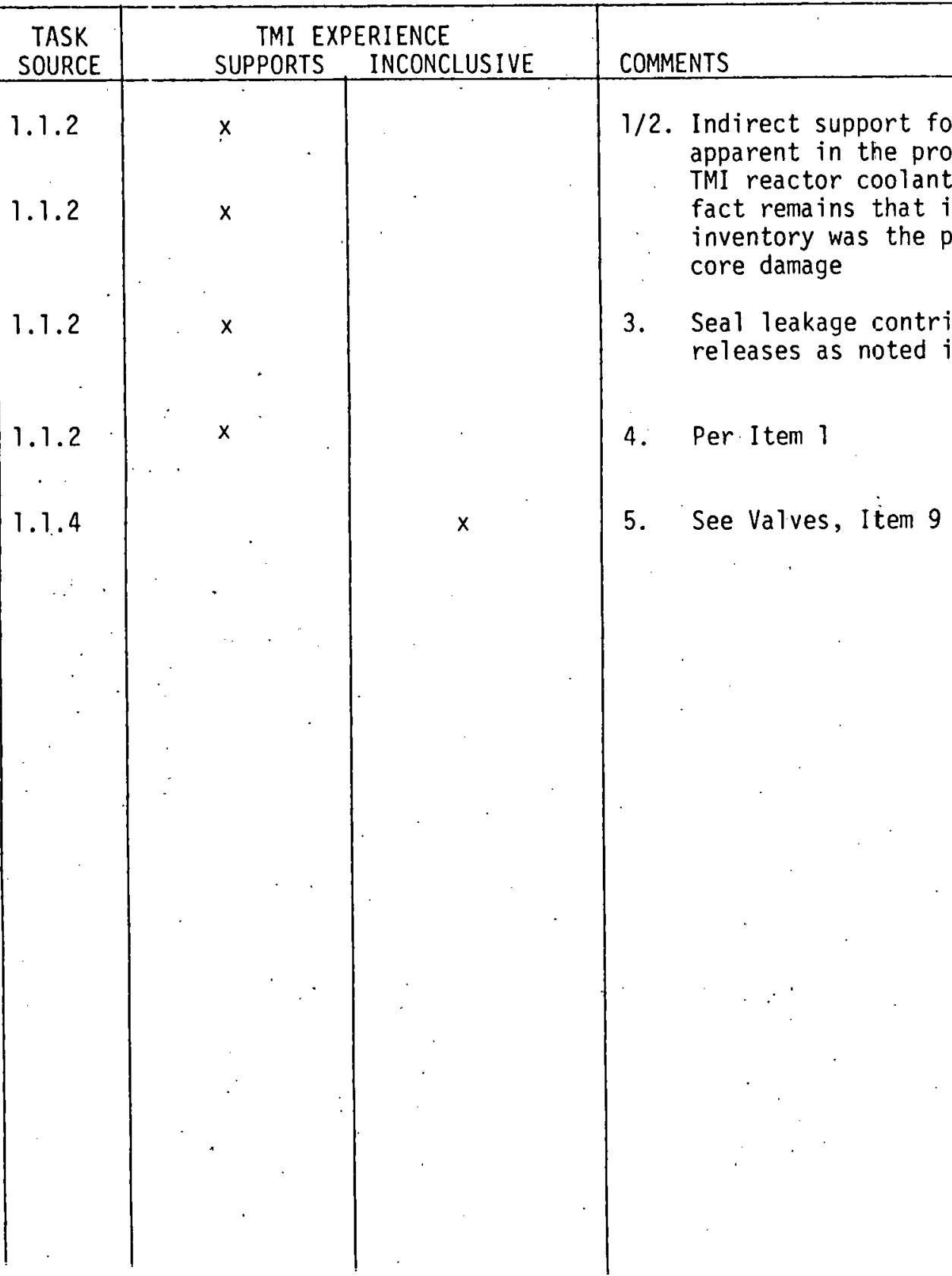


Based on the preceeding information the following observations and suggestions are made with regard to Sandia tasks.

1. Although significant attention is being devoted to the TMI events following the loss of feedwater transient, less is devoted to the initiating event. The NRC statement that the feedwater/condensate system operates close to design 1 imits during full power operation and that feedwater pumps tripped on low suction suggests the event may have been avoided through better pump design or selection.

2. Some pump problems in the short term at TMI were the result of control circuitry as opposed to pump failure suggesting a need to concentrate some attention in this area.

3. Although caviation was indeed a cause of RCP vibration and subsequent operator action to trip these pumps, it is not clear that RCPs that could operate at lower flow would have significantly altered the course of the TMI-2 accident. However, vibration (as well as low flow and other factors) played a significant role in the decision to terminate RCP operation. Hence, a pump design capable of withstanding cavitation (or one designed to vibrate less during caviation) and saturation conditions may or may not have been tripped. Vibration problems with the pumps, however, certainiy occupied operator thought processes which may have contributed to confusion and lack of attention to other conditions.

4. The loss of power to the oil pumps delayed attempts to restart RCPS. In cases where failure of pumps can affect operation of essential equipment, design attention should be focused. 
5. Plant procedures and equipment manuals were inconsistent with regard to RCP vibration indications and causes. Although apparentiy not significant with regard to the RCPs, such confusion could distract or utilize personnel whose attention could be focused elsewhere. 
3.4 STEAM GENERATORS

3.4.1 Summary of Research Projects

Sandia research programs related to steam generators have the following general objectives:

1. Improve qualification under normal and accident conditions

2. Improve understanding of operating modes and safety

\subsubsection{Related TMI Events and Actions}

The TMI-2 design includes two once through steam generators (OTSG). During the course of the TMI-2 accident, the OTSGs performed as discussed below.

Following the loss of feedwater, the operator properly placed attention on the OTSG water level. Actions within the first five minutes included verification of emergency feedwater pump start and level control valves traveling. After noting continued water level decrease, the operator placed the control valves in manual and raised the demand signals to full open. With continued attention focused on the SG level (now essentially dry) of the operator and shift supervisor, at approximately eight minutes into the event it was noted that the emergency feedwater header isolation valves were closed at which time the operator immediately opened these valves (NUREG-0600, I-2-4.). Approximately 13 minutes and 17 minutes were required for $A$ and $B$ OTSG to restore minimum level of 18" attributed to throttled feedwater flow to avoid thermal shock by the NRC (NUREG-0600, I-2-7). 
Over the next several hours, operators manipulated feedwater manually to maintain OTSG levels. At 0426 the operator tripped an emergency feedwater pump when OTSG " $B$ " level began increasing above low-level. Emergency pumps $2 B$ and $2 A$ were tripped at 0436 acid 0711 respectively.

"The emergency feedwater pump (EF-P2A) was started at 0735 hrs and operated until 0842 hrs to feed the "A" OTSG as needed to maintain $50 \%$ level on the operating range.

"The "A" OTSG level was raised at 1000 hrs to $94-97 \%$ on the operating range using the water from the hotwell via the condensate pump discharge/booster pump suction pressure to enhance decay heat removal. The "A" OTSG pressure during that period decreased from $140 \mathrm{psig}$ to $20 \mathrm{psig}$ and then to 0 psig by $1200 \mathrm{hrs}$. The emergency feedwater pump (EF-P2A) was started and operated for 8 minutes at 1109 hrs to assist in feeding the "A" OTSG which was near the discharge pressure of the condensate header.

"The "B" OTSG level was increased from $60 \%$ to $90 \%$ on the operating range at 1600 hrs using the emergency feedwater pump (EG-P2A) at 1534 hrs for 18 minutes in preparation for the continued plant shutdown." (NUREG-0600, I-2-9)

"The operations staff initialiy concluded that the B OTSG had a shell side leak based on the increasing reactor building temperatures coincident with a normal RCS pressurizer level. This conclusion by the staff was also supported by the lack of any reactor building radiation alarms early in the accident." (NUREG-0600, I-2-31) 
"The operating staff did not relate the continuing heat load in the reactor building to the loss of coolant accident even through the assumption of a B OTSG shell side leak to reactor building could not be supported. The RCS temperatures were stable and the B OTSG level was increasing with minimal feedwater required. Furthermore, the feedwater to the B OTSG was completely isolated at 0428 hrs by the operators because of difficulties in maintaining OTSG level.

"The substantial evidence of a LOCA was indicated by the continuing RB high temperature with the full reactor building cooling system in operation (10 million to 100 million BTU per hr heat removal capability) and the continuing low RCS system pressure.

"The operators completed isolation of the B OTSG at about 0527 hrs based on 300 psig difference between the A OTSG and the B OTSG. The operators did not recognize that the pressure differential was caused by inadequate backflow through the B loop after the RCPs were stopped in the B loop at 0514 hrs.

"The brief unisolating of the B OTSG at about 0656 hrs indicated to the operators that the B OTSG had suffered a tube leak; since the condenser off gas monitor (UA-R-748) alarmed." (NUREG-0600, I-2-30 through 32)

Following attempts to achieve natural circulation, "The operators stated that they did not feel that natural circulation was established because of the differential temperature across the A OTSG $\left(T_{h}-530^{\circ} \mathrm{F}\right.$, TC $-520^{\circ} \mathrm{F}$ at 0652 hrs and diverging), the low A OTSG secondary pressure ( $800 \mathrm{psig}$ and decreasing), and the minimum feeding and steaming rates for the A OTSG. At approximately 0610 hrs the $A$ loop $T_{h}$ had increased to $620^{\circ} \mathrm{F}$, the recorder off scale high; 
$\mathrm{T} \psi$ had decreased to about $480^{\circ} \mathrm{F}$ differential temperature of $140^{\circ} \mathrm{F}$; and the operators expected a differential temperature of $25^{\circ} \mathrm{F}$. Some heat was being removed through the steam condensing mode within the steam generators, but the continuous decrease in the A OTSG pressure indicated that the heat removal from the RCS was limited." (NUREG-0600, I-2-33 through 34)

During the next several hours, operators continued to monitor OTSG differential temperature in attempts to understand reactor status.

The NRC's conclusion of the impact of delayed emergency feedwater into the SG (NUREG-0600, I-4-10) is:

"The delay in automatic initiation of emergency feedwater for 8 minutes contributed to an early recovery towards normal values of certain RCS parameters upon which the operators concentrate. This recovery of key turbine trip/reactor trip RCS parameters misled the operators into believing that their actions had been successful in limiting the severity of the transient. This erroneous belief led them to initiate the routine subsequent operator actions that were normal for the assumed transient. These actions occupied the operators' attention and detracted from their opportunity to establish a correct analysis of the plant conditions. This investigation did not conclude what the ultimate course of events of the accident would have been, had emergency feedwater been introduced to the OTSGs as designed. Based on interviews conducted with 
the operating staff, it is concluded that once the accident was underway and after the valves were open, the knowledge that the valves were previously shut had no substantive impact on the actions of the operators during the remainder of the accident."

After considerable evaluation, the approved mode of long-term cooling involved utilizing both steam generators in water solid operation (NUREG-0557, Appendix B). In essence, the concepts involved pumps and heat exchangers to circulate cooling water in the liquid state in a loop through the OTSGS, the steam piping and the feedwater piping. The secondary side of the OTSG was maintained at a positive pressure relative to the primary system to ensure leakage would be from the secondary side to the primary.

\subsubsection{Required or Suggested Corrective Action}

The following item is under consideration by the NRC as a potential item of noncompliance:

"Technical Specification 6.8.1.a requires written procedures shall be implemented covering activities referenced by applicable procedures recommended in Appendix " $A$ " of Regulatory Guide 1.33, November 1972. Appendix A of Regulatory Guide 1.33 recommends written procedures covering "Loss of Feedwater" and "Turbine Trip". Unit 2 Emergency Procedures 2202-2.2, Loss of Feedwater, Revision 3, October 13, 1978, and 2203-2.2, Turbine Trip, Revision 7, October 25 , 1978, require that the operator verify that the OTSG levels are being automatically controlled at 30 inches on the SU range indication contrary to the requirement to control level at 30 inches, the level control valves were placed in "manual" 
and throttled to control RCS temperature and pressure before the 30 inch level was established. The A and $B$ OTSG levels remained below 30 inches from 0408 hours through 0420 hours and 0425 hours respectively. Moreover, the A OTSG level was below 30 inches between 0532 hours and 0543 hours. In both these examples, the affected OTSGs were taken to a dry condition as a result of this improper and/or inadequate manual control." (NUREG-0600, IB-7)

ACRS recommendations directly relevant to steam generators and Sandià research are:

Accident and Transient Analyses

The ACRS Recommends that further analyses be made of the course, consequence and probability of transients which would lead to gross overfilling of the secondary side of the steam generator in PURs and the equivalent event in BWRs in order to ascertain whether any additional measures are appropriate to provide additional protection of the public health and safety.

\subsubsection{Relàtion to Sandia Research Programs}

The following general observations are offered:

1. During the initial 8 minutes of the accident, the OTSG response to no feedwater contributed to an apparent early recovery of RCS paramaters. A thorough understanding of $S G$ operation under normal and abnormal conditions and imparting this knowledge upon operators is necessary. 
2. Throttled emergency feedwater flow, once initiated at 8 minutes, was reportedly a result of operator fears of thermal shock to the OTSG. Sandia research may serve to understand and improve performance to appropriately align operator thought processes to $S G$ susceptability to this phenomena. In addition, operator attention focused on OTSG following emergency feedwater flow initiation could have been devoted elsewhere.

3. Perhaps the most significant event related to the steam generators was the inaccurate operator conclusion that OTSGB tube leaks were the cause of key indications rather than a LOCA. Were these symptoms not present, earlier diagnosis of the safety valve being stuck open could have occurred.

The relevance of Sandia objectives (related to steam generators) to TMI events and literature is presented in table 3.4 . 
TABLE 3.4

Research Program - 4. Steam Generators

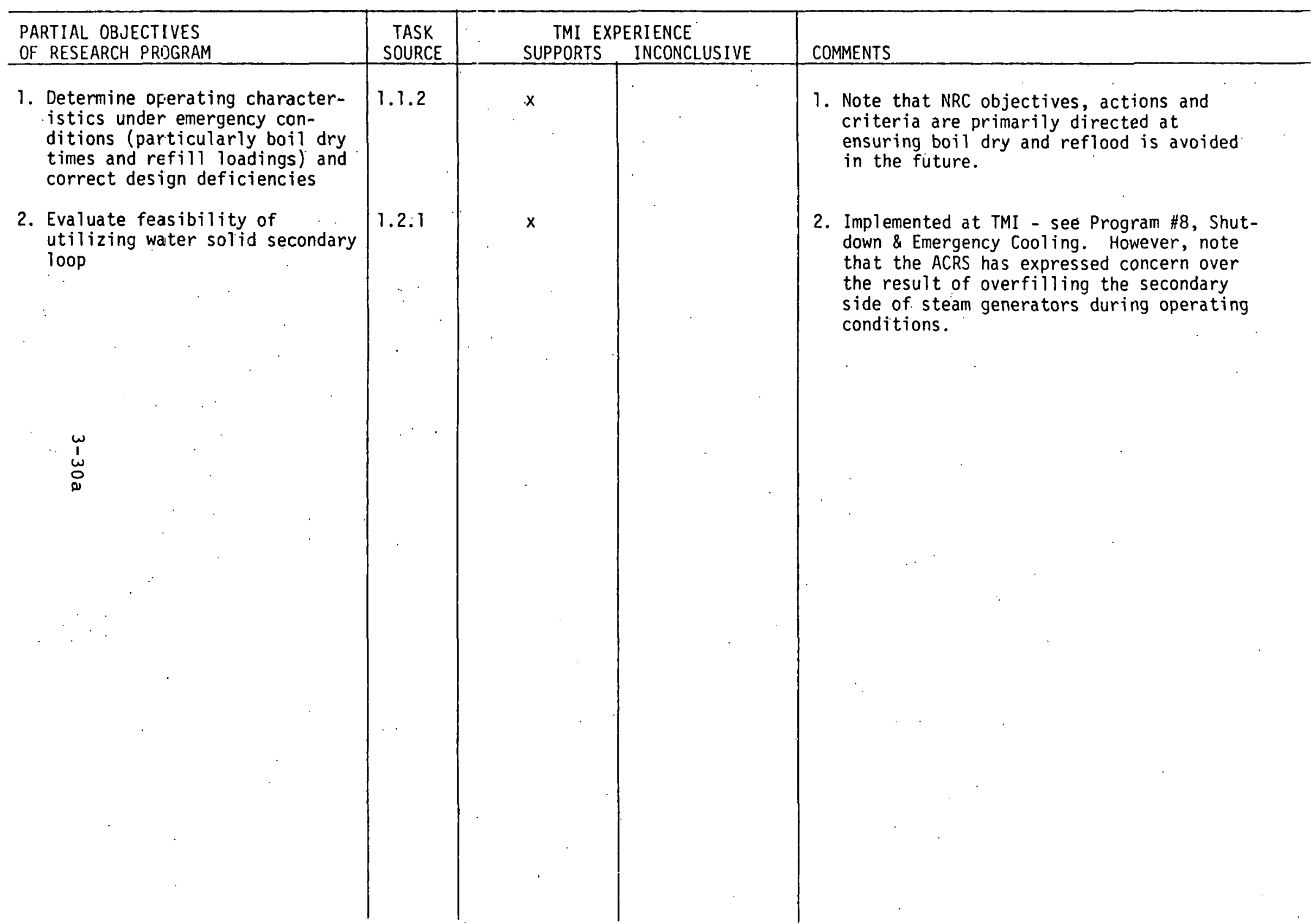




\section{$3.5 \quad$ PIPING}

3.5.1 Summary of Sandia Research Program

The summary objective of Sandia tasks in this area is to improve piping design towards minimizing piping failures.

\subsubsection{Relevant TMI Events and Actions}

Review of. TMI documentation has discovered two incidents of apparent pipe failure. In neither of these cases; however, are details currently available on the cause or effect of these failures.

1. "At approximately 0440, Auxiliary 0perator B was told by a CRO to check for makeup valve alignment for demineralized water to the makeup system. He noticed while assisting closure of $\mathrm{CO}-\mathrm{V} 12$ that efforts were underway to lower the hotwell level. He also noticed that the air supply line to the pneumatic actuator to the normal condensate reject line was failed and blowing air." (NUREG-0600, I-2-52)

2. "Between 0405 and 0653 during attempts to reestablish the condensate system "the operators discovered a leak in the $2 A$ condensate booster pump suction line and isolated pump locally to prevent spilling condensate water to the turbine building floor and sump". (I-2-27) 
During a review of long-term core cooling, the NRC (NUREG-0557) evaluated the structural adequacy of main steam piping which was to be used to transport cooling water in the liquid state.

"A specific concern that we have addressed in our review is the structural adequacy of that portion of the Main Steam piping system which as incorporated into the OTSG cooling system will contain solid water in lieu of the pressurized steam for which it was designed. Components in the system will not experience any significant dynamic loads. Special precautions will be taken during the initial filling and startup of the system to minimize the potential for water hammer. Loads that will be experienced include pressure, deadweight of water, and thermal expansion. Since the system will be operated at a maximum pressure of about half the design pressure of the piping and its maximum operating temperatures will be considerably lower than the design temperature of the main steam piping; stresses resulting from these loads will be minimal." (NUREG-0557, B-15)

\subsubsection{Required or Suggested Corrective Action}

As it appears that piping failures did not significantly contribute to the TMI-2 accident sequence, very little direct attention is being focused on piping. However, as reported elsewhere in this report, the capability of TMI and all other commercial reactor facilities to respond properly to a small LOCA is under close scrutiny. 


\subsubsection{Relationship to Sandia Research Program}

As stated above, piping failures are receiving minimal attention in this post-TMI-2 era. In light of thorough review of plant capabilities that is in progress, it would be inappropriate to exclude piping failures evaluation if the review process is to be complete. Although not directly a result of the TMI-2 accident, a recent (August 16, 1979) ACRS letter that addresses pipe failure is included in section 4 which exemplifies current concerns over pipe cracking.

The relevance of Sandia objectives (relative to piping) to TMI events and literature is presented in table 3.5. 
TABLE 3.5

Research Program - 5. Piping

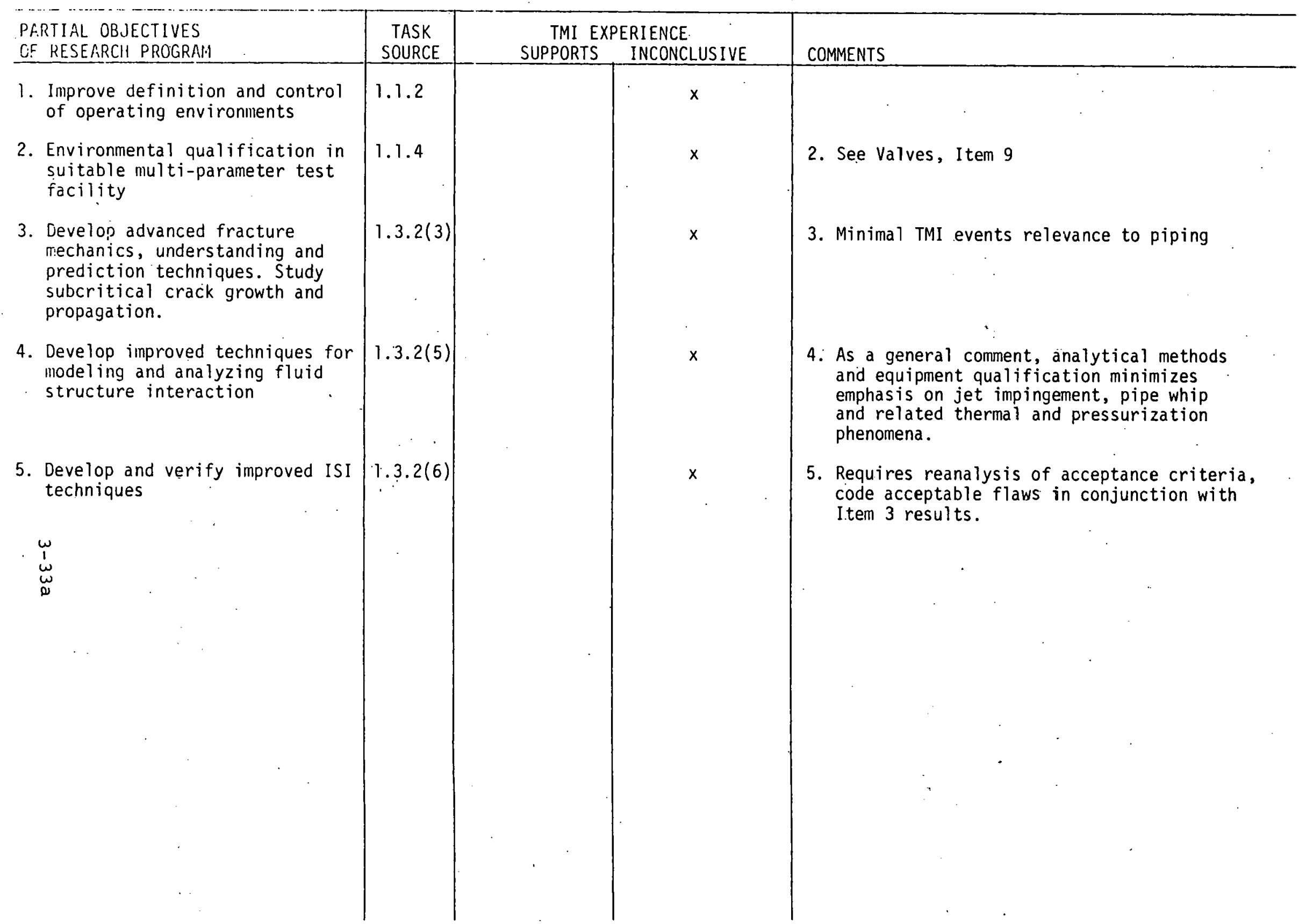


Of the specific NRC unresolved safety issues discussed by Sandia, the sole reference to these items identified is the following:

\begin{abstract}
"The rapid addition of cold RCS makeup should be avoided since the makeup inlet points are located in the RCS cold legs, and the cold fluid would travel into the reactor inlet nozzles, down the downcomer, then into the inlet plenum. The cold makeup could cause thermal shock and brittle fracture potential for the reactor vessel since there is no heating of the fluid until it enters the core. Therefore, continuous rather than intermittent RCS makeup should be considered. Consideration should also be given to provisions for heating of makeup water to the long term primary coolant temperature.
\end{abstract}

Fracture mechanics calculations have been performed for several cases that could be encountered in the planned cooldown of TMI-2. In all cases, the possible atypical weld metal in the lower head is limiting. Nevertheless, assuming reasonable mixing of the water, our calculations show that there is no need for concern about brittle fracture of the vessel unless extremely unlikely conditions occur." (NUREG-0557, 6-4)

In light of the NRC's above determination, TMI-2 events have had minimal relevance to Sandia Research Programs in this area. Table 3.6 summarizes Sandia objectives in this area and TMI -2 related events and literature. 
TABLE 3.6

Research Program - 6. NRC Unresolved Safety Issues

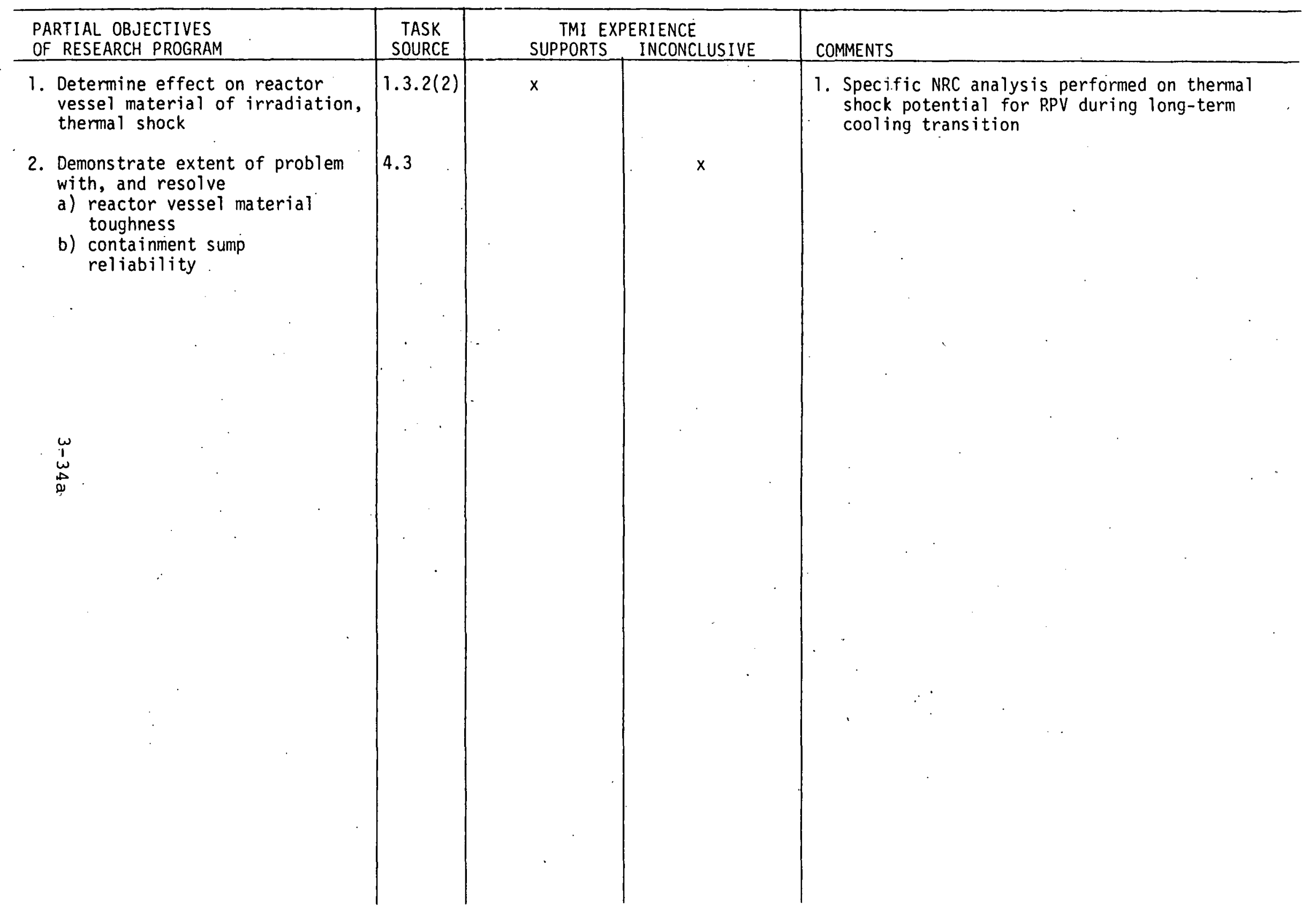




\subsection{FUEL PERFORMANCE}

\subsubsection{Summary of Sandia Research Program}

Sandia tasks grouped into this research project are principally aimed at (1) obtaining a better understanding of the phenomena (i.e., stress corrosion cracking, PCI, creep collapse, fuel clad thermal ratcheting, strain cycling, irradiation impact on ductility and DNB) that can cause fuel cladding failure, (2) applying. knowledge gained to improve fuel design or design methods, and (3) improving methods of detecting cladding failures or flaws while in service.

\subsubsection{Relevant TMI Events and Actions}

Specific TMI events and actions during and subsequent to the accident related to fuel and fuel failures have concentrated on:

1. Quantity and rate of cladding induced metal-water reaction forming hydrogen.

2. Fuel performance, including failure mode quantity and rate of radioactive material introduction into primary system.

3. Overall fuel core geometric response to degraded coolant inventory, flow and thermal transients.

The characteristics of fuel had a significant influence upon operator actions through the course of the accident and on-site and off-site radiological releases. In addition, the state of the fuel will significantly influence the methods and timing of decontamination and recovery operations. Directly applicable operator actions responding to fuel-related phenomena are treated by example. 
It is not the intent of this section to repeat the radiological sequence of events reported in NUREG-0600 and other documents. Rather, the fuel temperature, plant radiation levels and other characteristics which affected when and what operator actions were taken are discussed.

Between 0618-0630 plant operator intentions to enter containment to manually vent RCS hot legs were abandoned by the occurrance of radiation alarms. At 0654 operators start and run RCP 2B for 19 minutes because of radiation and uncertainty as to whether natural circulation was established. At 0656 operator opens and then closes "B" OTSG MSIVS (MS-V4B \& 7B), within 7 seconds. (Operator actions in cycling these vavles have not been explained. Operators speculate that this event may represent inadvertent actions associated with attempts to cope with the rapidly deteriorating situation, which included offgas radiation monitor alarms. It should be noted that operation of these MSIVs does not affect steam flow to the condenser if the turbine bypass controls are in "Hand", which they reportedly were at this time.) HP Technician reports over page that letdown sample lines from Unit 2 were reading $600 \mathrm{R}$. Auxiliary building evacuated. Unit 2 Shift Supervisor and Technical Superintendent then declared a site emergency. Declaration based on radiation alarms in more than one area. Notification of offsite authorities begins. (0600 sequence)

At approximately 0715 the control building was evacuated with exception of the control room, followed in ten minutes by a declaration of general emergency.

At 0743 there was an indication of rapidly increasing SRM count rate concurrent with a rapid pressure increase. This is the only time this occurs during the accident. All other increases in SRM count rate appear to correlate to periods of apparent increased voiding associated with decreasing RCS pressure 
and/or loss of heat, sink. Further, the alarm printer indicates a proliferation of "BAD" incore flux and temperature indications. The indications are consistent with an assumption that a core geometry shift has occurred. Operator begins raising "A" OTSG leve? back to $50 \%$ to $55 \%$ range.

On several occasions, operators in both Unit 2 and Unit 1 were advised or required to wear respirators. The extent to which communications and operator actions were impaired by these devices is unknown.

At approximately 1351, a pressure spike occurred in the containment that has subsequently been attributed to hydrogen burning. THE NRC investigation concluded

"that the staff on duty in the control room did not attach any special significance to the pressure spike. Those who actually saw the spike related it to opening of the EMOV and did not attach significance to another cause. It should also be noted that the recorder displaying the spike displays the trace for approximately 2 hours, after which the trace must be removed from the recorder or the recorder pulled out to the extended position in order to be viewed." (NUREG-0600, I-4-49)

With regard to specific timing and cause of fuel failure, NUREG-0600 concludes the following:

"The onset of significant release of activity from the fuel because of inadequate cooling cannot be fixed in time. Review of radiation monitor charts for the hot machine shop, 
structural damage to the core is thought to have occurred when an RCP was started at 0654 hrs. When the pump was started, a rapid quenching of the core is indicated by the SRM and IRM response addressed below. In addition, the core reflood was attended by a rapid pressure change."

When primary system parameters stabilized sufficiently after several weeks, preparations were begun for attempts to establish natural circulation. As previously discussed in Section 2.5 , the NRC's safety evaluation on TMI -2 transition to natural circulation is presented in NUREG-0557. This document devotes considerable discussion to calculations and models that were applied in attempts to assess the conditions of the TMI-2 core. The critical parameter used to characterize core conditions is core flow resistance. Calculations demonstrate that coolant flow rate through the core is extremely sensitive to this parameter. The ultimate decision on which method provided greatest assurance and safety represented a comprimise, in part, due to uncertainty in core configuration and physical conditions. In sum, "an understanding of core damage is an important factor in assessing the adequacy of core cooling in the proposed natural circulation mode".

\subsubsection{Required or Suggested Corrective Action}

Although physical access to the core is required to improve understanding of fuel failure mechanisms, there is little doubt that the cause of fuel failure is deprivation of adequate coolant. This situation was aggravated in part by the generation or release of non-condensabies from the fuel and fuel coolant interaction. Preventive action has been taken by the NRC to ensure other reactor operators are aware and react properly to similar 
situations through proper manipulation of controls, revised procedures and design changes.

With regard to hydrogen, the majority view of the NRC Lessons Learned Task Force is that:

"The hydrogen problem at TMI-2 was a short-term situation and fortunately was safely relieved by the apparent combustion of hydrogen in the containment building. The source of this hydrogen was the metalwater reaction of a sizeable fraction of the zircalloy in the core. This amount of hydrogen generation was well in excess of the amount required by the Commission regulations as a design basis for any type of postaccident combustible gas control system.

"The course of events at TMI-2 with respect to hydrogen production and control in containment has indicated a need for thorough reconsideration of the Commission's design basis for combustible gas control. systems. This should include both a re-examination of the reactor system effects (i.e., coupling the ECCS evaluation and the assumption of hydrogen produced by metal-water reaction) and the acceptability of 10 CFT Part 100 guidelines. for evaluation of offsite doses from purposeful releases from the containment. In general, the accident at TMI-2 raises the question of whether the short-term design basis for 
incore detector cabinets and the reactor building dome monitor indicates fuel failures occurring prior to 0630 hrs. Basically two failure mechanisms can be postulated for release of activity from the fuel.

"The first failure mechanism is associated with the pressure differential across the cladding and is related to the pin compression factors. Pin compression factors appear to have been violated within the first 20 minutes of the accident. Technical Specifications do not address pin compression factors. The temperature-pressure relationship as experienced in the transient are plotted (in NUREG0600). Review of activity levels in the RCS as monitored by chemical analysis and radiation monitors does not indicate untoward releases of activity prior to core becoming uncovered. Lower pressures and higher temperatures were experienced during the period when core became uncovered. There is a likelihood that there was some mechanical failure of the cladding during this period.

"There is almost virtual certainty that a zirconiumwater reaction took place based on the release of hydrogen from the RCS. The temperature design limit for loss of coolant accidents is $2200^{\circ} \mathrm{F}$ peak clad temperature Temperatures of this order were indicated by the incore thermocouples at approximately $0900 \mathrm{hrs}$ after the core was reflooded. It is thought that this temperature was reached earlier when the core was uncovered, al though there is no direct evidence of this. Significant 
post-accident combustible gas control systems (metalwater reaction) is underestimated and the long-term design basis (radiolysis and corrosion) is overestimated, resulting in a hydrogen recombiner design that is not capable of providing short-term protection any may not have been needed in the long term.

Because of these considerations, it is the conclusion of the majority of the Lessons Learned Task Force that provisions for the post-accident installation of recombiners should not be required as a short-term action. Such consideration should be part of the long-term reconsideration of the design basis for combustible gas control systems." (NUREG0578, A-22)

3.7.4 Relationship to Sandia Research Program

Consistent with the Sandia Research Program, the experience at TMI-2 demonstrated the need for the following:

1. A thorough understanding of fuel behavior and failure. mechanisms during the spectrum of degraded cooling over sustained periods of time.

2. Simultaneous correlation and development of accurate calculational models to accurately track and determine the physical state of fuel and core during such periods.

3. A thorough understanding of metal-water reaction phenomena leading to hydrogen generation, including 
TABLE 3.7

Research Program - 7. Fuel

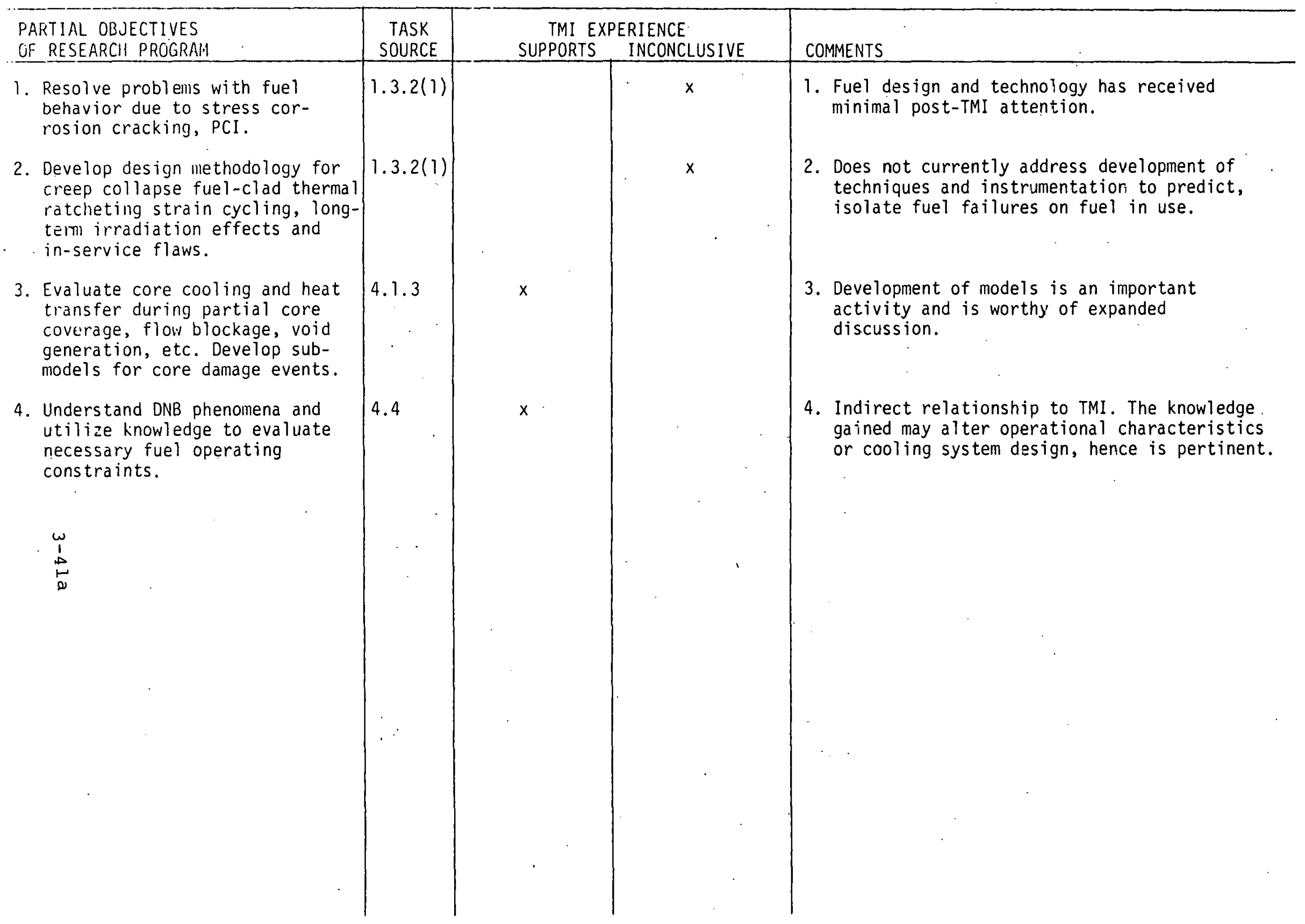


the rates of such reactions under a wide variety of circumstances. In addition, radiolytic decomposition leading to hydrogen generation needs to be better understood, quantified and factored into reactor design.

The relevance of Sandia objectives (relative to fuel) to TMI-2 events and actions is presented in table 3.8 . 
TABLE 3.8

Research Program - 8. Shutdown and Emergency Cooling

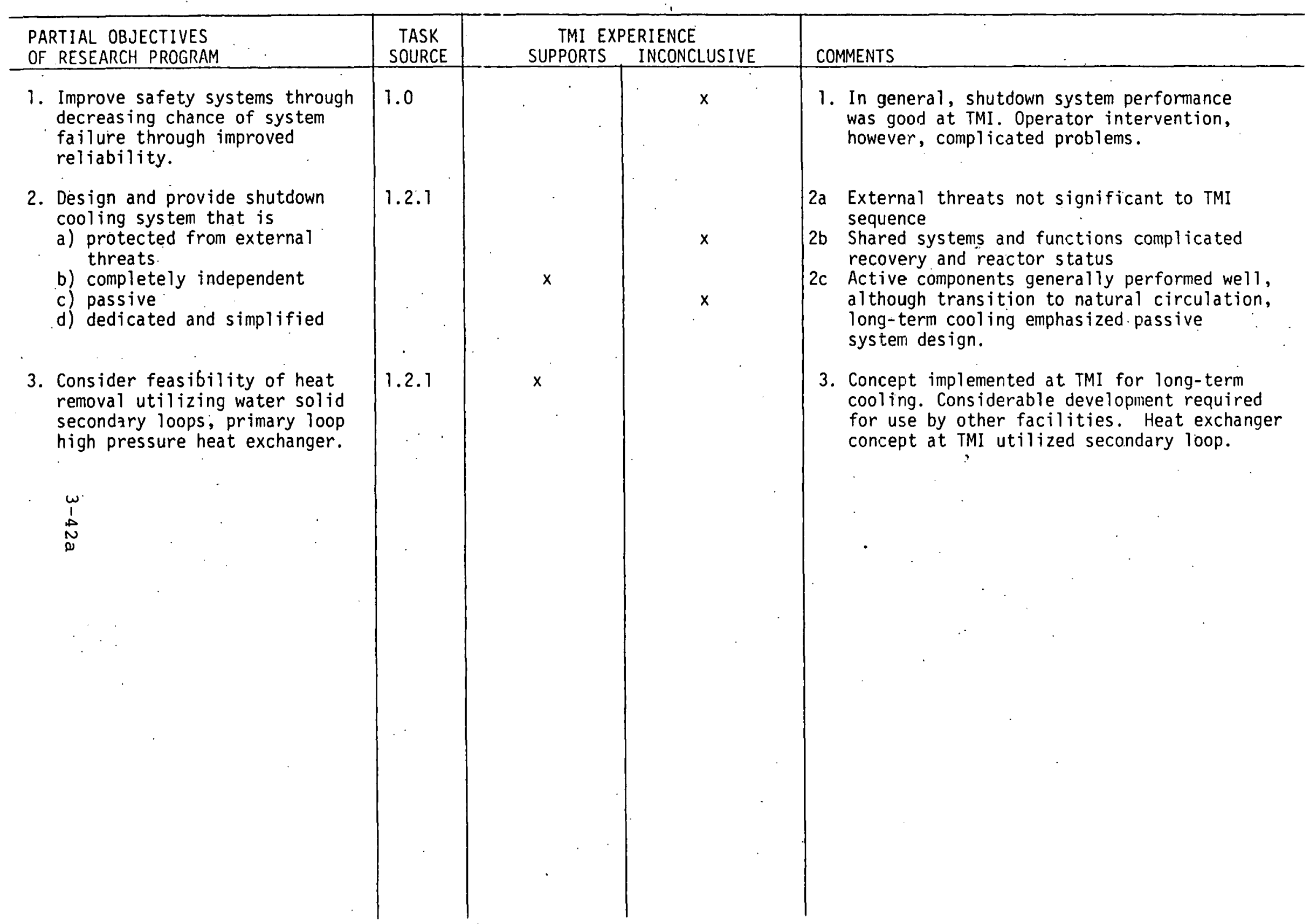




\subsubsection{Summary of Sandia Research Program}

Tasks in this area are aimed at (1) developing additional, completely independent shutdown (and emergency) cooling systems with a minimum dependency on operator action or active components, and (2) improving existing systems by simplifying. functions and design.

\subsubsection{Relevant TMI events and Actions}

How and why the TMI-2 shutdown cooling systems performed as they did during the accident is discussed in this section. The "why" is particularly significant as operator action, taken on the basis of available information and judgment, allowed perturbation and defeat of the design and operation of these systems.

The ability of systems to function as designed depends primarily upon the following:

1. Presence of appropriate initiating signals and proper functioning of control devices and instrumentation.

2. Proper functioning of active components such as pumps and valves and passive components such as piping.

3. Available auxiliary systems such as electrical power for pumps and valves, instrument air for valves, pump cooling and lubrication and sufficient water for maintaining system flow within acceptable limits. 
At TMI-2 emergency and shutdown cooling systems fallures and their cause are discussed below.

\section{Emergency Feedwater System}

On loss of normal feedwater, the emergency (often referred to as auxiliary) feedwater system is designed to activate and supply sufficient feedwater to the steam generators to remove primary system heat.

1. Failure to deliver emergency feedwater to OTSG for the initial eight minutes

Primary Cause: "Emergency feedwater header isolation vaives (EF-VI2A and 12B) closed." (NUREG-0600, I-2-5) These valves are not automatically opened on emergency feedwater system demands. They are required to be open during plant operation.

Related Events: "At approximately 5 minutes into the turbine trip transient, the operator noted that the emergency feedwater level control valves were continuing to travel to the open position. The valves were not supplied adequate air to operate. The valves fail 'as is' and only respond if air pressure is available. It can be reasonably postulated that the failure of the condensate polisher outlet valves to the closed position (loss of instrument air pressure) and the failure of the emergency feedwater valves to respond normally (loss of instrument air pressure) were related. Operator interviews revealed that the valves did not appear to operate properly." (I-2-4) 


\section{Subsequent emergency feedwater system response}

The ability of the emergency feedwater system to respond automaticall: was defeated by operator eariy into the accident. The NRC's evaluation of this action is reproduced below.

"The stopping of the steam driven emeryency feedwater pump (EF-PI) at $0426 \mathrm{hrs}$ and the motor-driven emergency feedwater pump (EF-P2B) (secondary emergency feedwater pump stopped) by placing the control switches for the steam supply valve (MS-V207) and the pump switch (EF-P2B) to the PULL-TO-LOCK position (nonautomatic) at 1040 psig in the OTSGs (greater than $600 \mathrm{psig}$ ) is a violation of the operating proceudre for unit cooldown, Step $4.14 \mathrm{a}$. The A OTSG pressure remained above 800 psig until approximately $0545 \mathrm{hrs}$. The emergency feedwater pumps start automatically upon loss of two main feedwater pumps if the control switches are in the NORMAL-AFTER-STOP position.

"Technical Specification 3.7.1.2 requires that the Emergency Feedwater System be "OPERABLE" in Modes 1, 2 and 3 above 800 psig OTSG pressure with two flow paths, two motor-driven emergency feedwater pumps, and one steamdriven dmergency feedwater pump. The failure to maintain the emergency feedwater system in the fully operable status subsequent to $0426 \mathrm{hrs}$ (turbine-driven emergency feedwater pump-EF-PI) stopped, and $0436 \mathrm{hrs}$ (motor-driven emergency feedwater pump-EF-P2B) stopped, by placing the 
control switches to the non-automatic (PULL-TO-LOCK) position, at 1040 psig in the OTSG (greater than 800 psig) is being considered as a potential item of noncompliance." (NUREG-0600, I-2-9)

High Pressure Injection, Makeup and Purification System (HPI)

The high pressure injection system is designed to perform the following functions during normal operation:

- "Provide makeup to the reactor coolant system for normal inventory control.

0 Provide injection water to the reactor coolant pump seals.

- Remove corrosion and fission products from the reactor coolant system during purification operations.

- Control the boron concentration of the reactor coolant.

- In conjunction with the pressurizer, accommodate temporary changes in reactor coolant volume due to small temperature changes.

- Maintain proper concentration of hydrogen and corrosion inhibiting chemicals in the reactor coolant.

o Supply borated makeup water to the core flood tanks.

- Provide makeup to the reactor coolant system for leakage and small breaks in the reactor coolant pressure boundary." (NSAC-1, App. HPI) 
In addition to the preceeding, the HPI system provides high pressure coolant injection following a LOCA.

Initially the HPI system automatically responded to the transient as designed. With the exception of the pump starting problems discussed in Section 3.3, automatic system response was as designed except when interfered with. The following excerpt from NUREG-0600, I-4-13 provides an overview discussion of the reason for insufficient RCS inventory:

"Interviews with the operating and training personnel (see Section 2.15) indicated that the operators would respond specifically to the pressurizer level in almost any circumstances, because they were trained to believe that water in the pressurizer indicated water over the reactor core.

"On the morning of March 28, 1979, the operators responded as previously during plant trips; after starting the second makeup pump and receiving an ES actuation, they noted the pressurizer level increasing from 155 inches and quickly bypassed the ES signal in order to throttle the HPI valves (MU-V16A, 16B, 16C and 16D) and stop the additional makeup pump. The HPI flow was essentially stopped within 4.5 minutes fillowing the reactor trip in response to the increasing pressurizer level to the near-full-scale condition, but not to the continuing low RCS pressure (below the ES setpoint of 1640 psig). 
"As noted in this report (Section 2.5), the operators had throttled the makeup pump flow/HPI flow to a minimum within 4.5 minutes after the reactor trip and were down to one pump (MUP-1A). Additionaliy, the letdown system was also utilized in an attempt to recover and maintain normal pressurizer level between $0403 \mathrm{hrs}$ and $0407 \mathrm{hrs}$.

"The interviews revealed that the makeup pump flow and letdown flow were operated in a normal manner between 0410 hrs and $0533 \mathrm{hrs}$ when the HPI flow was increased manualiy to appriximately $300 \mathrm{gpm}$. Moreover, records review revealed that the borated water delivered from the BWST to the RCS between $0400 \mathrm{hrs}$ and $0730 \mathrm{hrs}$ was 15,000 gallons or approximately $70 \mathrm{gpm}$ average with the major portion of the injection occurring from $0402 \mathrm{hrs}$ to $0405 \mathrm{hrs}$, and $0533 \mathrm{hrs}$ to $0730 \mathrm{hrs}$. During the majority of this $3 \frac{1}{2}$ hour period, the average net addition to the RCS was $25 \mathrm{gpm} . "$

With regard to the HPI system, the following NRC conclusions summarize the reason for improper system performance:

"Technical Specification 6.8.1.a requires written procedures shall be implemented, covering the activites referred as applicable procedures recommend in Appendix "A" of Regulatory Guide 1.33. This guide recommends procedures for combating emergencies; such as "Loss of Coolant". Unit 2 Emergency Procedure 2202-1.3, "Loss of Reactor Coolant/ Reactor Coolant System Pressure", Revision 11, Section B, Step 2.2.3, requires that the operator verify the high 
pressure injection is operating properly as evidenced by injection flow in all four legs (MU-V16 A/B/C/D), with flow indicated on MU 23-FE 1, 2, 3, 4.

"Contrary to above procedure requirement, the high pressure injection flow was throttled to minimum flow conditions by 0405 hours, and one of the two high pressure injection pumps was stopped during the continuing reactor coolant system low pressure conditions.

"Moreover, the high pressure injection system was routinely modified (flow throttled and makeup pumps stopped) throughout the day of March 28, 1979, during continuing low pressure conditions within the reactor coolant system following the period when the reactor coolant pumps were stopped and the high pressure injection system was the only certain mode available for the removal of core decay heat (Section 2.6, Details I)." (NUREG-0600, IB-9)

The reasons for operator action to limit HPI flow is clearly documented to be the belief that the primary system water inventory was not only sufficient but excessive. This belief was primarily due to high level indication in the pressurizer mislead the operators into believing that the primary system was "solid". This conclusion was also supported when primary system depressurization failed to appreciable lower core flood tank level. Operator action to maintain or decrease primary system water inventory was considered to be required to avoid a dangerous solid condition in which small temperature increases would cause large pressure spikes, potentially causing failure of primary system integrity. 
Core Flood Tanks

System Description:

"Core flood provides an Engineered Safety Features function to limit fuel damage in the event of a LOCA by flooding the core with borated water. The system consists of two tanks located within the reactor building. Each tank outlet connects to one of the two flooding nozzles located in diametrical opposition on the reactor vessel above the core zone. Each of the tanks and its related equipment function as an independent circuit; however, both circuits are required for the system to meet its design requirements. Release of the stored water to the reactor core is independent of actuation signals, electric power supplies, or operator action. The core flooding water is released by action of check valves in the outlet line from the tanks which are normally held closed by reactor coolant system pressure. The closed check valves open when the coolant system pressure is reduced below 600 psig. This pressure is maintained in the flooding tanks during normal operation by an overpressure of nitrogen gas. The loss of reactor coolant system integrity should ultimately lead to initiation of core flooding. Each tank contains approximately 7900 gallons of borated water at a minimum concentration of $2270 \mathrm{ppm}$ boron and is pressurized with nitrogen gas to $600(\stackrel{+}{-25})$ psig." (NSAC-1, App. (F) 
"At approximately 7 hours and 30 minutes after the start of the accident, the decision was made to depressurize the RCS so that the core flood tanks would be available to discharge their contents if the vessel required large quantities of water. Once having done so, further steps would then be taken to enable the staff to put the decay heat removal system into service.

"The RCS depressurization took approximately one hour, the RCS pressure reaching 600 psig at $1241 \mathrm{hrs}$.

"Starting at about $1212 \mathrm{hrs}$ and lasting for the next several hours, multiple level alarms were received on the $A$ core flood tank. No such alarms were received on the $B$ core flood tank. The investigation has concluded that these alarms were probably erroneous since the nitrogen pressure on both tanks was reported to have decreased to approximately $400 \mathrm{psig}$. This would imply a lever decrease well below the alarms that were indicated.

"This condition of the core flood tanks "floating"

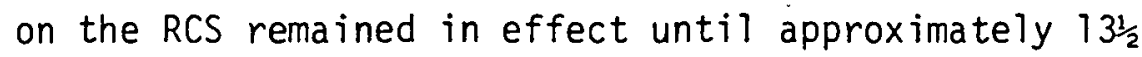
hours when the Station Manager was directed to take the plant solid. The plant staff has stated that, at that time, they believed the behavior of the core flood tanks demonstrated that the core was covered with water. The 
presence of the loop seals in the piping from the core flood tank to the reactor vessel precludes the tank level change behavior from assuring that the core was covered at that time." (I-4-30)

"The operators knew the pressurizer and both core flood tanks were positioned well above the core. They - assumed the core had to be covered with water; if a water level existed in the pressurizer, regardless of system pressure, or in both core flood tanks, at a system pressure below the nominal 600 psig cover gas pressure. The operators failed to recognize that the existence of saturated, even superheated conditions within the RCS, coupled with the actual piping configuration from these vessels to the RCS, allowed loop seals to form. The loop seals for the pressurizer, core flood tank $1 A$ and core flood tank $1 B$ are about 11 feet 5 inches, 14 feet 4 inches, and 17 feet 10 inches, respectively. Once loop seals formed, RCS pressure needed only to exceed the pressurizer vapor space pressure by about 13 psi and the core flood tank cover gas pressure by about $8 \mathrm{psi}$ to force both water levels to full scale, even with the RCS completely voided.

"Admittedly, the RCS should not normally experience saturated or superheated conditions and, without those conditions, the piping configuration would not have mattered." (NUREG-0600, I-4-33) 
"The interviews of operations personnel revealed that the core flood tank valves (CF-VIA and VIB) were. closed by operator actions at approximately $0600 \mathrm{hrs}$ to prevent the addition of additional borated water to the RCS when the RCS was believed to be in the solid water condition, as indicated by the nearly full pressurizer (level indicated at or near 400 inches). (Int. 95, 196, 109)

"The specific requirements and steps required to close the valves included unlocking and closing the valve motor operator electrical breakers at the motor control centers (2-11EB: CF-VIA and 2-21EB: CF-VIB) and closing the valves remotely (electrically from the control room). (Int. 95, 196, 109)

'The interviews did not determine the specific time the core flood tank valves (CF-VIA and VIB) were reopened, but it was apparent that the valves were opened prior to depressurization of the RCS at approximately $1300 \mathrm{hrs}$ resulting in the discharge of some amount of core flood tank (CF-TIA and TIB) water into the reactor vessel. The discharge of water into the RCS from the CFTs was confirmed through interviews and computer alarms." (NUREG0600, I-4-28) 
Reactor Building Isolation and ESF Acutation

"Technical Specification 3.3.2, Engineered Safety

Feature Actuation System Instrumentation, Section 3.3.2.1

requires that the ESFAS instrumentation channels shal1 be

OPERABLE as shown in Table 3.3-3, including the Safety

Injection and Reactor Building Cooling and Isolation

initiation from Reactor Building Pressure High with the.

minimum of two channels operable, in MODES 1,2 and 3 .

"Contrary to the above requirement, at 0800 hours on March 28, 1979, two the three ESFAS channels in Train $B$ were defeated, preventing the initiation of Reactor Building Cooling and Isolation and Safety Injection from Train B; and at 0820 hours on March 28, 1979, two of three ESFAS channels in Train A were defeated, preventing the initiation of Reactor Building Cooling and Isolation and Safety Injection from Train A. The Train A and Train B Reactor Building Cooling and Isolation Actuation Trains remained defeated until 0924 hours on March 28, 1979, when the channels were automatically reset (Section 2.6, Details I)". (NUREG-0600, IB-8)

The bypassing by operators of isolation and ESF functions obviously had severe repercussions on the ability of emergency systems to function and the ability to contain radioactive material. As discussed under the HPI systems, the operators were convinced that their actions were proper and necessary to maintain primary system inventory within acceptable limits. System operation, however, was necessary and performed in a proper manner when so allowed. 


\subsubsection{Required or suggested Corrective Action}

With specific regard to TMI, the following items are under consideration as potential items of non-compliance with relationship to shutdown and emergency systems. (NUREG-0600)

1. Failure to maintain at least two emergency feedwater pumps and flow paths in operable condition.

2. Failure to maintain Engineering Safety Feature Actuation System Instrumentation in operable condition.

3. Failure to maintain adequate HPI flow.

4. Failure to maintain CFTs in operable condition.

5. Failure to maintain Diesel Generators in emergency standby mode. (Al though not significant to the course of the TMI-2 accident, operators tripped and defeated $D G$ automatic start early into the accident.)

The following specific actions and recommendations regarding shutdown and emergency systems have been documented.

1. For several weeks following the March 28, 1979 TMI-2 accident, the office of inspection issued IE Bulletins to all operating reactor facilities. These Bulletins (reference 1) required specific, immediate action with regard to shutdown and emergency systems in the following areas:

a) Review operating procedures and operator training to ensure operators do not override ESF systems. 
b) Specify specific conditions for HPI operation termination.

c) Specify extent of operator reliance on instrumentation.

d) Verify emergency feedwater valves are properly positioned and other safety systems are operable.

Improvements in shutdown cooling systems have been suggested as follows:

1. In its letter of August 14, 1979, the ACRS recommended:

Studies to Reduce the Probasilisy c: an Accident

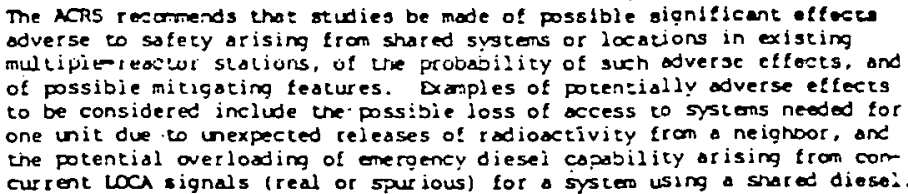

Decav hiea: Femova: Sirscens in ESTS

The ACRS recomends a reevaluation of the desion assis of the low pressure recirculasion hea: removal system of the ECS, inclueing system capabiliti; and long-tern reliabil by when circulating highly radioactive Ruid contsising particulates wien aight jeopartize certain components.

Systens Interactions Involving Ai:. Instrwent. or Hydroulic Lines

The ACRS recommends that each licensee be requested to teviev and evaiusce his as-built plant for possible significast systems interacions therein rupture in a medium ot high pressure ine could cause loss cf vitally important air. instrumen:, and hydraul ic lines and electies: circuies and equipment. For boiling water reactors, atcention should be given particularly to the lines related to actubion of the seres syster.

2. NUREG-0578 (included in section 4) recommends:

- Additional instrumentation to detect inadequate core cooling, and

- Automatic initiation of auxiliary feed systems (for those PWRs without provisions already) 


\section{NUREG-0560 recommends}

\footnotetext{
- A study should be made by NRC, the licensees, and designers of the design basis for the residual heat removal (RHR) system with regard to its availability and operability as a low-pressure heat removal system when the reactor coolant system is contaminated.
}

\footnotetext{
- Plant instrumentation should be provided to give improved information on reactor coolant level and margin to bulk coolant saturation.
}

Modifications to TMI systems were, of course, required prior to transient to long-term natura? circulation. These modifications, referenced elsewhere in this report, are included in section 4 . (refer to 4.4) as presented in NUREG-0557, Appendix B. Of particular applicability to this research program, however, is the design and accommodation of the standby reactor coolant pressure control and makeup system. This system as installed in the fuel building provides backup pressure control, boron and vessel makeup through a combination of active and passive components. The TMI experience demonstrates the ability to modify and add components and systems to existing systems in adequate time to assure safety given some accident sequences. 
3.8.4 Relationship to Sandia Research Program

The following general statements have a factual basis from the TMI-2 accident.

1. The ability of personnel to defeat emergency systems prior to the accident existed, occurred and contributed to the course of the accident.

2. The capability of, and ease by which operator override and/or defeat of emergency systems was significant during the course of the event.

3. Active components of emergency systems performed well.

4. Design problems with shutdown and emergency system existed. One relatively simple system (CFT) failed to perform when it should have, apparently from design problem of failure to design for circumstances encountered.

5. Failure of the CFT system to operate reinforced operator misunderstanding of conditions in primary system.

6. Operator utilized emergency systems that serve functions during normal operation in non-emergency modes apparentiy intentionally manipulating controls to keep such systems in the more familiar operational modes.

7. Systems capable of serving a variety of functions were often alternately dedicated to one or another of such functions. Occasionally, automatic controls and operator action would attempt different application of a system or component.

The relevance of Sandia shutdown and emergency cooling system objectives to TMI-2 events and literature is summarized in Table 3.8 . 


\subsubsection{Summary of Research Program}

The summary objectives of the Research Program in this area are to improve containment structures and system ability to control radiological releases. These research programs pursue many diverse paths towards accomplishment of these objectives. The containment concepts to be studied imply a spectrum of approaches from use of highly qualified structures with essentially zero potential for radioligical release to use of vented containment concepts in which release is controlled to minimize health impact. Systems capable of lessening structural requirements (for example, hydrogen control systems to minimize high pressurization potential) are to be studied and optimized. The problems encountered at TMI during the accident are presented in this section.

\subsubsection{Relevant TMI Events and Actions}

During the course of the accident and recovery operations, containment and containment system problems were encountered of the following general nature:

1. Inability to gain access to containment due to radiation during and following accident.

2. Inability to determine quantity and location of radiological material in containment.

3. Inability to control radioactive material egress from containment and eventual release.

4. Inability to recognize, quantify and respond to hydrogen content. 
Each of the preceeding problems impacted the ability of operators to control the reactor and course of events and determined the quantity and timing:= releases: Examples of each problem are presented below:

1. Inability to gain access to containment due to radiation during and following accident.

At. approximately 0620, "discussions were held considering an entry into containment to manualiy vent the RCS hot legs. The occurrence of radiation alarms halted further consideration of this option. Area radiation monitor (ARM) alarms were received at the sample station and the letdown sample lineup was secured. Loop ' $A$ ' hot leg temperature peaked at about $750^{\circ} \mathrm{F}$ ". (NUREG-0600, IA-41)

2. Inability to determine quantity and location of radiological material in containment.

"There were no radiation alarms in the $R B$ with the exception of the intermediate closed cooling alarms, which were considered normal and routine. This absence of alarms led the operators to conclude there was not an RCS leak. These detectors were located near the RB sump, and it was known by the staff in the control room that the rupture disc had blown on the RCDT at 0415 hrs (Int. 3, 15, 30, 95). The operators also noted that these alarms had occurred previously. The $R B$ radiation monitor (HP-R-227) had been found flooded, under positive pressure, and manually isolated by the operators at 0550 hrs. Records review 
recalled that the monitor had reached $50,000 \mathrm{cpm}$ at 0518 hrs. The monitor had been flooded previously and reported to the NRC." (NUREG-0600, I-2-30)

3. Inability to control radioactive material egress from containment and eventual release.

"Investigators have concluded that reactor coolant flowing through the makeup and purification system was the major source of releases both initially and for the duration of the accident. The reactor coolant makeup and purification system continually takes a portion of the water out of the reactor coolant system and passes the water through demineralizers then through filters and into the makeup tank (Ref. 119). The makeup pumps return water from the makeup tank to the reactor coolant system (RCS). The rate of return to the RCS is varied to provide the inventory control, with the inventory need being determined by pressurizer level. In addition, a small but important amount of the water is pumped to the reactor coolant seals. This system isolated automatically on reactor building isolation but was quickly returned to service in order to maintain seal water to the reactor coolant pumps and control pressurizer level." (NUREG-0600, II3-9)

4. Inability to recognize, quantify and respond to hydrogen content. 
"The 28-psig pressure spike in the TMI-2 containment occurred at 13:50:21 (approximately 9 hours 50 minutes after the start of the accident) on March 28, 1979 based on data. (Alarm Printer, Ref. 14) An operator had just been directed to open the EMOV valve. Concurrent with his manipulation of the controls, some operators and the Station Manager heard a "double thump", and the alarms and automatic equipment functions associated with high pressure in the containment actuated." (NUREG-0600, I-4-47)

"Based on interviews conducted during this investigation, it appears that the response of personnel present in the control room to this pressure spike was varied, including total lack of awareness that it occurred. No statements that have been obtained indicate that anyone present postulated that the pressure spike was due to the rapid burning of hydrogen." (NUREG-0600, I-4-48)

\subsubsection{Required or Suggested Corrective Action}

With specific regard to the TMI-2 accident, NUREG-0600 identified the following potential items of noncompliance:

"At 0800 hours on March 28, 1979, two of three ESFAS channels in Train B were defeated, preventing the initiation of Reactor Building Cooling and Isolation and Safety Injection from Train B: and at 0820 hours on March 28, 1979, two of three ESFAS 


\begin{abstract}
channels in Train A were defeated, preventing the initiation of Reactor Building Cooling and Insulation and Safety Injection from Train $A$. The Train $A$ and Train B Reactor Building Cooling and Isolation Actuation Trains remained defeated until 0924 hours on March 28, 1979, when the channels were automatically reset." (Section 2.6, Details I)
\end{abstract}

NRC IE Bulletins issued shortly after TMI required licensees to review containment isolation design and procedures and prepare to implement changes necessary to ensure isolation (reference 1)..

The NRC lessons learned report (NUREG-0578) recommendations regarding containment and isolation. are included in their entirety in Section 4. In essence, NUREG required review and implementation of containment isolation provisions, preventive maintenance and leak reduction, inerting of certain BWR containments and other short-term provisions for hydrogen control and determining likely paths of radioactive material from containment for existing plants. NUREG-0560 recommendations are similar.

The ACRS recommendations, on the other hand, address filtered venting or purging of containment as follows (reference 3 ):

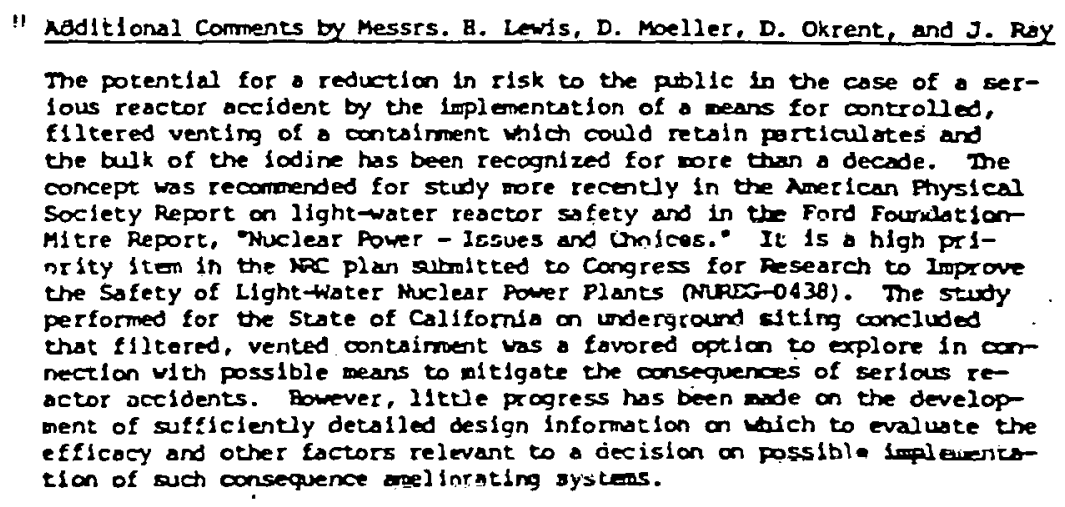

Tho m-2 sceldent soggests that the probabllity of a serious aceident in mich - flltered vented contaliment could be usesul is larger than many s anticlpoted. 


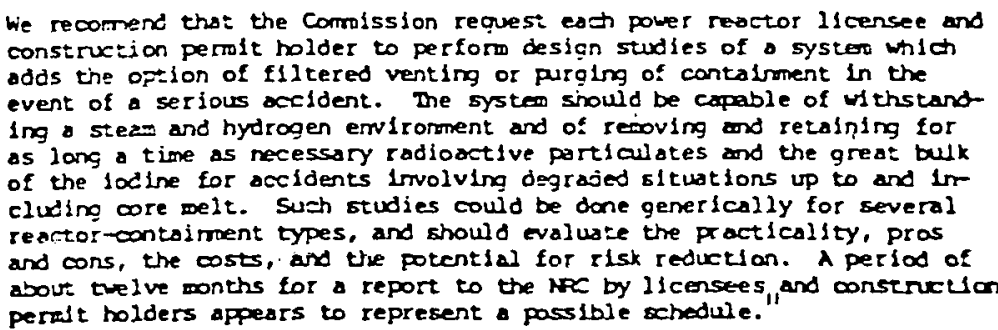

Environmental qualification of containment systems has also drawn ACRS attention as follows:

Envircrienta! Ciselification of systems in Contsinmen:

The ACRS recorrends a review and reevaluation of the curtent basis for judging cnviromenta: Thelification requitements for equipmen: in contaimen: and in other buildings were a tostile enviroment might result. The same reviev

should be mode o: the lacations of vital sensors ond other measurement devices.

The pros and cons e! modified enviromentsl ouslification and equipmen: $1 \propto 0$

tion should oe exmined with due consideration given to the difficuities of

modifying existing equipment.

3.9.4 Relationship to Sandia Research Program

The following general observations of TMI events are directly applicable to Sandia Research Programs:

1. As a result of operator action, design and leakage containment did not function to effectively contain radioactive material. Once radicactive material breached containment, control over releases was minimal and sporadic.

2. Hydrogen control systems were not adequate for the TMI accident. Hydrogen burning did occur, although the significance of this phenomena was not apparent to personnel.

The Sandia Research Program advocates thorough review of containment functions and systems. Recommendations and requirements issued to date are aimed at either improving or maintaining existing plants' ability to accomplish containment functions or providing future plants with alternate means of accomplishing the objectives of minimizing health impact. 
TABLE 3.9

Research Program - 9. Containment Functions and Systems

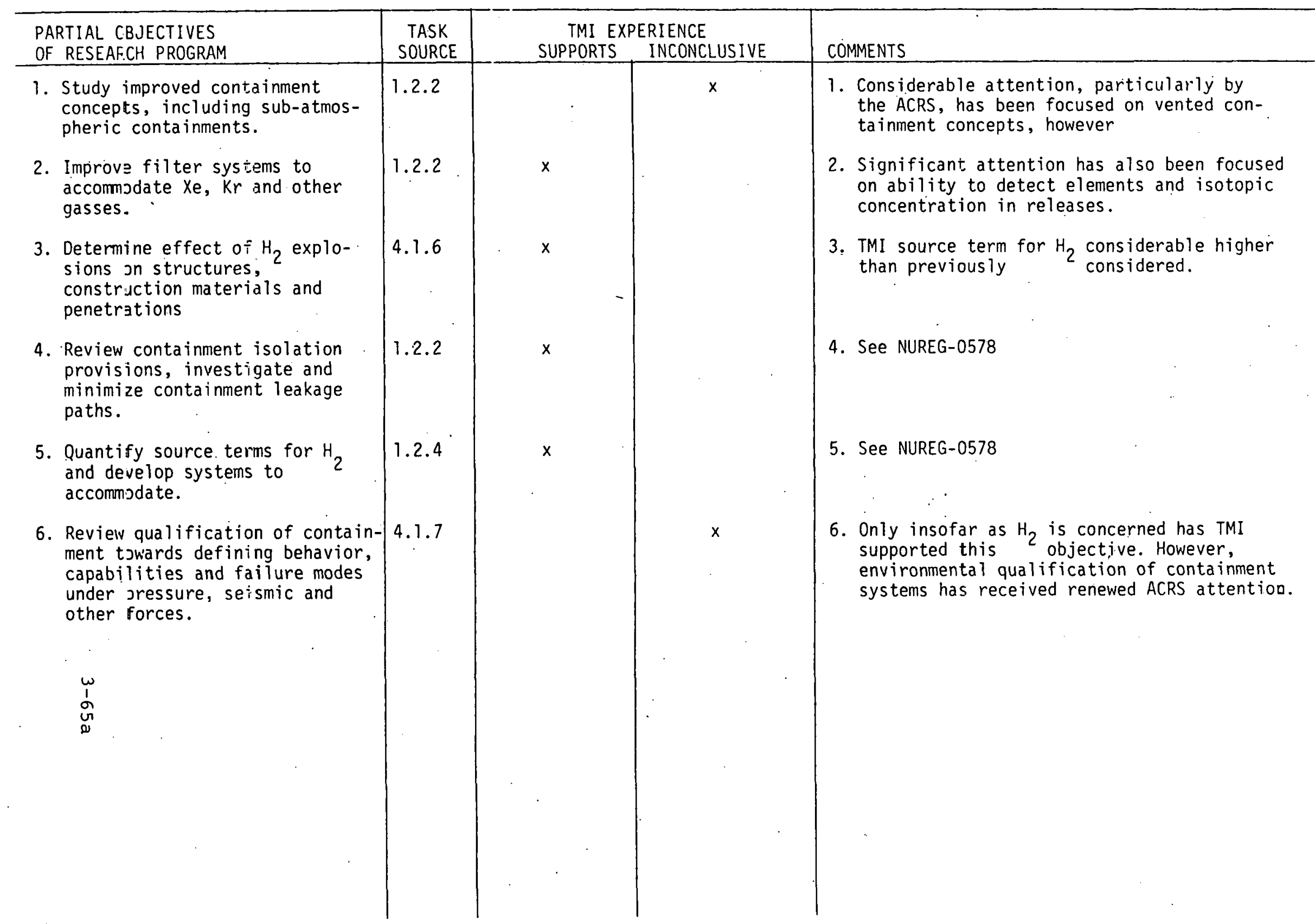


A summary of Sandia objectives and TMI events and 1iterature related to containment functions and systems is presented in table 3.9 


\subsection{TEST AND MAINTENANCE}

\subsubsection{Summary of Sandia Research Program}

The summary objectives of Sandia research are to reduce test and maintenance errors (and hence to assure system availability when required) and to increase test and maintenance efficiency.

\subsubsection{Relevant TMI Events and Actions}

The following test and maintenance related events have been identified in NUREG-0600:

1. A previous loss of feedwater transient, $11 / 3 / 78$, resulted from an instrument technician opening a power control breaker by mistake. OTSG indicated "dry" for a period of time following reactor trip. (I-7-45)

2. TMI personnel were aware of a work request that was pending for maintenance on the auxiliary building sump tank and miscellaneous waste tank to replace ruptured diaphragm. (I-1-54)

3. The specific initiating cause of the March 28 turbine trip has not been determined (1-4-5). However, it is likely that maintenance activities, "probably as a result of actions taken to clear the resin blockage in the transfer line" caused loss of feedwater. (page 1)

4. Emergency feedwater block valves were closed during the initial minutes of the loss of feedwater transient. "The 
investigation has not been able to determine the specific cause of the ... valves being closed during the initial part of the transient." (I-4-10) The summary of test and maintenance activities related to these valves is presented in NUREG-0600.

5. The operational status of area, process and atmospheric monitors are reported on II-1-22. Although monitors required by Tech Specs were operable, the investigation concluded

"If the Unit 2 makeup tank area radiation monitor had been operational during the accident, it could have provided an accurate measure of increasing radiation levels in the auxiliary building. This monitor did respond to increasing radiation levels, but it did not respond accurately. The nuclear sampling room air monitor could have been used to collect air samples when reactor coolant samples were taken in this room. Because the control tower air monitor was inoperable, there was no real-time monitor of Unit 1 control room air radioactivity until the monitor was placed back in service on March 30 at 0600." (II-1-24)

6. "In examining the bases for alarm setpoints for Unit 2 monitors, an investigator determined that the setpoints for air particulate monitors were incorrectly based on one-half of the Unit 1 Technical Specification release rate limit of $0.63 \mu \mathrm{Ci} / \mathrm{sec}$ rather than the one-half of Unit 2 Technical Specification limit of $0.3 \mu \mathrm{Ci} / \mathrm{sec}$. The licensee had reduced the alarm setpoint by $25 \%$ to account for possible meter error. (II-I-26) 
7. "There have been a number of maintenance problems with the waste gas system since plant startup. Examples are:

Work request 4979 Waste gas compressor, WDG-P-1B, overpressurized.

Work Request.4985 Waste gas compressor, WDE-P-1A, makes loud noise.

Work Requese 4262 Waste gas compressor, WDG-P-1A, no sea? water level in tank, check level control pump operation.

These work requests were outstanding at the time of the accident. In addition, Control Room Operator $\mathrm{J}$ stated that makeup tank vent valve MU-V-13 was suspected to be leaking (Int. 57). Some of these problems may have caused releases to be larger than they would have otherwise been." (II-1-28)

8. "Three Mile Island Nuclear Station Surveillance Procedure 1302-5.24, Revision 3, dated December 19, 1974, specifies the method of calibration and requires that it be performed annualiy. Contrary to the above, as of March 29, 1979, eight environmental air samplers had not been calibrated since 1974. (See Details II, Section 1.7.1.1)." (II-F-4)

\subsubsection{Required or Suggested Action}

With specific regard to TMI, several of the items in the previous section are currently under consideration as potential items of noncompliance as indicated in NUREG-0600, Sections IB and IIF. NRC IE Bulletins required 
the following test and maintenance related activities of all 1 icensees (reference 1 ):

1. Review procedures to ensure valves are returned to correct positions following necessary manipulations.

2. Review and modify as necessary. your maintenance and test procedures to ensure that they require:

a. Verification, by inspection of the operability of redundant safety-related systems prior to the removal of any safety-related system from service.

b. Verification of the operability of all safetyrelated systems when they are returned to service following maintenance or testing.

c. A means of notifying involved reactor operating personnel whenever a safety-related system is removed from and returned to service.

3. All operating and maintenance personnel should be made aware of the extreme seriousness and consequences of the simultaneous blocking of both auxiliary feedwater trains at the Threee Mile Island Unit 2 plant and other actions taken during the early phases of the accident.

Probably as a motivating factor for licensees NUREG-0578 recommends revised limiting conditions for operation base on safety system availability. In part, this recommendation (A-60 through A-64) is aimed at requiring licensees to devote more attention and greater caution to test and maintenance activities. 
These recommendations are included in section 4. The following clipping (reference (I) demonstrates the contribution of procedural requirements to plant availability and safety:

NRC AUTHORIZES ARKANSAS ONE NUCLEAR PLANT TO RESUME OPERATION

The Nuclear Regulatory Commisaion tasf issued an Ordez Wedneaday night permiteing, Arkansas Nuclear One, Unit 1, located near Rugeliville, Arkansas, to reaume operatior.

On June 2, the NRC ataff ordered the Arkansas Power and light company, the licensee, to keep its unit l nucleat powe plant in a cold shutdown concition until deficiencies were corrected in procedures for operation of the reactor. While Unit 2 was preparing for startup following refuelino--and after taking steps to comply with requirements imposed by NRC following the March 28 accident at Three Mile Island in Penrsylvania-an NRC inspector, in the control room during a routine inspectio:. noted that the auxiliary (emergency) feedwater system controls

were not in their proper position. In absence of a procedural

requirement to return the system to normal, there was no assurance

that emergency feedwater would be provided automatically if needec however, no safety hazard existed at the Arkansas Unit I plant because of the improper action.

The NRC staff has determined that APGL has taken specific ections in response to the order and are assured that the conditions of the order have been met. 


\subsubsection{Relationship to Sandia Research Program}

The test and maintenance activities that contributed or may have contributed to the TMI-2 accident and its severity can be grouped into four general categories.

1. Test and maintenance activities that failed to return systems to proper state when completed.

2. Test and maintenance activities that were not performed so that systems and components were not in serviceable condition.

3. Test and maintenance activities that were unsuccessful or inaccurate (setpoints, calibration).

4. Test and maintenance activities causing operating system to malfunction.

A summary of Sandia objectives (in test and maintenance) and their relevance to TMI are presented in table 3.10. 
TABLE 3.10

Research Program - 10. Test and Maintenance

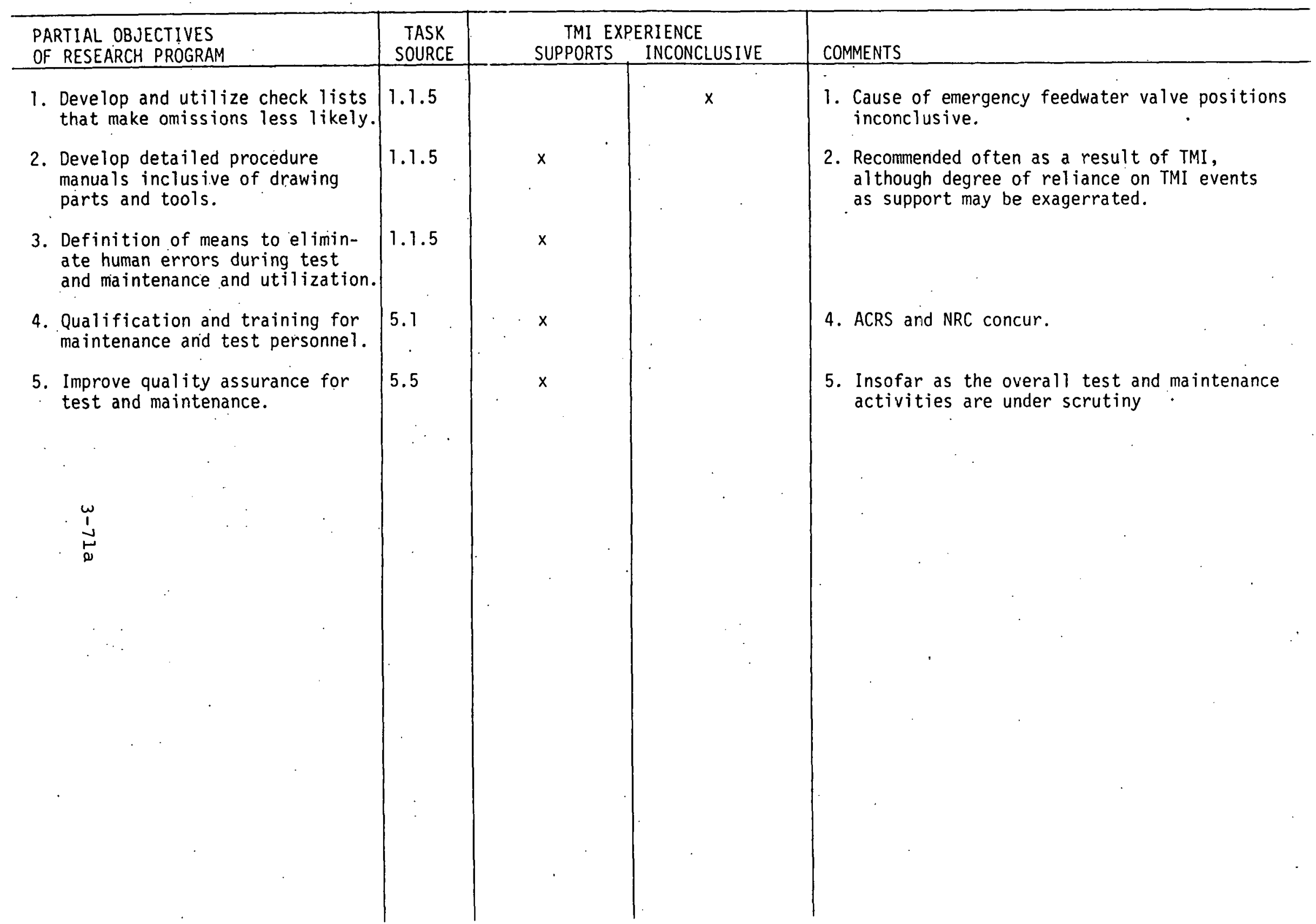


$3.11 / 12$ EMERGENCY AND DISTURBANCE CONTROL

\subsection{1/12.1 Summary of Research Program}

Emergency and disturbance systems major design basis can be summarized as:

1: Provide capability of diagnosing and displaying plant, system and component conditions quickly and accurately.

2. Provide capability to inform operators of probable consequences of various actions.

3. Provide capability to recommend operator action during operation, transient and accident conditions.

In addition, Sandia tasks related to optimizing control room layout, utilizing human engineering and minimizing operator error through increasec training and procedures relate directly to the ability of an operator to quickly. and accurately assess plant status and initiate proper action. Inasmuch as a single system would reasonably be designed to serve both functions, emergency and distrubance control systems are treated as a single entity in this report.

\section{1 $1 / 12.2$ Relevant TMI-2 Events and Actions}

Previous work (reference 12) has recently characterized what occurrec at TMI and the benefits and emergency and disturbance control system would have provided. The material is reproduced in Section 4. The following general examples characterize situations in which a disturbance or emergency control system would be useful: 
1. Recognition of initial loss of feedwater.

2. Recognition and interpretation of lack of emergency feedwater flow into OTSG.

3. Recognition and interpretation of inventory problem in RCS.

4. Recognition and interpretation of saturation and voiding in primary system.

5. Recognition and interpretation of significant . radiation levels.

6. Recognition of relief valve status through available temperature, flow instrumentation.

7. Recognition and interpretation of CFT level, valve status and effectiveness.

8. Advisory capability with regard to emergency planning.

\subsection{1/12.3 Required or Corrective Action}

Although recommendations and requirements have been forthcoming on instrumentation, operator response and procedures, etc., the implementation of short-term "fixes" for operating reactors has not addressed imposition of licensing requirements for a disturbance or emergency control system. It is apparent, however, that many individuals and organizations consider system development and utilization to be important.

1. Emergency and disturbance control systems of necessity require the ability to quickly and accurately determine status. ACRS recommendations (reference 3) concerning status monitoring are: 


\section{Sta:us Mon!: $0: 109$}

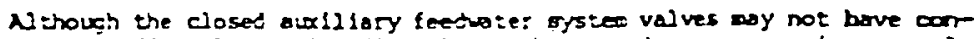

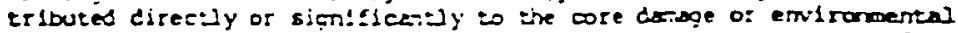
releases at $\mathrm{z}-2$, the pientidily such wore severe cansequerces of ur ovallabllity of enineered safecy feasues in plants of aty type is of concem and deserving of alter:ior.. Siscus porit toring not dependent chlefly or $t \pm$ inlstrative contsol, and tuis posslbly less cubject to bu man error, clat: help assure the ovasjab!l1ty of essertal feicures.

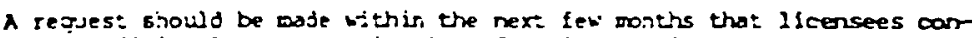
alder asditlond status monito:ing of various exineered safety feacures and thelt appoting services. The NRE S=aff siuld begin studies on the advantages axd disajvarioges o! suth mon!toring on about the sane time scale. Fesponses iror. licensees shouid be expected in about one year. ot wich tion the tre suaf should be in a position to reviev and evaluther.

2. A necessary prerequisite to effective systems is the ability to model complex accident sequences. In this regard, the ACRS has recommended the following:

1. Acclient Aulvsis

The AORS recomends that an onalysis, be undertiken of postulated accidents involving a rear. line ruptute followed by a soill break in the primary system, arisine from an open relief valve, a stem generator woe break or some other opening. The analysis chould not only review the capability of englneered safesy features to cope with sxh an event but olso exarine the symptoms ovaliable to the operator and determine the adequscy of existing operating procecures.

and

\section{Reactor Sofety Reseord}

The ACS recocmends that safety research on the behovior of Iight-mater reactors during onomalous tassients be inftlated as soon as possible and be assigned a higb pilority. The $10 \mathrm{R}$ would expect to see plans and proposais wthin abour three months, prelisolnary results with an additional six moiths, and more copprehensive results within a yas.

Of partlcular interest wiuld be the development of the copabi21ty to simulate a vide range of pastwated translent or aceldert conditions. Inclualing varlous abrormal or lov probablllty nechanlcal fallures, eletrical Eallures, or hanan errors, in order to gain increaced inigbt into measures that can be taken to imove safety.

The new prosas of resestch to leprove resctor sofoty has been inlelated only recentiy, and then only on a relatively mall cale. The Combetes reiterates its previous recondexdations that this progran be puraund and its expassion sought by the Cocrission wth oreater senes of urgency. 


\section{Malvis is of Iransiencs}

The ATS recomends that each licensee and holoe: of a construction permi: be asked to make a decalled evaluation of his cugrent capabllity to Htb stax station blociout (lass of offsite and onsite $A$ p power) Incluting additianal complication factors that might be reasonably considered. The evaluation should include exasination of natural circulation capability. the continuling ovailabllity of conponents neejed for long-term cooling. and the potential for Leprovedent in capability to survive extended stetion blockout.

The ATR also recomends that ea=h licensee and construction peralt boldet should examine o vide rame of anomalous transjen=s and degraded oecidert condltions wich alght lead to water hamer. Hetiods of contralling or preverting such conditions siould be evaluates, as should researci to provioe a better basis for suzh evalustlass. The connttee expects it

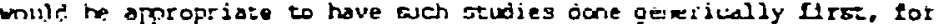
classes of reactor designs and syster types.

3. Sandia tasks identify the need foroperating procedures to be studied to determine the best means or writing such procedures. The ACRS has apparently concurred in such a program as follows:

Operating Procedures

The AcRs recommends that a study be made on tow operating procedures sho:lle thest be witten. For example; should procodures be characterized in ce rms best be written. For example; should procedures be choracterized in cerms cf evenes or in terms of sympeoms, or both? should the operator actions be keyed to changes in symptons? Is the friority of operator action llxed so as to optimize pollic sofety? Hou. does one decersine mether o given pro ceoure is understood by the operator, and that the operacor will carry it our properly?

The ACRS also recommends that a gystematic examination be node of steps that the operator should be odvised not to take, wien and hy. Che exempie of such step could arise in connection with the operator's capabllity to iso-

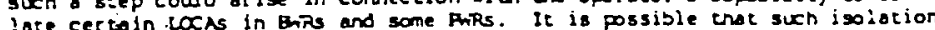
tol cerno ingentory could

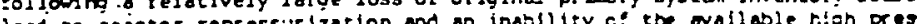

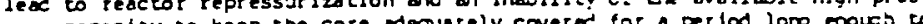
sure capolity to ke ep the core before the situsion was tecontzed ax renedied.

and

The Conittee recomends that procedures be developed by all operators of Pwrs for linitiating nstural clrculation in a safe manner and for pro viding the operator with assurance that circulation has in foct been established. These procedures should take into account the behovilor of the systems under a varlety of abormel condlilass.

As a first step, the Ne Staff should inltiate immediately a survey of operating procedures for achleving natural clrculation. Including the case then offsite power is lost. At the save time, the operators of ald Phr plants should be requested to develop detalled analyses of the behavior of thels plants folloving antlelpated trassients and small breaks in the primary syseco, wth aproris late conslderation of potertial alnormal conditions, operator errors and tallures of equiprest, power pourcas, of instrumentstion. These analyses are necessary for the development of suliable operating procedures. The reviev and evalustion of these analyses by the NCC Suff should recelve a pelorlty consistent Mth the prlority.beling given to changes in operating procedures. 
Safety asperts of Individual reactors during norral operation and under acciden: conditions are levieved in detall by the RRE SEafi and discussed with the ACPS. Leceptable 11 int Technlcal Specifications, subnitted by the licensee and approved by the NRR Staff. Cperating procedures for severe transients hove recelved less detailed revlew by the NR stas.. It appears that such piocedures wuld benefle froo review by an interdisaiplinary tea wich includes personne expert both in operations and in systeo behavios. Niso, for the lomer ters, there may be pert: in considerling the aevejopment of more sandard ized formats for suth procedures.

$-\ldots$

4. In specific regard to providing capability to predice or alter the course of a transient or accident, the ACRS in its May 16

letter states:

\section{Instrmentation to Follow the Coltse of an Acciden:}

The ability to follow axe predict the course of an coident is essential for its mitioation and for the provision of credible and rellable predictions of potential offsite conseguences. Instruentation to follow the course of an orcidert in power redstors of all types bas long been a concem of the ATS, 15 the sibject of Regulatory Quide 1.97 (whlch has not yet been leplenented on an operating plant), and is the subjec: of an NE Siafi Task $\lambda T i$ ion Plan for the resolution of generic lasues.

The Combltee believes that the positions of Regulatory Culde 1.97 should be revieved, and redefined as necessary, and that the Task Action Plan shoult be reexanined, as soon as manpower is ovallable. The lessans learred from MII-2 should be the bases for these reviens. For exarple. Inptoved sopling procedures under accident concitions showlo be consldered.

Although revieu and rexionination of exlsting citerla ny take nowe tine, the studies conpleted to date, together with the understanding gained fros the accldent at Th-2, ahould provide sufficlent basis for plarned and approprlately phased actions. The Comitte belleves that the installation of ifroved instrumentation on operating reactors of all types abould be midenay wthin one year.

5. Operator training and qualification has also been a focus of ACRS recommendations:

Operato: Troining and Quallfication

The KRC Staff showld exasine operator quallfications, training, and I1censing to determine what chanos are needed. Consideration should be glven to educational baskground, to tralning methods, and to content of the tralnim prograr. Aitention should aiso be glven to testing methods. with soecific concern for the abillty of the testing methods to predict operator capabillty. Dxanination of licensing procedures sbould deter- ine wether they are responsive to new information that is developed about plant or operator performance. Effort should also be made to determine wether results of exarinations can be correlated with operator ablilty. Requallficotion tralining and testing Ehould be siollarly examined to insure that they take account of information that is developed by operation in the plant, and to determine that relevant informstion about other plants is made ava!lable to operators, and is made part of the tralning and requallfiestion program. As part of this and of other more extensive studies, continuing attention mest be given to the other more intorsition wich an operator cas assimllate and use in normal and in onergency situations ax to the best method of presenting the in formation to the operator. The use and limitations of simulators for operator tralning should receive careful consideration. 
6. Although evaluation of available data and statistics have principally been included in Research Program 16, Risk Method Utilization, the ACRS recommends that application of data to training and qualification of personnel is advantageous:

\section{Evalusilon of Licensee Event Resorts}

Eecause of the potentially valuble inforiation contained in Licensee Event Fepots (IERs), the Combitiee recomends tha: the NRe stasf establist formol procecoures for the use of this information in the training of supervisory and maintenance seafts and in the licessing and requalification of operating personsel o: commercial nuclear power plants. The information in LRs may aiso be useful in anticipating safety problens. $\lambda t$ the present time sone usllities rolitinely request that they be provided copies of all LERs appliesble to plants of the type they operate o: to specific systens and corponents in a glven class of plants simisar to their plant. Certain reastor vendors have ande sicslar requess and use the ters to review and evaluate the performance of thelr plarts. In - Afition, the NEC operator licensing staff has indicated that they use i in reviewing operating experlexce as comercial faclilties. would tend to indicace that a fomilizes procrar of LER revieu wuld be useful in the training, licensino and reoulisication of nuclear power plan: personse:. The exten: to wi.jch such a procram could be used to anticipate sofety problens should also be considered.

7. Finally, NUREG-0560, the first major NRC study completed in May, recommends the following:

For all classes of operating plants, additional analyses should be performed of reactor coolant system breaks in the range of very small breaks (e.g., representative of a stuck PORV or small line rupture) and carried out until a stable, long-term cooling condition is established.

NRC should develop (and utilize for audit calculations) quick engineering types of analyses methods capable of both realistic and conservative application to operating transients and small break LOCAs from initiation through stable long-term cooling and of other events such as a small break in a main steam line or a steam generator tube rupture. 
- A study. should be undertaken by NRC of actions that could make the operator a more effective recovery agent or incident/accident mitigator. Such actions would extend the defense-in-depth concept through the use of on-line diagnostic computer systems to seek ways to prevent (inhibit) inappropriate actions and promote productive intervention.

- Operator training should be restructured to give more emphasis to protecting the reactor core under potentially degraded plant conditions.

- Emergency procedures-should be written in real time as an aid for operators to study and memorize those aspects that deal with the initial short-term response. The procedures should be written in conjunction with results available from analyses to promote proper understanding and proper identification of critical decision points.

- Operators must have a better understanding of any limitations and must have a proper understanding of the plants. Each senior operator must direct activities and must not act simply as another operator.

More emphasis is neèded on human engineering in control room design to improve operator comprehension and response.

A study should be made to see whether there are design deficiencies that may be corrected to reduce the frequency of feedwater transients. The reliability of auxiliary feedwater systems should be improved. 
TABLE 3.11

Research Program - 11/12. Emergency and Disturbance Control

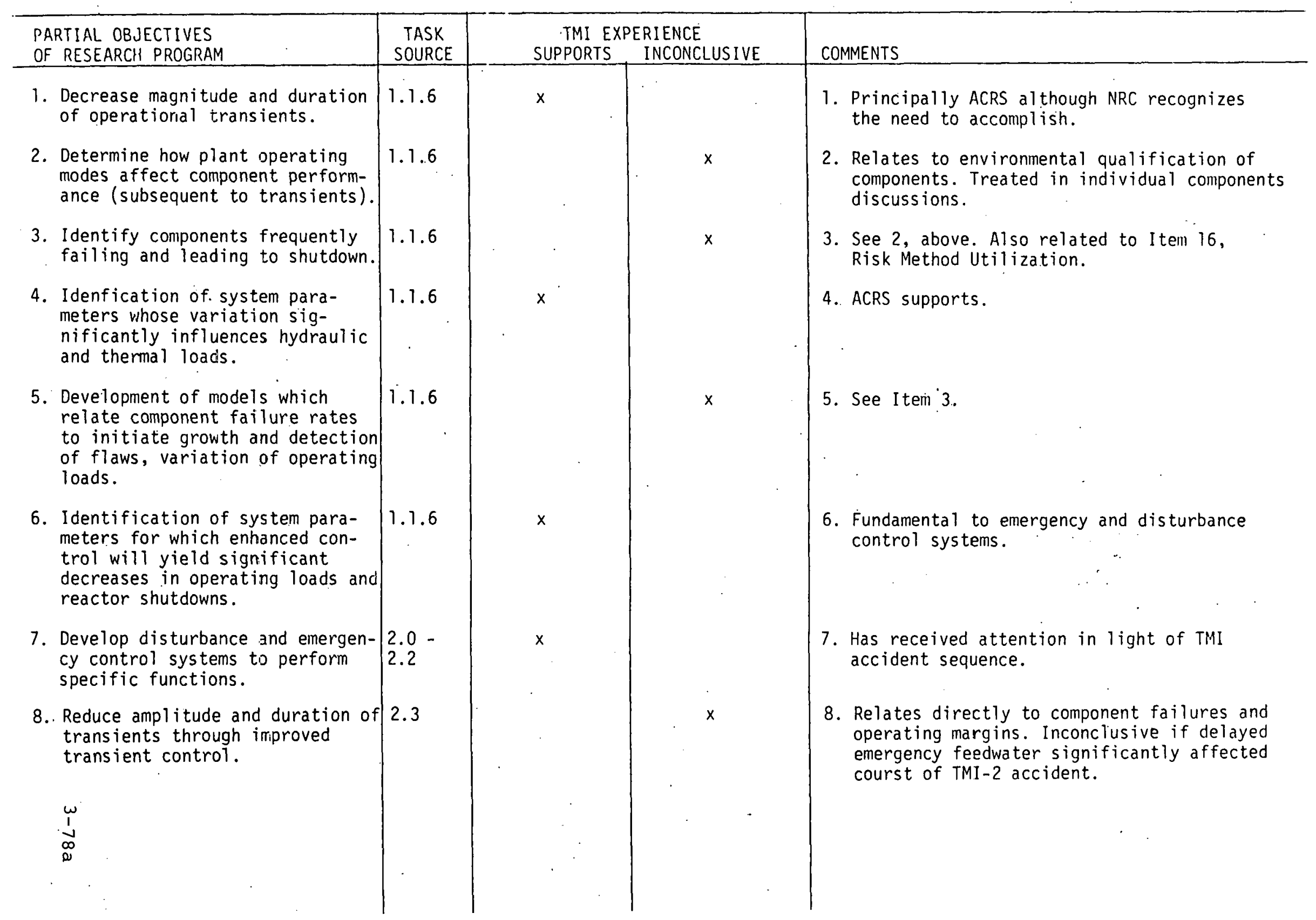


Research Program 11/12 (continued)

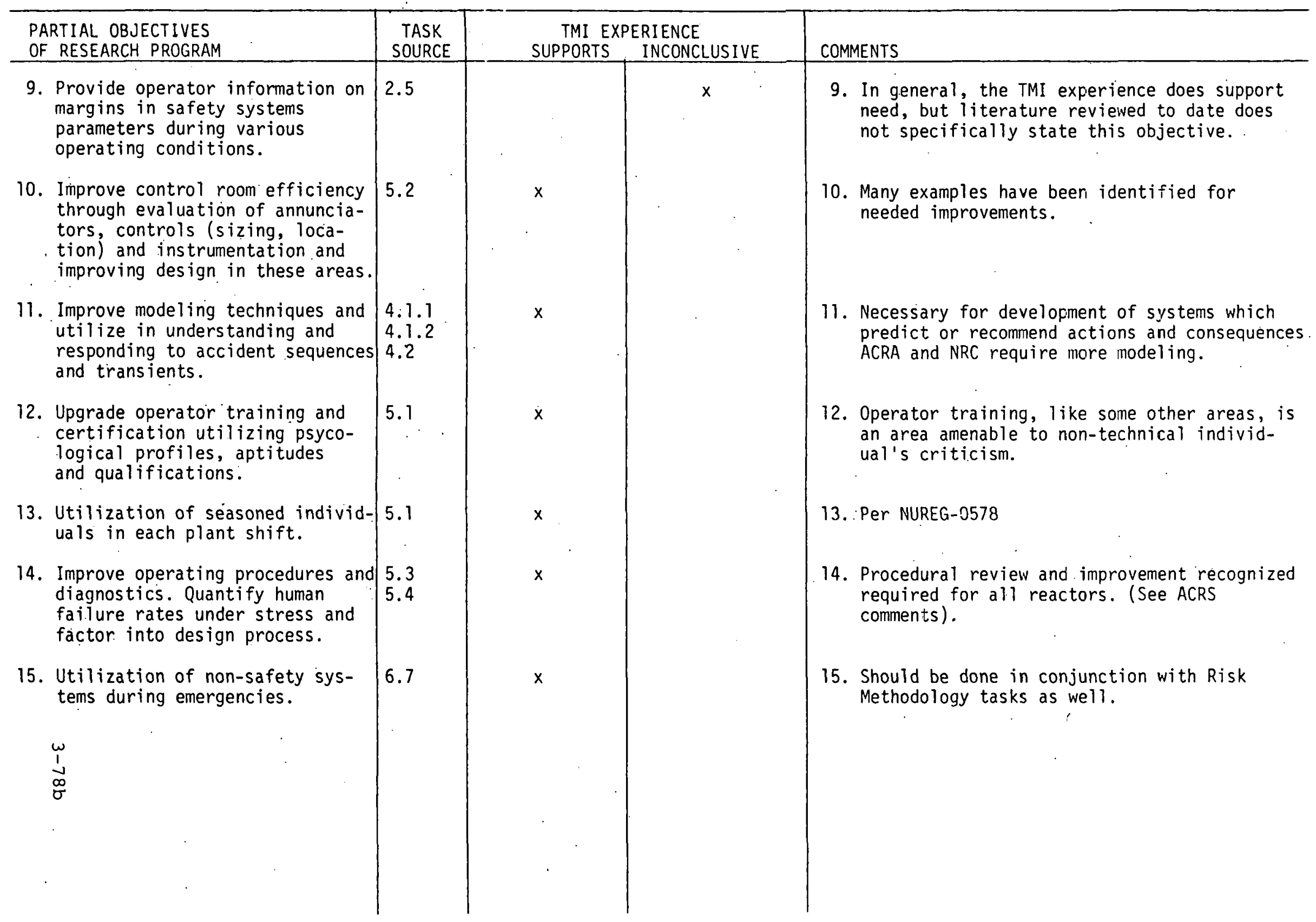


The Sandia Research Program in this area is designed to assimilate and evaluate information related to nuclear plant vulnerability to fires, earthquakes, sabotage and other phenomena, provide design guidance in these areas and to eventually be factored into nuclear power plant design. Inasmuch as the TMI-2 reactor accident was not appreciably affected by these phenomena or events, minimal post-TMI investigative or policy effort has been focused here. However, although sabotage was investigated and essentially rule out, concerns were raised as to the physical security of the facility during emergency conditions (NUREG-0600, II-2-18 through 21). Likewise, the threat of earthquakes and fires was evaluated and accommodated to the extent feasible during transition to natural circulation (NUREG-0557) and during continual operator endeavors to maintain the plant in a stable condition.

In related areas, the ACRS has commented on design guidance as follows:

\footnotetext{
Desian, Construction, and Operotion Review

The ACRS recommenis that consideration be oiven to the need for joint review by the nuclear stean system sueplier, the architect-enoineer, and the opera:ing utility, prie: to operation of a reactor, to consider, amono other things. the adequacy of incerfaces ane otner feacures developed under the oeg is of multipie supoliers, the accerability of tecmical specificatsons and other safety-telated operational limits, anc the secpacy of operationai and occident procedures.
}

In the past, plant protective features in these areas have been approve: toward assuring adequate protection over the plant lifetime. With all systems operable, this has resulted in indirectly determining what constitutes an acceptable risk. At TMI it was necessary to ensure certain critical functions remainec even though some of the equipment and systems were degraded or inoperable. ATthough the probability of failure of these systems may have been less due to 
fire, earthquake or sabotage for the short time periods (days or weeks) involved, the consequence of failure would probably have been more severe. The TMI experience suggests that Sandia may wish to include evaluation and quantification of risk and resultant design guidance evolved for situations in which degraded protection (either diversity, redundancy or separation) is present but the required duration of performance is relatively short.

The relevance of Sandia objectives in this area and TMI-2 events and literature is summarized in table 3.13 . 
TABLE 3.13

Research Program - 13. Design Guidance

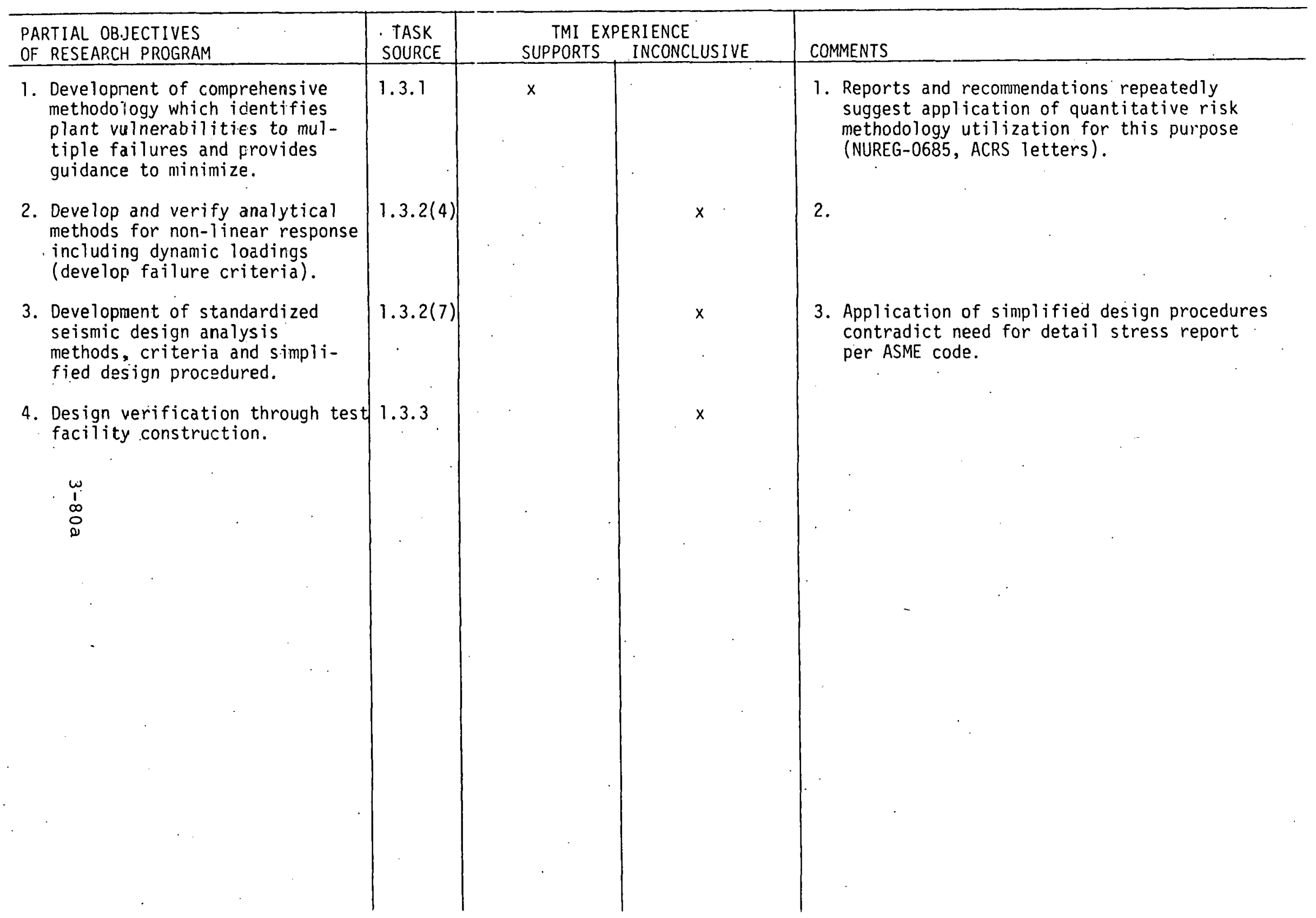


3.14.1 Summary of Sandia Research Program

In recognition of TMI problems, Sandia research in this area is aimed at the following:

1. Definition, training and organization of emergency response teams.

2. Definition and organization of emergency equipment including hardware, monitoring equipment, data retrieval and communications.

3. Definition and implementation of plant specific design changes necessary to interface with emergency equipment.

4. Development of equipment and analytical methods to assist emergency efforts.

\subsubsection{Relevant TMI Events and Actions}

Previous sections have relied heavily upon NUREG-0600 and other documented sequences of events at TMI. Unfortunately, similar detailed documentation for days through weeks of the accident are not available. The following general discussion of the role of emergency reponse at TMI is derived from a number of sources which provide insight into the role of emergency response. This discussion is by no means complete. However, its intent is to provide an overview of the types of problems encountered.

Actions of an emergency response nature at TMI can be summarized as directed at three major objectives, as follows: 
1. Maintain plant and equipment in operable state towards obtaining safe conditions and eventual cold shutdown. This includes maintaining access to vital equipment.

2. Maintain radioactive releases at a minimum and/or in a controlled manner.

3. Proceed with recovery, decontamination and cleanup operations.

During the initial hours of the accident, specific operator actions were taken to maintain the plant and equipment in operable states as discussed elsewhere in this report. Specific actions were also taken to limit or control radioactive releases. These actions include declaration of a site emergency (0655, NUREG-0600, II-2-5), declaration of a general emergency (0724, NUREG0600, II-2-6) and organization and specific activities of the licensee's emergency response organization, such as determining radiation levels in plant and at release points, organizing security, health physics, etc. "Initially, the emergency response organization approximated the 'planned' organization established in the emergency plan and procedures. . ." (NUREG-0600, II-2-8) This organization was perturbated, however, as time progressed. Plant personnel felt

"this was necessary because the Emergency Plan and procedures did not contain adequate provisions to deal with radiological controls under the type of conditions that existed in the plant. During an interview, the Supervisor, Radiation Protection and Chemistry stated, 'The procedures themselves do not address in any great detail in-plant radiation protection support. . . or coordination of maintenance and operations... I can also say quite honestly, in my own mind, I never conceived of the type of 
maintenance and operations activities that would have to go on in areas of such tremendous radiation dose rate levels as we had'." (NUREG-0600 II-2-14)

"By about 2000, the operational elements of the emergency organization had generally 'stabilized' the reactor to the point where their actions were generally not of an emergency response nature. The radiological elements of the emergency organization were, however, still responding to emergency conditions, attemptint to reestablish routine radiological controls in plant (protective actions), continue in-plant, onsite, and offsite radiological monitoring (assessment actions), and implement corrective actions to terminate or reduce actual or potential releases of radioactive materials." (NUREG-0600 II-2-17)

With regard to notifications and communications,

"The investigator determined that the licensee's communications facilities and provisions generally were adequate to support implementation of the emregency plan with respect to initial notifications and the relay of updated information regarding radiologica) aspects of the response. Early in the event, however, it became apparent that additional telephones were needed to support the operational aspects of the emergency." (NUREG-0600, II-2-24)

The NUREG-0600 discussion is reproduced in its entirety in Section This document does not note Governor Thornburgh's testimony before the Senate Nuclear Regulation Subcommittee that (Reference 8 ) 
"there was a 'garble gap' between Harrisburg and Washington which contributed to confusion. However, he said that 'throughout the crisis, I felt I was getting the best information available from the widest range of sources, and I still believe that?."

and that of the NRC Commisioners (Reference 4)

"HENDRIE: You decide whether you ought to be one, Harold, but it seems to me that we ought to back volimer up with coverage, as this could go around the clock for the next couple of days. I don't know what you can do to improve the communication situation, but it is certainly lousy.

Now, Joe, it seems to me I have got to call the Governor -

FOUCHARD: I do. I think you have got to talk to him immediately.

HENDRIE: - to do it immediately, We are operating almost totally in the blind, his information is ambiguous, mine is non-existent and - I don't know. it's like a couple of blind men staggering around making decisions. Let me get - "

Concerns over maintaining plant equipment in an operable state and maintaining radioligical releases at a minimum occasionally required conflicting actions. In testimony before the President's Commission on TMI, the following was reported (Reference 7 ): 
"Floyd had taken over unit 2 operations early in the morning of March 29, the day after the accident began. He told the commission that on March 30 he deliberately vented radioactive gas from make-up tanks so as to depressurize them and save a primary system coolant pump. 'I had that one source of water between me and a loca (loss of coolant accident),' he said. Floyd said he did this with the concurrence of utility and NRC officials at the reactor site. He also said he continued to vent the tanks for days, believing that he could cease venting if a helicopter flying over the unit picked up increasing levels of radiation.

"NRC officials were completely surprised by Floyd's statements. 'This is the first time I've heard that,' said NRC director of reactor regulation Harold Denton. He and other officials at NRC have contended that those radiation releases were unexpected. And Denton told the President's commission later that day that the unexplained 1,200 mrem $h r$ reading picked up by the helicopter during the venting had caused him to recommend evacuation of the area around the plant."

The emergency equipment utilized imported to the site included monitoring equipment, shielding, hydrogen recombiners, pumps, heat exchangers, piping tanks, shipping casts and communication gear. NUREG-0557, Appendix B provides a description of how specific components were utilized to modify the plant systems for transition to natural circulation.: Portions of this appendix is reproduced in section 4 . 
3.14.3 Required or Suggested Corrective Action

NUREG-0600 identifies the following potential items of TMI facility non compliance during the initial three days of the accident:

1. "Contrary to the above [Tech Spec], during calendar year 1978, all individuals having emergency responsibilities were not trained in that two Emergency Directors, one Accident Assessment individual, eight Radiological Monitoring Team Members, and 37 Repair Party Team Members had not received the training specified in Procedure 1670.9. On March 28, 1979, during an emergency, at least four individuals assigned to Radioligical Monitoring Teams and seven individuals assigned to Repair Party Teams performed these emergency duties without having been trained as specified." (II-F-2)

2. "Contrary to the above [Tech Spec], a retraining program meeting or exceeding ANSI N81.1-1971 recommendations has not been maintained for members of the Radiation Protection and Chemistry staff in that only 2 of the 10 topics specified were included in the program." (II-F-3)

3. "States in Table 1 of Section 2.1 that a Site Emergency exists when there is a:

a. Loss of primary coolant pressure, coincident with high reactor building pressure and/or high reactor building sump level (Condition c); or b. Reactor building high range gamma monitor alert alarm (Condition e). 
Contrary to the above, the shift supervisor:

a. Failed to declare a Site Emergency at 0415 hours on March 28, 1979, at which time Condition "c" of Table 1 of Section 2.1 of the Three Mile Island Emergency Plan had occurred; and

b. Failed to declare a Site Emergency at 0635 on March 28, 1979, at which time Condition "e" of the Three Mile Island Emergency Plan had occurred." (II-F-5)

4. "FSAR Section 12.3.2.10 states that a Radiation Work Permit (RWP) is required for all personnel working in radiation areas except in emergency situations. In emergency situations the entry should be made by qualified personnel carrying radiation monitors and each entry must be documented.

Contrary to this commitment, during the period March 28-30, 1979, an emergency situation, individuals were permitted to enter high radiation areas with radiation levels much greater than 1000 $\mathrm{mrem} / \mathrm{hr}$ and with unknown levels of airborne activity, without an RWP, and these entries were not documented." (II-F-9)

NUREG-0578 identifies several short-term recommendations related to emergency response. Although some of these recommendations are included in section 4 , the following summaries are provided:

1. Shift Supervisor Responsibilities

Review plant administrative and management procedures. Revise as necessary to assure that reactor operations command and control responsibilities and authority are properly defined. Corporate management shall revise and promptly issue an operations policy directive that emphasizes the duties, responsibilities, and authority and lines of command of the control room operators, the shift 
technical advisor, and the person responsible for reactor operations command in the control room (i.e., the senior reactor operator).

\section{Shift Technical Adv1sor}

Provide on shift at each nuclear power plant a qualified person (the shift technical advisor) with a bachelor's degree or equivalent in a science or engineering discipline and with specific training in the plant response to off-normal events and in accident analys is of the plant.

Shift technical advisors shall serve in an advisory capacity to shift supervisors. The licensee shall assign normal duties to the shift technical advisor that pertain to the engineering aspects of assuring safe operations of the plant, including the review and evaluation of operating experience.

\section{Control Room Access}

Review plant emergency procedures, and revise as necessary, to assure that access to the control room under normal and accident conditions is limited to those persons necessary to the safe command and control of operations.

\section{Onsite Technical Support Center}

A separate technical support center shall be provided for use by plant management, technical, and engineering support personnel. In an emergency, this center shall be used for assessment of plant status and potential offsite impact in support of the control room command and control function. The center should also be used in conjunction with implementation of onsite and offsite emergency plans, including communications with an offsite emergency response center. Provide at the onsite technical support center the as-built drawings of general plant arrangements and piping, instrumentation, and electrical systems. Photographs of as-built system layouts and locations may be an acceptable method of satisfying some of these needs.

\section{Onsite Operational Support Center}

Each operating nuclear power plant should establish and maintain a separate onsite operational support center outside the control room. In the event of an emergency, shift support personnel (e.g., auxiliary operators and technicians) other than those required and allowed in the control room shall report to this center for further orders and assignment. 
The ACRS recommendations of direct relevance to Sandia Research Programs in emergency response are:

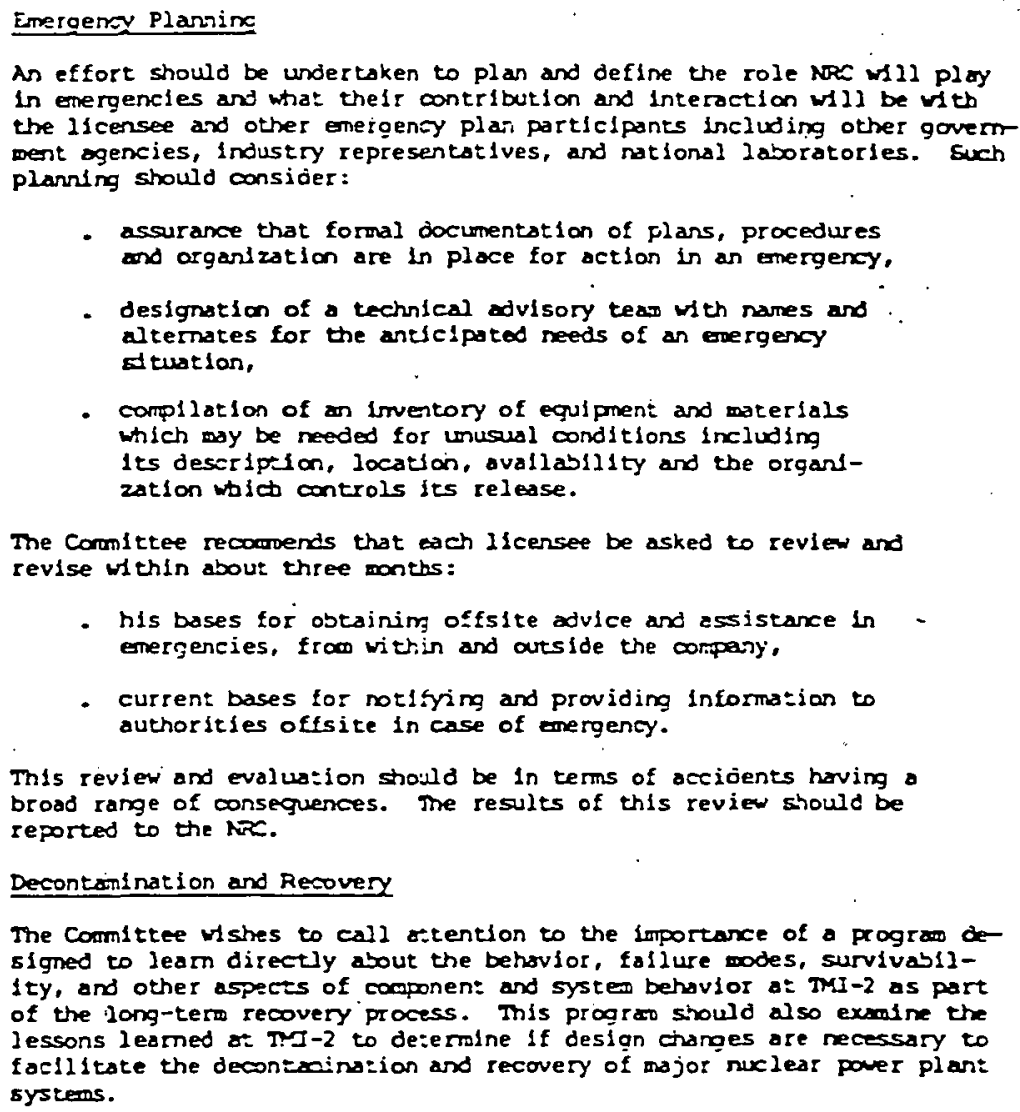

- assurance that formal documentation of flass, procedures and orgasization are in ploce for action in an emergency.

- designstion of a technical advisory teas with names and. alemates for the anticlpated needs of an energency dtuation,

- compliation of an imventory of equipment and materials Which may be needed for unusual conditions including its description, location. ovallabll1ty and the organlzation wich controls its release.

The comlttee recourends that weh IIcersee be asked to review and revise whin about three months:

- his bases for obtainim offsite advice and assistance in emergencies, frow within and ourside the compays,

- current bases for notifying and providing informatian to authorities offsite in case of energency.

This review and evaluation should be in terms of accioents having o broad range of conseguences. The results of this review should be reported to the NFC.

\section{Decontoinination and Recovery}

The comlttee Wshes to call atention to the fmportance of a prograw osigned to learn directly about the behovior, fallure modes, survivability, and other aspects of componen: and systes behuvior at MMI-2 as part of the long-term recovery process. This prograt should also examine the lessons learned at TM-2 to de:emine if desian changes are necessary to facllitate the decontraination and recovery of major nuclear pover plant systeons.

Certain direct and immediate actions have been taken by the NRC related to emergency preparedness as follows:

1. IE Bulletins (Reference 1) required all licensees to

"Review your prompt reporting procedures for NRC notification to assure very early notification of serious events." 
2. "The Nuclear Regulatory Commission also has announced that it has installed dedicated telephone lines between its operations center and 68 of 70 operating reactors, as well as 14 fuel cycle facilities. This is intended to avoid the collapse in communications which characterized the first few days after Three Mile Island." (Reference 10 6/5/79)

The subject of emergency plans and nuclear reactors has received considerable political attention. In particular, the U.S. Senate (References 6 and 6 ) has passed legislation requiring nuclear reactors in all states not having an approved emergency plan by June 1, 1980 to be shut down. The House of Representatives companion bill is not expected to be acted on until after the August recess.

Selected industry representatives' reactions are presented below which directly relate to emergency response:

1. TMI experience demonstrated a need to consider industry emergency support teams, emergency equipment pools, operator training and design philosophy in recognition that "some prospect of unpleasant surprises will always remain". (Reference 13, Dr. Shepard Bartnoff, comments reproduced and included in section 4. )

With specific reference to the TMI emergency response, Pennsylvania Governor Thornburgh recommended, in testimony before the Senate (Reference 8 ) that "crisis management should be directly carried out at the site". 


\subsubsection{Relationship to Sandia Research Program}

The TMI experience and relationship to the Sandia research program is summarized in table 3.14. Emergency response is an area where considerable technical, quasi-technical and non-technical studies are in progress. Although a thorough review of these studies, their scope and status is beyond the scope of this report, such a review may serve to focus Sandia research in the most productive manner. 
TABLE 3.14

Research Program - 14. Emergency Response

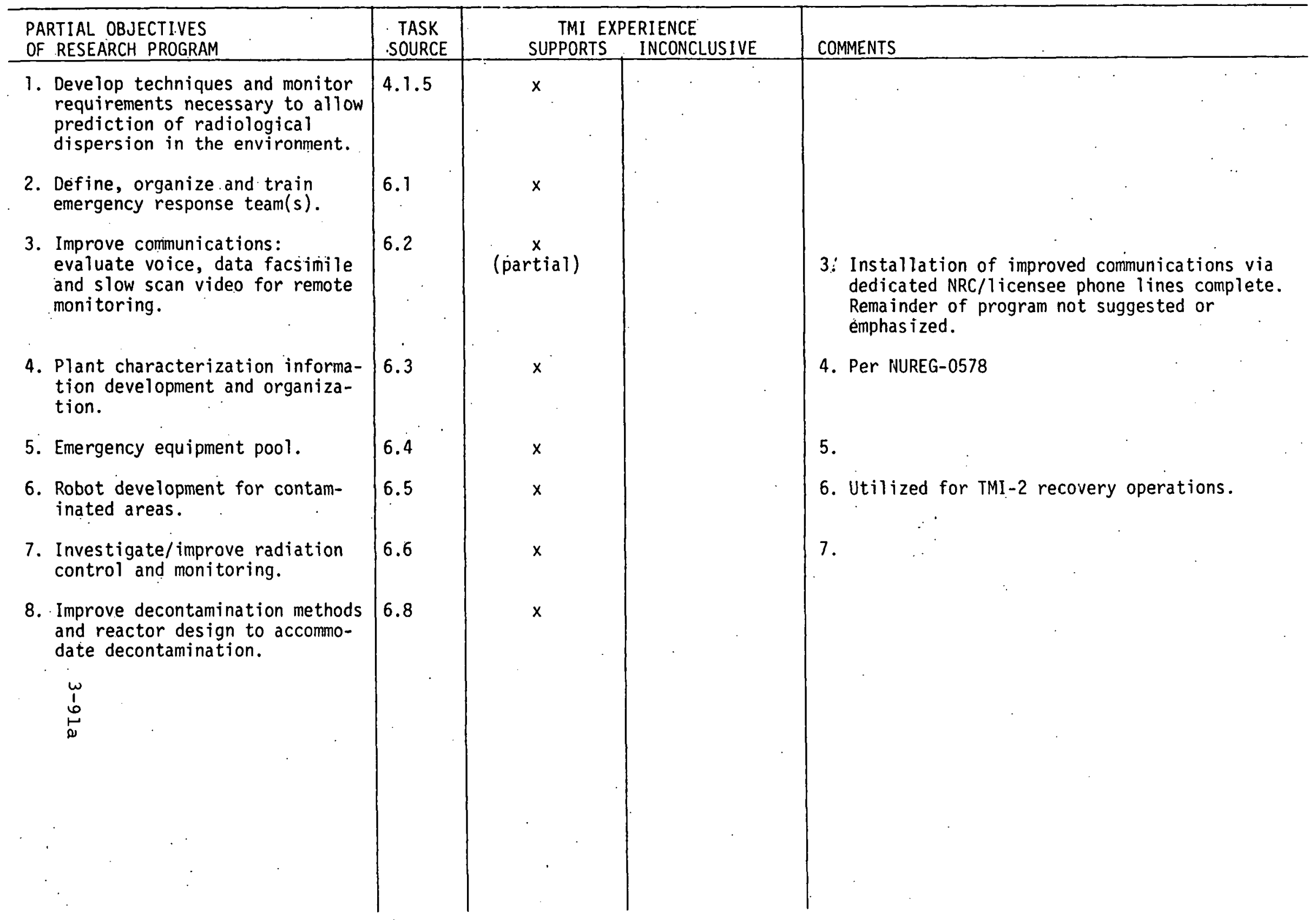




\subsection{SITING}

\subsubsection{Summary of Sandia Research Program}

The purpose of the Sandia Program is to conduct a full value/impact analysis of remote siting and to identify and evaluate alternate siting options.

\subsubsection{TMI-Related Studies and Findings}

The accident at TMI has instigated a spectrum of investigations into nuclear plant design, regulations, inspections and indeed siting. The TMI-2 accident brought national attention onto those aspects of siting associated with health impact, mainly demography, meteorology and nearby transportation, health and civil defense facilities. In the recent "Report of the Siting Policy Task Force:, NUREG-0625, the NRC presents a detailed discussion of current siting practices and identifies nine recommendations to modify siting policy as follows:

\section{Recommendation 2}

Revise Part 200 to change the way protection is provided for accidents by incorporating a fixed exclusion and protection action distance and population density and distribution criteria.

2. Specify a fixed minimon exclusion distance based on limiting the individual risk from design basis accidents. Furthermore, the regulations should clarify the required control by the utility over activities taking place in land and water portions of the exclusion area.

2. Specify a fixed minimon emergency planning distance of 20 miles. The physical characteristics of the emergency planning zone should provide reasonable assurance that evacuation of persons, inciuding transients, would be feasibie if needed to mitigate the consequences of accidents.

3. Incorporate specific population density and distribution limits outside the exclusion area that are dependent on the average population of the region.

4. Remove the requirement to calculate radiation doses as a means of establishing minimon exlusion aistances and low population. zones. 
Recommendation 2

Revise Fari 200 to reauire consiäeration of the potential inazaras posed by mon-mace activities onc natural characteristics of sites by establishing minimum stancioff distances for:

2. Major or commerical airports,

2. LNG terminals,

3. Large propane pipelines,

4. Iarge natural gas pipelines,

5. Large quantities of explosive or toric materials,

6. Major doms, and

7. Capable fauits.

\section{Recommendation 3}

Revise Part 200 by requiring a reasonable assurance that interdictive measures are possible to limit growndwater contamination resulting from class 9 accidents within the immediate vicinity of the site.

\section{Recommendation 4}

Revise Appendix A to 20 CFR 200 to better reflect the evolving technology in assessing seismic hazards.

\section{Recommendations 5}

Revise Part 200 to include consideration of post-licensing changes in offsite activities:

2. The NRC staff shall inform local authorities (planning commission, county conmissions, etc.) that control activities within the emergency planning zone (EPZ) of the basis for determining the acceptabizity of a site.

2. The NRC staff shall notify those federal agencies as in Item $I$ above that may reasonably initiate a future federal action that may influence the nusiear power plant.

3. The INRC staff shali require applicants to monitor and report potentialzy adverse offsite developments.

4. If, in spite of the aciions describec in Items 1 through 3 , there are offsite developmerts that have the potential for significantly increasing the misk to the public, the NRC stajf iill consider restrictions on a case-iy-case basis. 
Recommendation 6

Continue the current approach relative to site selection from a safety viewpoint, but select sites so. that there are no unfavorabie charactemisiics requiring unique or unusual design to compensate for site inadequacies.

\section{Recommendation ?}

Revise Part 200 to specify that site oproval de establisine at the eariiest decision point in the review and to provide criteria that woulc have to be satisfied for this approach to be subsequently reopened in tine licensing process.

\section{Recommendation 8}

Revise Part 52 to provide that a final decision discpproving a proposea site by a state agency whose approval is fundamental to the project would be a sufficient basis for NRC to terminate review. Such termination of a review would then be reviewed by the Commission.

Recommendation 9

Develop common bases for comparing the risks for all extermal events.

As noted in Section 2.7, NUREG 0625 does not address the economic aspects of site selection identified in the Sandia Program Plan.

\subsubsection{Relationship to Sandia Research Program}

Power plant site selection processes require detailed evaluation of economic factors, particularly when more than one candidate site for a power plant must be evaluated. It is essential that siting criteria recognize the economic considerations involved so, as to avoid eliminating the nuclear option 
on economic and cost basis. The economic implications must be determined for the NRC recommendations identified in NUREG-0625 and properly weighed against the risks associated with more or less stingent criteria. The Sandia Program is necessary to complement and balance the NRC's program as indicated in table 3.15 . 
TABLE 3.15

Research Program - 15. Siting

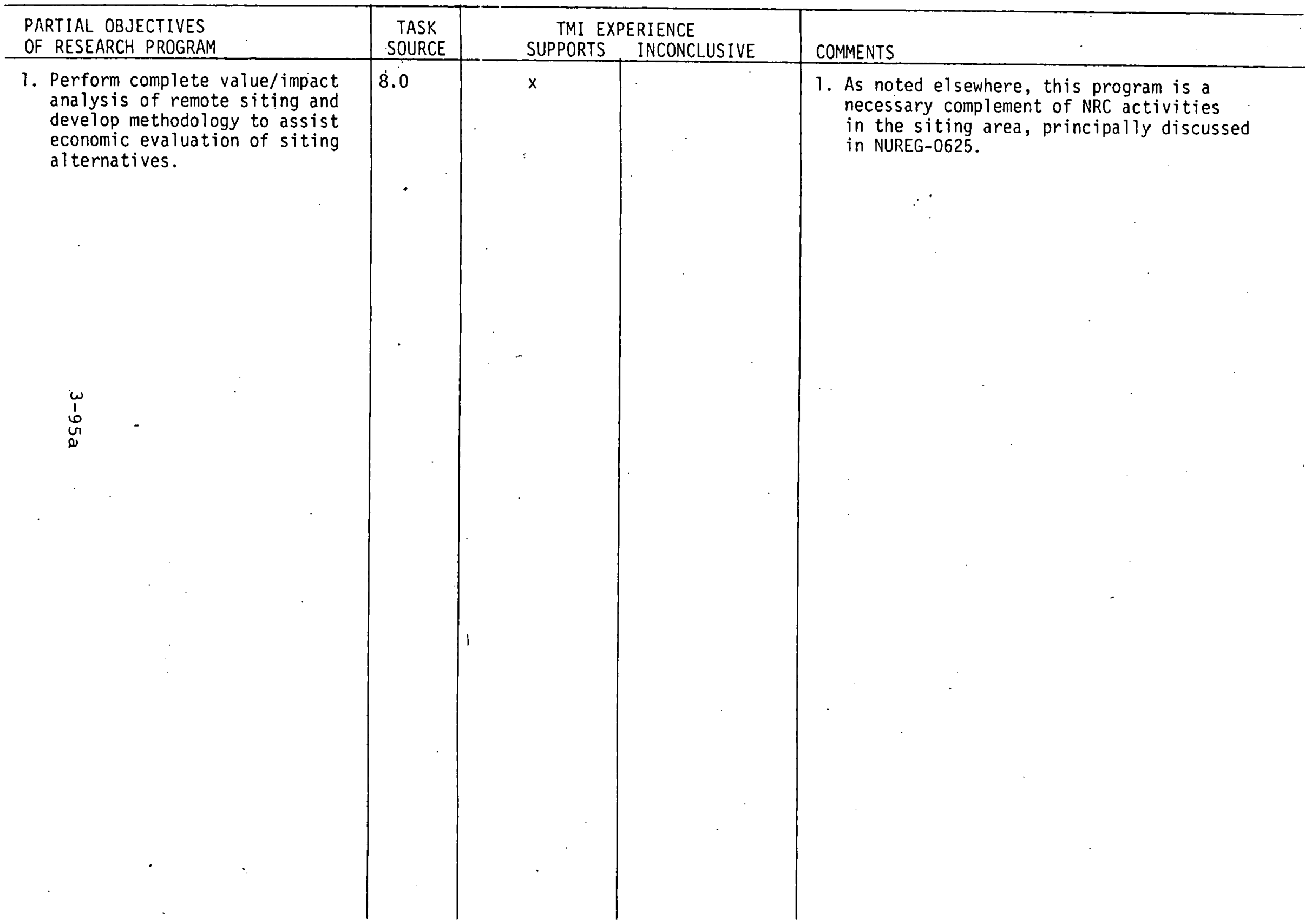




\title{
3.16.1 Summary of Sandia Research Program
}

Sandia tasks in this area are aimed a quantifying safety goals and developing and utilizing risk methodology for design basis and design decisions for nuclear power plants.

\subsection{6 .2 Post-TMI Recommendations}

As a result of TMI, renewed and accelerated attention is being given to risk method utilization. The following examples and commentary are directly or indirectly a result of TMI-2.

1. With regard to quantitative safety goals and their application, the following ACRS letter is included in its entirety:

\author{
Rionorable Joseph M.. Bendrie \\ Chalrman
U. S. Mrelear Requlatory Cocmission \\ Washingtor. D. C. 20555
}

Subject: REPORT ON QAATITATIVE SALTTY GOLS

Dear DT. Eendrie:

The Aavisory Comittee on Reactor Safeouards recomends that consideration be given.by. the Nuslear Regulatory Comission to the establishment of guanticative safety goals for overall safety of nullear power reatcors. This could be helpful, for exaple, in developing Criteria for NFC astions concerning operasing plants. The ACR recognizes the difficulties and uncertainties in the quantification of risk and understands that in many situatlons engineering judgment will be the only or the prinary basis for a decisior. Nevertieless, the ATS believes that the existence of guantl tative safety goals and criterio can provide important yardsticis for such judgnent.

The ACRS believes that sush NRC goals and criteris stould be pro posed for comment, not only by the public but by the Congress: Ultimately the congress siould be asked to express its views on the suitability of suth goals and criteria in relation to other relevant aspects of our techological society. such as large dans, and manuacturing, storage, or disposal facilities for hazardous chemicals.

The ACRS believes that it is time to place the discussion of risk, nuclear and nonnuclear, on as quntlative basis as feasible.

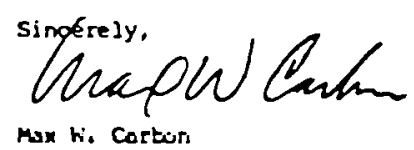

Mrx h. Cortor

Onalrman 


\section{The ACRS's Interim Report \#3 on TMI (reference 3 ) contains}

the following:

\section{Single Fallure Criterion}

The NRE should begin a study to determine if use of the single follure crlterion establishes an aporoptiate level of rellability for reactor safety systems. Operation experience sugoests that matiple fallures and common mode fallures are excountered it th sufficies: frequency that they need more specific consideration. This study should be accoropanled by concurrent consideration of how the licersix process can be modifled to take acount of a net se: of criteris as appropriate.

\section{and}

\section{Rellablilty of Electrie Parer Sipplies}

During the past several years there have been several operating experiences imolving a lass of $\lambda$ i pover to hrortant engineered sofegusds. The AGS belleves it liportan: tha: a corpretensive reexalination be made by the kec and the reactor llcenses of the decurcy of design, testing. and maintenarne of offsite and onsite $A=$ and $E$ power spolles. In particula:, fallure modes and effects analyses should be maje, 1 is no: alreaty performed, mie systemaile testing of power syster reliabllity, ir clutine dbnormal o: anmalous systed translents, should be considered, and loproved gality assurance and status nonitoring of powe: supply systers should be sougt:.

3. In an August 14 letter (reference 3 ) the following additional ACRS recommendations relate to risk method utilization:

Studies to I morove satety

The ACRS has previously recommended on several occasiors tiat the lac staft utllize the dethodology of probabilistic malysis to exomine the teliability of the design of systens important to safety, both for existing reactors and a it might opply to reactors to be construeted. For example, on juiy 12.1978 the ACRS, in a letter trom R. F. Fraley to L. V. Cossick, recomended ind the NRC Stafl provide enaluation of the rellability of the auxiliary feediater systems of current PWRs and aWRs in terms of various transients ax incidents.

Recentiy, fcllowing the Three Mile island Accident. the NAC Staff performed short-terr, intensive review of the auxiliary leedwater system for combustion
ongineering and westinghouse operating Pwhs and found many itens of interest. including some which suggested a need for early regulacory action wo ranedy deficiencies. The ACRS recomends that this sane procedure be applied, as expeditiously as pxactical, to exch of the other systens of imporiance to safery in onder to ascerts in whether there are other features on operating reactors wrranting early or near-ten improvements.

\section{and}

\section{Studies to Roduce the Prntability o: an Aceldent}

The ACRS recomends that studies be made of posslble signt:lcant effects adverse to salety orising from smared systems or locations in existing multiple-rector stations, of the probasility of such adverse effects, and of possible mitigating teatures. Dasples of potentially adverse effects to be considered include the possible loss of access to systens needed for one unit due to unexpected releases of radioxtivity from a neichoor, and the potential overloading of omeromey diesel capobility arising from cor

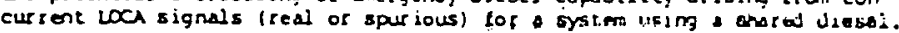


Studies to Roduce the Probabllity of an Accident

The ACRS recommenss o systerntic reevaluation of the common-mode fallure potential of comeressec eis sogies used for control or service in both

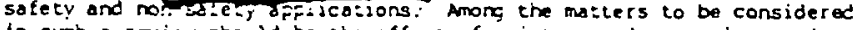
in such a review should be the effect of moisture ard corrosion products, Ind a totai loss of ait supply. Also of concern is any interconnection of corpressed oit supplies to both safety and non-sofety devices and to other sluid systens. Consideration stould be given to the meniney of seperation rules for dir oystems.

Studies to Reduce the Proosbility of an Acriden:

The ACPS reconmends tha: studies be thoo of Ule incerrelotionship between the operation and interconection of the aux 1 iary feejucter system, the main feecwater syster, the ounospheric dump ax the control system, in board of the isolation values on the main feedwte: and maln steam dines in order to ascertoin wether there are signlfieant undesirable interactions inder varfous postulated ccident scenerios.

4. NUREG-0625, Report of the Siting Policy Task Force, contains several recommendations with regard to risk method utilization. Appendix B to NUREG-0625 contains a discussion of Regulatory Agency use of risk assessment to develop criteria. The following NUREG0625 recommendation is pertinent to the Sandia Research Program and is included:

\subsubsection{Reconmendation 9}

Develop common bases for comparing the risks for all extermal events.

\section{Discussion}

There are no quantitative bases for judging and managing the conservatism used to establish the severity of all natural phenomena and the resulting degree of safety afforded by associated design provisions. This is in part the result of the various earth science and engineering disciplines independently developing analytic techniques that result in a lack of common means to quantify and compare the risks from natural phenomena. Because of this, the staff management is hindered in its ability to control modifications to natural phenomena severity analyses and to control design requirements to accommodate these natural phenomena. The same situation exists for man-made external events. In the opinion of the Task Force, the overall risks from all external events need to be established to provide uniform quantitative bases for comparing the requirements in all disciplines dealing with natural phenomena and external events. 
The Task force believes that an interdisciplinary effort should be undertaken with the objective of developing quantitative risk comparisons of all external events and natural phenomena. The disciplines should include seismology, hydrology, meteorology, mechanical and structural design, and accident analysis as well as probabilistic risk analysis. The study should result in the development of a methodology that will permit the conservatism in these varied disciplines to be better managed.

5. NUREG-0560 recommendations also support increased risk method utilization:

All classes of operating plants should be reanalyzed using failure mode and effects analysis to identify realistic plant interactions resulting from failures in non-safety systems, safety systems and operator actions during transients and accidents. Associated analyses should be performed for a sufficient time duration to establish that a stable plant condition had been reached including natural circulation. Explicit consideration should be given to the effects of a loss of onsite or offsite power.

- An improved system, including reporting and data assembly, should be developed by the NRC to more effectively evaluate actual data from operating experience to assess whether the trend of data from the occurrence of equipment malfunctions or other everits indicates excessive challenges to the plant safety systems. 


\subsubsection{Relationship to Sandia Research Program}

The documentation presented in the previous section provides a very clear indication that risk methods will be used to a considerably greater extent in the future to assess and assure reactor safety. Emphasis on the development and use of these techniques in the LWR Safety Technology Program will allow Sandia to take a leadership role in this area. Although a detailed discussion of the many ways in which the use of risk methods can contribute to the assessment and assurance of safety is the subject of a report in itself, the listing below should serve to stimulate some creative thoughts along this line.

Future Applications of Probabilistic Risk Assessment in LWR Safety Technology Program

- Supporting prioritization of safety technology projects

- Evaluating differences in important safety issues among reactor and plant design concepts

In Design

- Performing trade-off studies on aiternative designs and procedures

- Identifying interface problems of potential safety significance

- Assuring that sources of common-cause failures are eliminated from the design 


\section{In Operation}

o Supporting continued development of accident

topology for use in

+ defining important emergency operating procedures

+ developing disturbance analysis techniques

- Evaluating the effect of design or procedural modifications

- Maintaining a current record of design or procedural modifications

In Regulation

- Providing a framework for assimilating failure experience to update understanding of important safety issues

- Allocating regulatory manpower to important issues

- Developing effective standard technical specifications

o Assuring the effectiveness of new regulatory guides (e.g., sabotage and fire protection)

- Devising alternatives to the single failure criterion

The most difficult task faced by Sandia in stimulating increased emphasis on the utilization of risk methods will be in fostering the use of these methods among NSSS vendors, architect-engineers and utilities. To obtain this involvement it will be necessary to show the safety and cost incentives to employ risk methods. Perhaps by building on the experience at TMI and the resultant interest in design and procedural considerations for existing power plants, this task can be somewhat simplified.

The relevance of Sandia research in this area to TMI events and literature is summarized in table 3.16 . 
TABLE 3.16

Research Program - 16. Risk Method Utilization

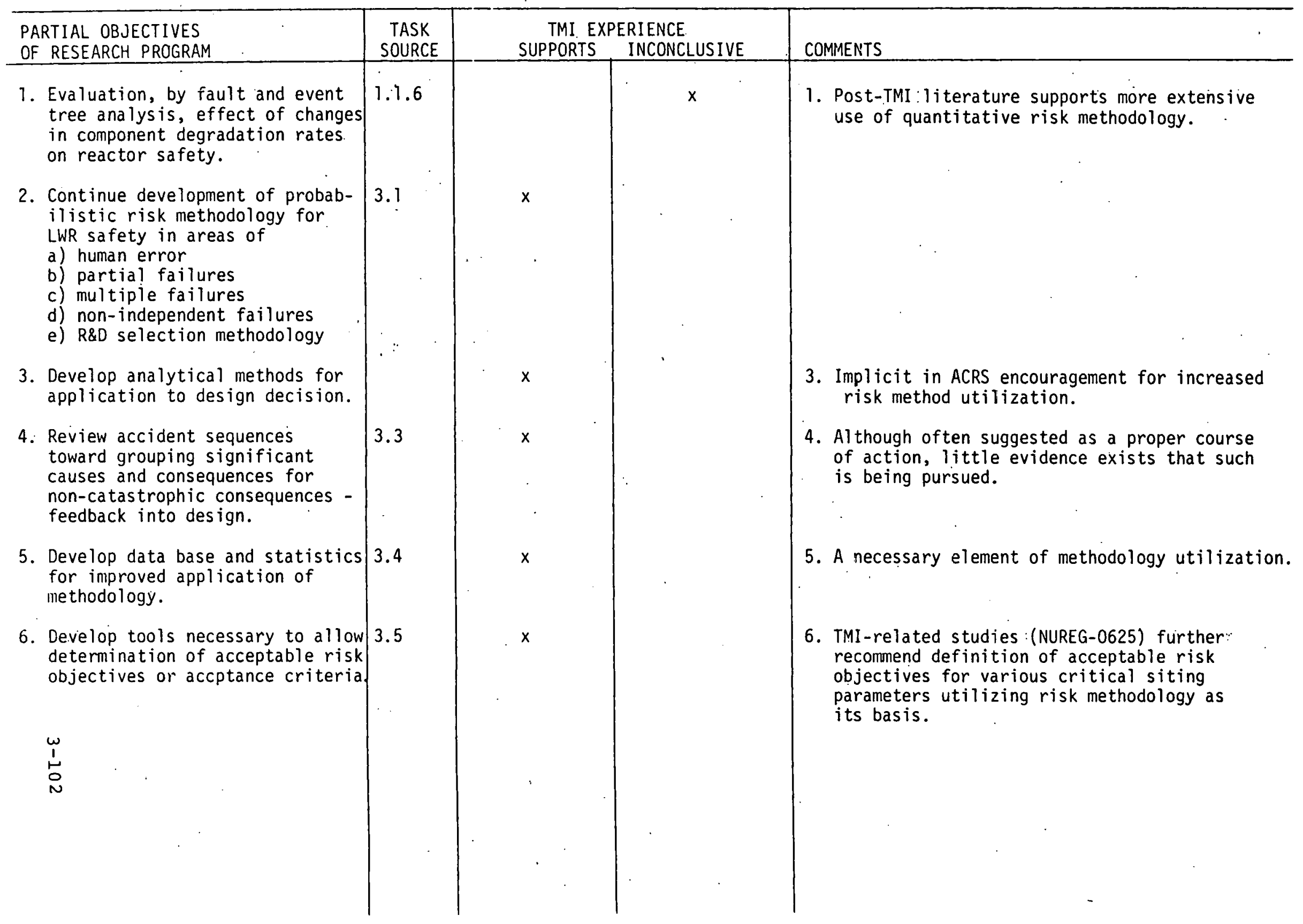


TABLE 3.17

Research Program - Miscellaneous

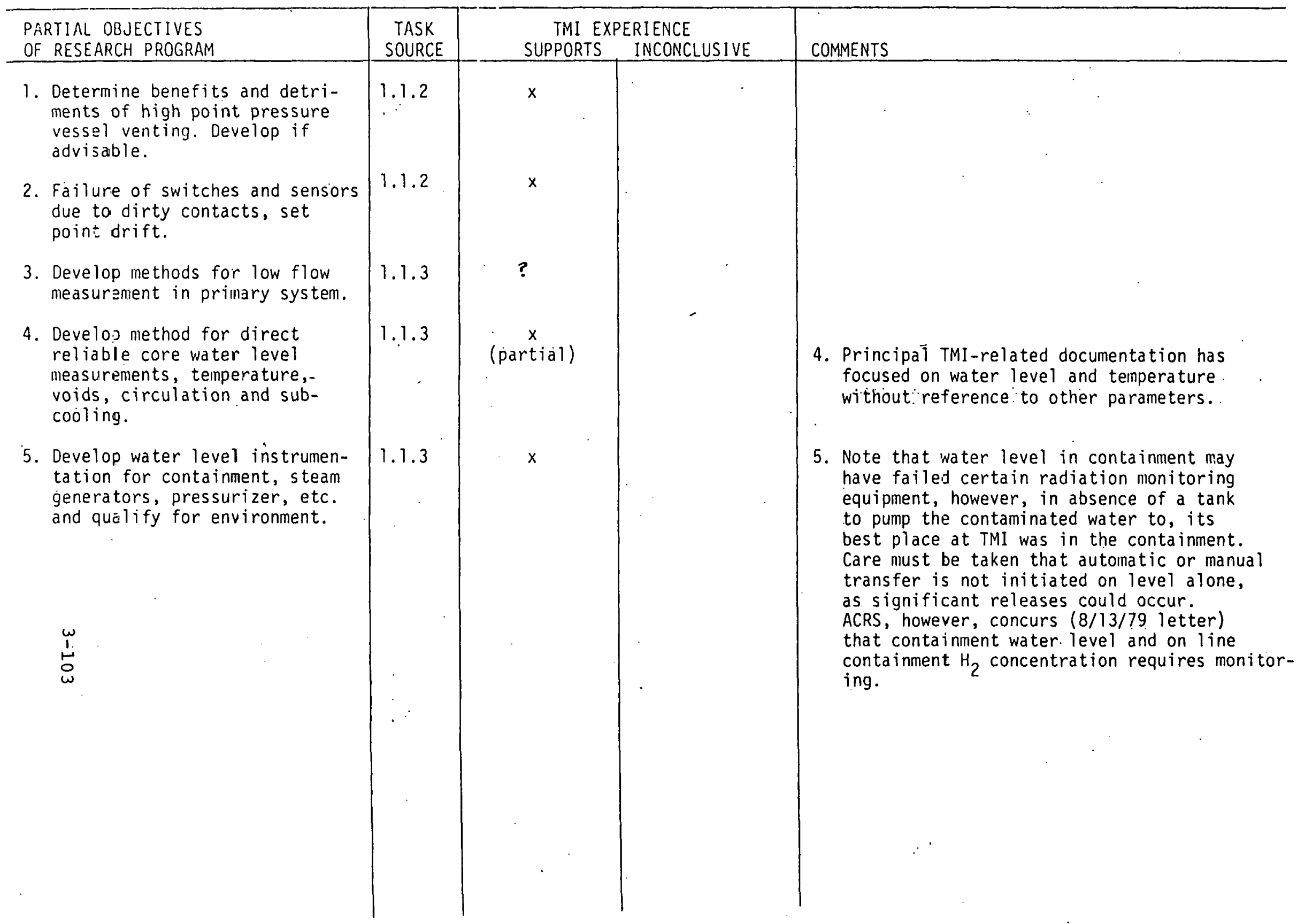


Research Program - Miscellaneous (continued)

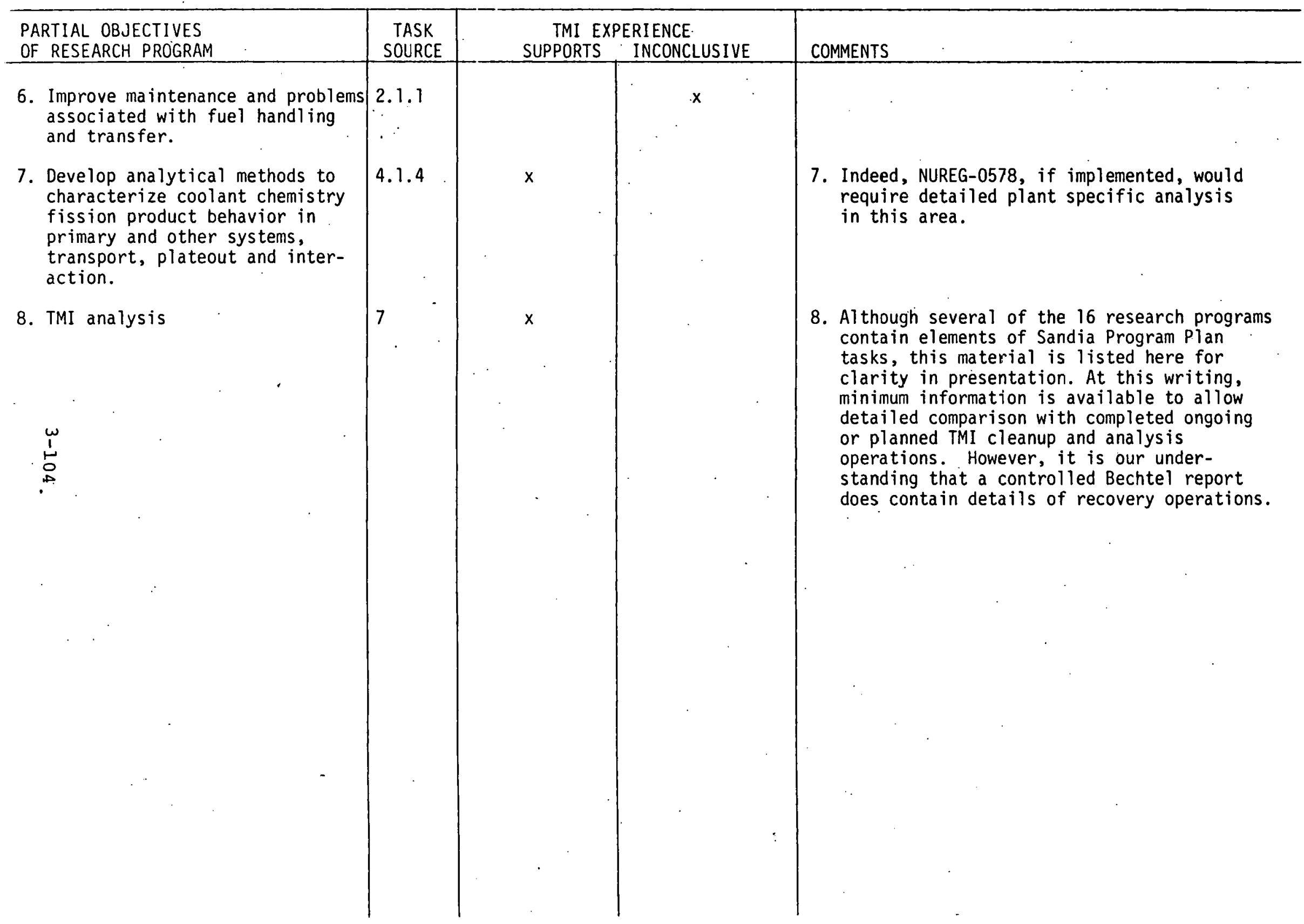




\section{References*}

1. USNRC, Office of Inspection and Enforcement IE Bul Tet in 7905, 4/1/79, 79-05A, 4/5/79, 79-05B, 4/21/79, 79-06, 4/11/79, 79-06A, 4/14/79, 79-06A Rev. 1, 4/18/79, 79-06B, 4/14/79, 79-08, 4/14/79, 79-10,5/11/79.

2. USNRC, Office of Inspection and Enforcement, Preliminary Notification, Series 79-67, March 28, 1979 - May 29, 1979, daily issuances.

3. A. ACRS - Letters, M. Carbon to J. Hendrie, 4/7/79, 4/18/79, 4/20/79

B. ACRS - Letter, M. Carbon to J. Hendrie, Interim Report \#2 on TMI-2, 5/16/79

C. ACRS - Letter, M. Carbon to J. Hendrie, Interim Report \#3 on TMI-2, 5/16/79.

D. ACRS - Letter, M. Carbon to J. Hendrie, Report on Quantitative Safety Goals, 5/16/79

E. ACRS - Letter, M. Carbon to J. Hendrie, Lessons Learned Recommendations, $8 / 13 / 79$

F. ACRS - Letter, M. Carbon to J. Hendrie, Studies to Improve Reactor Safety, 8/14/79

G. ACRS - Letter, M. Carbon to J. Hendrie, Pipe Cracking in Light Water Reactors, 8/16/79

4. Transcripts of NRC Commissioners' Meetings
A. $3 / 28 / 79$
B. $3 / 29 / 79$
C. $3 / 30 / 79$

5. S.562, 96th Congress, 1st Session, In the Senate of the United States, July 17 (legislative day, June 21), 1979 An Act to authorize appropriations to the Nuclear Regulatory Commission.

6. Nucleonics Week, McGraw-Hill Publication, May 3, 1979, pp 3-4.

7. Nucleonics Week, McGraw-Hill Publication, June 7, 1979, p 6 (Testimony of Floyd).

8. Nucleonics Week, McGraw-Hill Publication, April 26, 1979, p 5 (Testimony of Thornburgh).

* Major reports summarized in Section 2 are not repeated. 
9. Inside NRC, MCGraw-Hill, Inc. August 6, 1979 pp 1-14.

10. The Energy Daily, Volume 7 number 106, Tuesday, June 5, 1979.

11. USNRC, Office of Public Affairs News Releases Nos.:

$$
\begin{array}{lcl}
79-64,3 / 28 / 79 & 79-78,4 / 23 / 79 & 79-106,6 / 15 / 79 \\
79-65,3 / 28 / 79 & 79-79,4 / 25 / 79 & 79-175,7 / 3 / 79 \\
79-66,3 / 29 / 79 & 79-89,5 / 21 / 79 & 79-118,7 / 6 / 79 \\
79-67,3 / 30 / 79 & 79-96,6 / 4 / 79 & 79-119,7 / 9 / 79 \\
79-71,4 / 11 / 79 & 79-97,6 / 4 / 79 & 79-122,7 / 17 / 79 \\
79-72,4 / 11 / 79 & 79-104,6 / 14 / 79 & 79-125,7 / 19 / 79
\end{array}
$$

12. Technical Assessment of Disturbance Analysis Systems, A.B. Long, Electric Power Research Institute, April 1979.

13. TMI-2: Technical Insights after the Fact, Dr. Shepard Bartnoff, presented at the Atomic Industrial Forum Workshop on Reactor Licensing and Safety, May 15, 1979. 
Relevant Background Material

NUREG 0396, Planning Basis for Develodment of State and Local Government Radiological Emergency Response Plans in Support of Liaht water Nuclear Power Plants, USINR, USEPA, Task Force on Emergency Planning, December 1978.

NUREG $75 / 171$, Guide and Checklist for Development and Evaluation of

State and Local Government Emergency Response Plans in Support of

Fixed Nuclear Facilities, USNRC-Office of International and State Programs (December 1974).

NUREG 0107, Safety Evaluation Report related to Operation of Three Mile Island, Unit \#2, Metropolitan. Edison, NUREG 0107, September 1976, including Supplement 1, undated, and Supplement 2, February 1978, USNRC.

Regulatory Guide 1.101, Emergency Planning for Nuclear Power Plants, Revision 1, USNRC, March 1977.

Regulatory Guide 1.92, Instrumentation for Light Water Cooled Nuclear Power Plants to Assess Plant Conditions During and Following an Accident, Rev. T, August 1977.

Code of Federal Regulations, Vol. 10, Energy, Parts 0-199 (10 CFR)

A. 10 CFR 50, Appendix E, Emergency Plans for Production and Utilization Facilities.

NUREG 0103, Standard Technical Specifications for Babcock and Wilcox Pressurized Water Reactors, Revision 7, Revision of January 1, 1977.

EMD-79-9, Higher Penalties Could Deter Violations of Nuclear Regulations, U.S. General Accounting Office, February 16, 1979.

EMD-79-16, Reporting Unscheduled Events at Commercial Nuclear Facilities: Opportunities to Improve Nuclear Regulatory Commission Oversight, U.S. General Accounting Office, January 26, 1979. 
Memorandum, A.R. Rasytoczy, Chief, Analysis Branch Task Force to D.F. Ross and R.J. Mattson, Short-Term Task Force Program in the Analys is Area, June 26, 1979.

Nuclear Safety, Technical Progress Review, Vol. 20-4, July/Aug. 1979. Preliminary Report on the Three Mile Isiand Incident, W.P. Costo \& W.B. Cottrell.

Federal Register/Vol. 44, No. 138/July 17, 1979/Proposed Rules, 4148341484 Adequacy and Acceptance of Emergency Planning Around Nuclear Facilities.

Report, TVA Nuclear Program Review, Task Force on Nuclear Safety. Tennessee Valley Authority, May 1979.

NUREG.0586, Rev. 1, Title Lists Publicly Available Documents Three Milelisland Unit 2 Docket 50-320, USNRC, July 1979.

EMD-78-110, Areas Around Nuclear Facilities Should Be Better Prepared for Radiological Emergencies, U.S. General Accounting Office, March 30 , 1978.

NUREG 0090, Vol. 2, No. 1, Report to Congress on Abnormal Occurrences January - March, 1979, USNRC, July 1979.

Letter, U.S. Comptroller General to Senator R.S. Schweiker regarding nuclear plant operators, May 15, 1979.

NUREG-0553, draft, Beyond Defense in Depth, cost and funding of State \& Local Government Radiological Emergency Response Plans and Preparedness, USNRC, March 1979.

Interim Report on the Three Mile Island Nuclear Station Unit 2 (TMI-2) Accident, Metropolitan Edison Company, May 15, 1979. 


\section{SIGNIFICANT EVENTS DURING ACCIDENT}

\subsection{Turbine Trip}

4.1.1 Apparent Cause

Ti.e cause of the initial trip of the steam generator feed pumps (FW-P-1A/IB) that initiated the turbine trip followed by a reactor trip has been attributed by some members of the plant staff to water in the instrument air system. It has been stated that water in the instrument air system at the condensate polishing system will cause the condensate polisher air-operated effluent valves M12, M22, etc., to go closed (Int. 102, 123). While a turbine trip is an anticipated operational event that occurs relatively frequently during the operation of a plant, the investigation studied the possible causes of the turbine trip to determine if a precise initiating cause could be determined, thereby eliminating the need for conjecture.

\subsubsection{Plant Air Systems}

A partial review of the history of the instrument air service air system was conducted during this investigation.

A licensee concern as to the capacity of the air system was recognized early in the construction/preoperational phase of TMI-2. (Problem Report No. 
913; Ref. 18) The solution of the capacity problem was cross-connecting the station service air system to the instrument air system as a normal mode of operating the two systems. Discussions with licensee personnel indicate that there is a change pending that would isolate part of the station service air system. This change and its status were not pursued for details. The mode of air. supply operation on March 28, 1979, was the cross connected system.

The investigator reviewed Instrument and Control Log Book I, (designated as "Mercury" Daily Log), which indicates that there was water in the air system at the condensate polishers on October 19; 1977. While the log called for attempts to determine the cause, discussions with licensee personnel knowledgeable of this occurrence indicate that the cause was not determined. The air lines were cleared of water, and the system functioned correctly.

The investigator noted that reference is made in the I\&C Shop Log, May 12, 1978, that condensate polisher air lines were again filled with water, at a time when operations staff members were working on the condensate polishing system.

The licensee installed local air dryers at various points in the instrument air system to prevent the accumulation of moisture. In particular, an air/water separator was installed in the condensate polisher instrument air line in series with two pressure regulators. This arrangement processed all air to the condensate valve controls and instruments located on the condensate polisher local control panel. This water/air separator utilizes a buoyant valve plug that rises and allows water to exit the line while keeping the air above the water. It also contains a fine mesh screen. Air lines at the control panel are $1 / 4$ and $3 / 8$ inch diameter copper tubing. Observation of this separator in its current status shows an accumulation of iron-rust-colored particles at the screen location of the air/water separator.

\subsubsection{Post Accident Testing}

The licensee has performed tests on the condensate polisher instrument air system subsequent to March 28, 1979. Discussions with the licensee staff 
working on these tests indicate that, on isolating instrument air from the condensate system, the condensate outlet valves for each polisher tank go closed.

Their tests indicated that introduction of water into the air system did not affect the polisher outlet valves, in that the air-water separator functionec properly. They proceeded to change the test procedure and they removed the air/water separator. In that test, on introduction of water, the outlet valves fluttered and then stabilized open. In all testing cases involving water, the polisher inlet valves remained open. The testing with water consistec of allowing about 15-gallons of water to enter, with the air, at the condensate polisher control cabinet.

The licensee, during testing, inspected the service station air supply connected to the condensate system. He found that the check valve (Tag No. RO-I 51) in the 1 inch station service air line, approximately 115 feet from condensate resin tank No. 7, was "frozen" open. The shutoff valve in that line is open when resin transfer is in progress. The open shutoff valve and open check valve allowed a path for water to enter the station service air-instrument air system on March 28, 1979 (Procedure 2106-2.2, Revision 9; Ref.).

The licensee report on their testing and investigation effort has not been completed.

The actual circumstances described at the time of the trip (Int. 102. 143) indicate that significant amounts of water were found in the station service and instrument air receivers. The No. 7 condensate polisher was being "flushed" with water having an exit pressure of 160 psig into the condensate polisher No. 7 tank. The 1.60 psig water and the service air, at 80 to 100 psig, were being used simultaneously. Discussion with the auxiliary operator who was working on the condensate polisher tank No. 7 on March 28, 1979, revealed that the air was being used to "fluff" the resin while introducing high-pressure demineralized water to transfer the resin. 
Discussion and taped interview (Int. 123) indicate that at the announcement of the turbine trip/reactor trip, the condensate polisher panel indicators showed condensate polisher isolation, which indicates no condensate flow. Condensate flow charts have been reviewed by the investigator and confirmi an abrupt termination of flow (Flow Charts for Condensate Polisher Tanks 1, 2, 3, 4, 5, and 8; as well as Polisher Outflow Chart; Ref. 19).

\subsubsection{Pump Interlocks and Wiring Errors}

Discussion with a licensee engineer indicates. that he also found that the solenoid switch wiring for the polisher valve controls was not in accordance with drawings in at least two polisher units. This could affect the status of the valves on power failure. The details on this aspect are not available at this time, but should be available in his pending report. He also stated (Int. 166) that there was a wiring error related to the condensate/condensate booster pump auto/manual switch such that on a trip of condensate booster pump CO-P-2A, its paired condensate pump CO-P-IA would trip. This wiring error was isolated to the $A$ pump pair so that the condensate $B$ pump would remain on line when its paired booster pump tripped.

Once the condensate polishing system fails to allow condensate water to flow, the condensate booster pumps will trip on low suction pressure and condensate pump IA will trip because of the wiring error. Once the booster pump trips, the main feedwater pumps will trip on low feedwater pump suction pressure. The loss of both feedwater pumps trips the turbine.

\subsubsection{Evaluation}

The tests performed to date do not demonstrate conclusively that condensate polisher valve closure will not occur with water in the condensate polisher valve instrument air lines as reported by the interviewed operators.

To validate the initiating cause of the turbine/reactor trip as the presence of water in the air system producing condensate polisher flow isolation,

$$
4-8
$$


a confirmatory test would be needed. The test performed by the licensee casts some doubt on the apparent initiating cause, but the investigators consider the testing performed thus far to be insufficient to be conclusive.

This investigation was not able to identify the specific initiating cause which led to the turbine trip on March 28, 1979. The initiating cause is of interest for reasons stated in Section 4.1.1. However, failing to identify a specific cause is not a concern in that this plant was designed to sustain a turbine trip irritiated by a loss of main feedwater as a routine operational event: The availability of the condensate system is not critical to the sequence of events in this accident.

\subsection{Closed Emergency Feedwater Block Valves}

\subsubsection{Sequence}

At approximately 8 minutes after the start of the accident, the operator found the OTSG level at 10 . inches on the startup range. The operator considered this level to indicate that the OTSG was "dry." (This level indication is appropriate for a steam filled OTSG with no liquid phase present.) The operator verified that the emergency feedwater (EFW) pumps were running and examined the valve 1 ineup, and found that the $E F-V 12 A$ and $12 B$ valves were shut. The position-indicating lights on $12 A$ were obscured by a caution tag hanjing from another valve controller. The position indicating lights for $12 \mathrm{~B}$ may have been obscured by operator as he leaned over the panel. (This was due to the light positions on the panel and the operator's location, not his physical stature.) The operator drove the valves open; resulting in the dry OTSG being fed with relatively cool water. (Int. 4,9)

It should be noted that on March 23, 1979, an NRR Operator Licensing Branch (OLB) examiner conducted operator examinations which included the EFW System. The valves were open on that day based on control room indications. Moreover, a routine scheduled surveillance test was performed on the $A$ and $B$ 
NRR Lessons Learned Task Force

Short-Term Recommendations

TITLE: Performance Testing for BWR and PWR Relief and Safety Valves (Section 2.1.2)

\section{INTRODUCTION}

General Design Criteria 14, 15, and 30 of Appendix A to 10 CFR 50 require that the reactor coolant pressure boundary be designed, fabricated, and erected to the highest quality standards and be tested to ensure an extremely low probability of abnormal leakage, rapidly propagating failure, and gross rupture. These criteria also require that the design conditions of the reactor coolant boundary not be exceeded during any condition of normal operation, including anticipated operational occurrences.

Proper operation of reactor coolant system relief and safety valves is vital for conformance to these design criteria. The inability of a sufficient number of these valves to open could lead to a violation of the integrity of the reactor coolant system pressure boundary. The failure of one or more of these valves to close results in a direct violation of the reactor coolant system pressure boundary integrity.

When the reactor coolant system relief and safety valves open, the flow through these valves is normally saturated steam. Some reactor coolant system transients and accidents as well as alternate core-cooling methods can result in solid-water or two-phase steam-water flow through these valves. Present qualification requirements for these valves include only flow under saturated steam conditions.

The purpose of this recommendation is to require qualification of relief and safety valves under expected operating conditions, which would include solid-water and two-phase flow conditions.

\section{DISCUSSION}

The reactor coolant system relief and safety valves are connected to the pressurizer steam space on PWRs and to the main steam line on BWRs.

On PWRs, transients and accidents that result in increasing reactor coolant system temperatures can cause an expansion of the coolant volume in the reactor coolant system so that the pressurizer fills with water. As the system pressure increases, two-phase and solid-water flow can occur through the reactor coolant system relief and safety valves.

On BWRs, transients or accidents requiring operation of the high-pressure coolant injection system or operation of the reactor core isolation cooling system can result in two-phase or solid-water flow through the relief and safety valves if the reactor vessel level instrumentation malfunctions.

In addition, on both PWRs and BWRs, certain alternative core cooling methods require coolant injection with ECCS systems and coolant discharge through 
relief and safety valves. These cooling methods may result in two-phase or solid-water flow through the relief and safety valves.

Solid-water or two-phase flow through the relief and safety valves can greatiy increase the dynamic forces on valve internals, piping, and supports over those. that would be expected from saturated steam flow conditions. Present ASME qualification requirements for safety valves inciude only flow under saturated steam conditions. Because the safety analyses have not given credit for the pressure-relief capability of the power-operated relief valves, the ASME Code also does not address qualification requirements for these valves.

To date, there have been a number of instances of improper operation of relief and safety valves. These examples include valves opening below set pressure, valves opening above set pressure or failure to open, and valves failing to reseat when open. The failure of the power-operated relief valve to reseat was a significant contributor to the TMI-2 sequence of events.

It is not clear whether these past instances of improper operation resulted from inadequate qualification of the valve or from a basic unreliability of the valve design.

Appropriate qualification testing of the relief and safety valves can verify the capability of these valves to function under the required conditions, thereby minimizing the possibility of multiple common-mode failure of these valves due to challenges from conditions for which the valves are not qualified. Qualification testing will also provide some of the information necessary for assessing the basic reliability of the valve design since failures or successes of qualified valves will be a partial indication of valve reliability.

Current valve test facilities may have to be modified or expanded to test valves under various flow regimes since two phase slug flow and solid-water. flow regimes will require higher mass flow rates and can result in greater dynamic forces. The time period for completion of this qualification testing has been chosen to allow for modification or expansion of the test facilities. The extended time for completion of this qualification testing is considered appropriate since this testing is considered to be confirmatory of valve performance capability.

It, should be noted that this requirement for qualification testing does not include testing under ATWS conditions at this time. Analyses of ATWS events have shown that the pressurizer relief and safety valves could discharge twophase and subcooled water at pressures in the range of 2800 psi to 4800 psi and at temperatures in the range of $650^{\circ} \mathrm{F}$ to $700^{\circ} \mathrm{F}$. It is possible that the final resolution of ATWS in PWRs (expected in calendar year 1980) would permit some plants to reach a peak pressure of 3800 psi subject to showing that the integrity of the primary coolant systems is maintained. It may be prudent; therefore, that test facility modifications include the capability of testing during ATWS conditions since it is likely that adequacy of any ATWS solution would depend on the verification of acceptable valve behavior. 


\section{POSITION}

Pressurized water reactor and boiling water reactor licensees and applicants shall conduct testing to qualify the reactor coolant system relief and safety valves under expected operating conditions for design basis transients and accidents. The licensees and applicants shall determine the expected valve operating conditions through the use of analyses of accidents and anticipated operational occurrences referenced in Regulatory Guide 1.70, Revision 2. The single failures applied to these analyses shall be chosen so that the dynamic forces on the safety and relief valves are maximized. Test pressures shall be the highest predicted by conventional safety analysis procedures. Reactor coolant system relief and safety valve qualification shall include qualification of assocjated control circuitry piping and supports as well as the valves themselves. 
NRR Lessons Learned Task Force

Short-Term Recommendations

TITLE: Direct Indication of Power-Operated Relief Valve and Safety Val-ve Position for PWRs and BWRs (Section 2.1.3.a)

\section{INTRODUCTION}

General Design Criterion 14 of Appendix $A$ to 10 CFR 50 requires that the reactor coolant pressure boundary be designed, fabricated, erected, and tested to have an extremely low probability of abnormal leakage, rapidly propagating failure, and gross rupture. Although the application of this criterion has empliasized the integrity of passive components in the reactor coolant system, such as the reactor vessel and the piping, this criterion should also apply to the valves that provide isolation for the system. 'Failure of relief and safety' valves to close has been the cause of events that result in small break LOCAs. Unambiguous indication of the position of the valves can aid the operator to detect a failure and take proper corrective action.

IEEE-279 requires that, to the extent feasible and practical, protection system input shall be derived from signals that are direct measures of the desired variable. However, only indirect indication of safety or relief valve position is generally provided and can be misleading, as was the case at TMI-2. Although the pressurizer power-operated relief valve was stuck open, control panel lights indicated that the valve was closed because the signal was derived from a sensor of solenoid actuation rather than a sensor of the valve position itse'lf.

The purpose of this position is to provide the operator a more positive indication of valve position and therefore provide additional assurance that the integrity of the reactor coolant pressure boundary can be maintained or a loss of integrity directly diagnosed.

\section{DISCUSSION}

The purpose of relief and safety valves is to operate in conjunction with the reactivity control system to limit system overpressure during anticipated operational transients or accidents. In some PWR plants, additional poweroperated relief valves are provided so that operation of the safety valves is necessary only for the more severe transients or accidents. Since these relief valves are not part of the ASME Code requirements for overpressure protection, they can be and are isolatable with remote-operated block valves.

The consequence of the failure of these valves to close is the loss of coolant and depressurization of the reactor system. Based on incomplete data, there have been five known instances, out of about 230 actuations in about 200 reactor-years of service, of the failure of a relief valve in a PWR to properly close. The failure rate per demand is not significantly different between the three types of PWRs, but the demand rate in the past varied by a factor of ten, from approximately 0.4 to 4.0 demands per reactor-year. In all 
instances, except for the one at TMI-2, the consequences were not significant. In BWRs there have been about 53 inadvertent blowdowns due to improper operation of the safety/relief valves located on the steam lines. Incorrect operation of these valves has produced the most frequent losses of primary system integrity. These events, however, were terminated without any violation of a safety limit.

A positive indication of the position of these valves can aid the operator in diagnosing a failure and in taking appropriate corrective action. Thus, the consequences of a failure of these valves can be reduced if the operator can reliably determine that a valve has failed to close. The present methods of indicating the position of safety and relief valves are generally indirect, either by measuring the temperature in the discharge piping or by indicating the status of the operating solenoid. These signals can be ambiguous. Temperature increases with a leaking valve, recovers slowly after a valve actuation and, because the valve discharge lines are sometimes connected to a common header, can increase for all valves when only one is open. Indication of the solenoid position will not, as occurred at TMI, necessarily reveal the position of the valve stem. Direct indication of the valve position, such as a reliable position indication of the valve stem, detection of flow by acoustic methods, or measurement of the flow rate in the discharge pipe, would reduce the ambiguity and aid the operator to take corrective action.

\section{POSITION}

Reactor system relief and safety valves shall be provided with a positive indication in the control room derived from a reliable valve position detection device or a reliable indication of flow in the discharge pipe. 


\subsubsection{Power-Operated Relief Valve}

\section{Finding}

All B\&h' plants except for Davis-Besse I have Dresser power-operated relief valves (several different models). Davis-Besse 1 has a Croșby Model HPN-SN valve.

Failures have occurred on both the Dresser and Crosby valves and improvements have been made in the valves and their controls. At the moment, the staff has no basis for rating one better than the other.

As related to the TMI-2 accident, the failure of the PORV to close changed a lossof-feedwater transient into a small loss-of-coolant accident. This was not immediately apparent to the operators. The effects of two-phase flow have not yet been fully evaluated.

Interim measures have been taken to reduce the number of times the PORV would be required to operate during the life of a plant by IE Bulletin 79-05B and the shutdown provisions that include (a) installation of an anticipatory reactor trip or turbine trip, (b) improving the reliability of the auxiliary feedwater, (c) lowering the réactor trip pressure set point, and (d) raising the set points for the PORV. Other actions may be necessary before subsequent start-up of the B\&W plants.

\section{Recommendation}

A more direct and positive indication of valve position is needed. Consideration also should be given to the merits of upgrading valves and the associated control and power equipment to safety grade, thereby achieving greater valve reliability; or, as an alternate, consideration should be given to the merits of closing the relief and block valves during power operation. In addition, an evaluation and possible testing of the PORV with regard to two-phase flow conditions should be made. These actions should be taken by NRC and B\&W. 
Honorable Josept M. Hendrie

Chairman

U.S. Nuclear Regulatory Commission

Washington, D.C. 20555

\section{SUBJECT: PIPE CRACKING IN LIGHT WATER REACTORS}

Dear Dr. Hendrie:

- There have been a significant number of occurrences of pipe cracking in boiling water reactors (EWRs), the Duane Arnold incident in 1978 representing the most severe example thus far. For pressurized water reactors (PWRs), leaks and deterioration of steam generator tubing have been significant problens and recently, cracking of a related but unpredicted type has been found in PwR stean generator feedwater nozzles.

The Nuclear Regulatory Commission's Pipe Crack Study Group issued a report in 1975 (NURDG-75/067) wich reviewed BVR pipe cracking and made reconmendations to reduce the incidence and severity of cracking. A second report (NURBG-0531) was issued in early 1979 which again examined the status of the incidence of pipe cracking and made further recommendations, primarily related to the influence of the choice of material and to the potential for inservice inspection.

The ACRS believes that it is appropriate to extend the scope of the NRC Staff review beyord that examined in NURS-0531. The relatively high frequency of BWR pipe cracking suggests that there may be a significant probability of a loss of coolant accident (LOCA), particularly a small LOCA, and that it may be relevant to examine, in greater depth than usual, a range of matters including the following:

1. The reliability of the safety features needed to cope with such an event.

2. The possibility of determining the location of a leak or break more rapidly and more directly than is now the practice.

3. The adequacy of operational procedures for such LocAs, including combinations of circumstances that could arise in connection with such an event.

Furthermore, the seeming long-time existence of large, deep cracks in the recirculation pipes at Duzne Arnold suxcesss that a range of possible accident

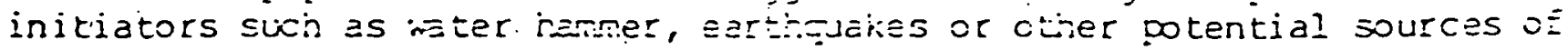


large additional forces could lead to a previously unexplored accident suri as concurrent multiple. failures. If so, consideration may have to be given to further malysis of the course of such an event in order to ascertain whas, if any, additional measures are needed to reduce the probability of the accicent or to mitigate its consequences.

The presence of the large, multiple cracks at Duane Arnold in sections of the pipe in wich no inservice inspection was required, points to a need for 2 comprehensive reexamination of all safety-related piping systens for similar or equivalent design, fabrication or construction Elaws, as well as the adequacy of the NRC reguiremerits for inservice inspection. Furthermore, high priority should be given by both the industry and the NRC to the early implementation of improved crack detection capability.

Some types of cracking in PWRs and BWRs can be retarded through the control of water purity. For example, most foreign and some domestic BwRs deaerate the primary coolant during reactor startw. The NRC Staff is considering a regulatory guide on this matter. A progran should be initiated to develop optimum water specifications, particularly in the areas of EWR prinary coolant and PWR secondary coolant.

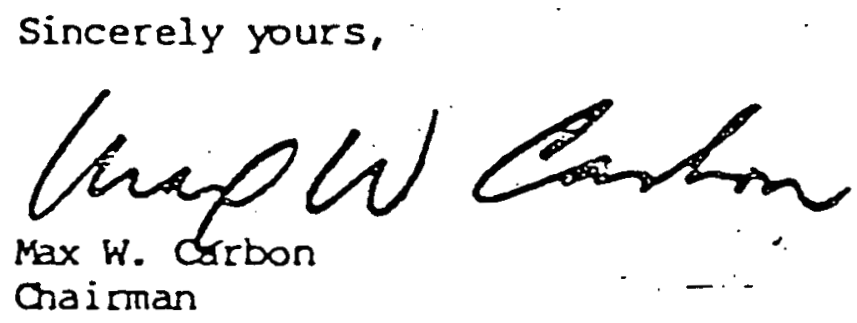

\section{References}

1. NURDG-75/067, "Technical Report - Investigation and Evaluation of Cracking of Cracking in Austenitic stainless Steel Piping in Boiling Water Reactor Plants," Pipe Crack Study Group, U.S. Nuclear Regulatory Comnission, October 1975.

2. NUREG-0531, "Investigation and Evaluation of Stress-Corrosion Cracking in Piping of light Water Reactor Plants," Pipe Crack Study Group, U.S. Nuclear Regulato:y Commission, February 1979.

3. "Metallurgical Investigation of Crackirg in a Reactor Vessel Nozzle, SafeEnd, Final Report," Southwest Research Institute, dated Decenber 261978. 


\section{Finding}

Only the bypass controls for demineralizers were compared in detail, but this area alone indicates some variation in potential for loss of feedwater events among the B\&W plants. Therë are, however, other initiations due to human error or equipment failure that would lead to a loss of feedwater transient. The B\&W once-through steam generators have much smaller water inventories than those associated with Combustion Engineering and Westinghouse plants. As a result, the B\&W steam generators boil off on loss of feedwater much more quickly. This leads to a more rapid increase in primary pressure on loss of main feedwater in B\&W plants and therefore requires greater performance and reliability of the AFW delivery.

The auxiliary feedwater system tends to limit the overpressure excursion by providing some continuation of heat rejection capability to the steam generators. Actions given in IE Bulletin 79-05B should prevent subsequent overpressure and reduce the loss of primary system inventory through the PORV and permit the HPI to refill and depressurize the primary system more quickly.

\section{Recommendations}

\section{Once-Through Steam Generator (OTSG)}

The safety aspects of the OTSG for B\&W plants should be defined and included in operating procedures that deal with transients and smail break LOCAs. Included should be the results of a sensitivity study of the water inventory and time for boiloff to consider the potential benefit of increasing the operating water level in OTSGs for B\&W plants.

\section{Main Feedwater Systems}

Feedwater transients have been initiated from a variety of human and equipment failures. Although some improvements can and should be made to feedwater system reliability and to identify and correct design deficiencies, the occurrence of feedwater transients cannot be eliminated. Thus, the emphasis should be on coping and mitigating the consequences of feedwater transients.

\section{Auxiliary (Emergency) Feedwater Systems}

Goals should be established by NRC and means developed to make the auxiliary feedwater system more reliable. Short-term action is required by the recent shutdown orders and IE bulletins and should be followed by a longer term reevaluation of system reliability and interactions. Increased surveillance should be considered for all PWR plants. 
NUREG-0557.

APPENDIX B

TMI-2 PLANT MODIFICATIONS

FOR ACHIEVING COLD SHUTDOWN*

MAY 1979

*This report was prepared based on information available to the staff prior to the plant being placed in a natural circulation. mode of cooling on April 27, 1979. It is expected that certain plant changes different than those described herein may result and will be evaluated in a subsequent report. 
TMI-2 PLAITT IOOJIEICATTIOIS

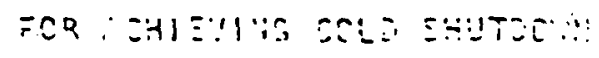

Table 2 Contents

1. Background

2. Steam Generator Madi ications

a. Steam Generator "A" Modification - Short/Long Term

1) Design Conceot

2) Modification

$3 ;$ systen" Eya? wa:ion

j. Steam Gererator "B" Modification - Stiart Term/Long Tera.

1) Design Concept

2) Modification

3). Svstem Evaluation

c. Mechanical Design Evaluation (Steam Generator A/B)

d. Structural Evaluation. (Steam Generator A/B)

e. Inctrumentation and Control (Steam Generator $A / B$ )

f. Radislogical Evaluation (Steam Generator $A / B$ )

3. Reactor Coolant System Pressure Control

a. System Evaluation

b. Mechanical Design Evaluation

c. Structural Evaluation

d. Instrumentation and Control

4. Decay Heat Removal

a. Upgrade of Existing DHR Steam Leak Tightness

b. Skid Mounted DHR System

1) Sustem Evaluation

2) Mechanical Design Evaluation

3) Structural Evaluation

4) Instrumentation and Control

5. Electrical Systems Modifications

a. General

b. Soecific S\%stem Modifications

7. Sua!ity fssurance 


\section{Background}

In order to bring TMI-2 to a cold shutdown condition, modifications will be made to various plant systems in phases to be carried out over a period of the next few weeks. These modifications will permit a gradual transition from the current plant operating mode to one which provides a stable long term cooldown mode of operation.

The first planned modifications will be made in conjunction with the transition from forced primary coolant circulation (by the reactor coolant pump) to natural circulation through the core. To accomplish natural circulation, the secondary side (shell) of the steam generators will be operated water solid. Water will enter through the main feedwater ring and exit through the main steam line.

In order to provide for water solid operation, certain modifications to each steam genera tor secondary flow loop will be required. The design of modifications to steam generator " $B$ " has accounted for possible contamination as a zesult of suspected tube leakage in the steam generator. 
To sazkuo oressure control sapajility o: the grinary systen juring natural circulation, a new pressure control and rskeup system will be provided. This system is essential in the event of loss of pressurizer heaters and level indication. Criteria and procedures for letdown and overpressure control of the primary system will be established prior to going into this mode of operation.

Because of suspected leakage in the existing olant decay heat removal system, a program will be conducted to identify and correct leaks to provide as leak tight a system as possible. Also, an additional skid mounted decay heat removal train will be connected into the existing system as a backup. Connections will be provided to the new train for a possible addition of a dedicated decay heat removal and cleanup system. located in its own permanent structure.

To facilitiate early completion of design and installation of these system modifications, system functional capability following a seismic event has not been a design requirement. If a'seísmic event should occur and damage the modified systems, the seismic Category 1 MMI-2 Decay Heat Removal System and Reactor Coolant Makeup System could be used to remove core decay heat and control primary system pressure as necessary.

More detailed descriptions of these modifications are included in the foll lowing pages. 


\section{Etean Generatar Yadifizetionri:}

a. Modifications to Steam Generaior "g" for 'ater Solid operations

\section{1) Design Concest}

The short and long tern concept for water solid operation of Steam Genurazor A have Leen consslideted. Ore sances:

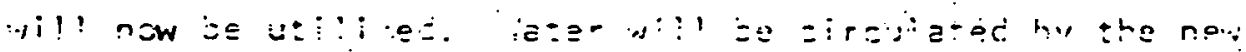
punp through the sinel! side je a new heat exchanger and into the secondary side of the steam generator A in a closed loop to remove heat. Frm the steam generator. The tube side of the new heat exchanger will be cooled by the existing Nuclear Services River llater Systom (HSRi's) which sunplies water from the river and returns it to the mechanical draft cooling tower. Refer to Figure 1 for a schematic je this fiow path. Provisions will be made for sustem pressure and expansion control by utilizing the existing 3rd stage feedivater heaier shell and its nigrogen supply es a pressurized surge țank. The design also includes provisions for sampling, jemineralization and chemical addition capability. For the initial phase of operation, all values, will be manually operated and instrumentation will groyide local read out.

The new lood of heat remoyl equigment thas been designed to operite a: a prossure hichor than the exzocted reactor costant sys:en oressure thus assuring in-lejlage g? sesorjo\% s\%s:on 
liquid into the orinary system in the event of stam generator tube leakage.

2) Motification

This scheme will involve installation of a ne:v high pressure train consisting $0^{f}$ a pums, heat exchanger, yalves and piping located in the turbina bul!ding jasemant. Tie logn will be gonnectes to :he main stean turbine bypass line perween the connection to the main steam lines and the condenser, and to the main feedwater line between the feedwater pumo and 3 rd stage feedwater heater FW-J-6A. Horizontal runs of piping will be supported for static loads and secured to suonorting structures to prevent lateral motion. Vertical runs of piping will be secured to permanent structural members as required. Additional piping will be rejuired for the surge tank (3rd stage feedwater heater $F(-J=6 A)$, chemical addition tank and demineralizer. In addition, the interconnections between the $A$ and $B$ feedwater heater trains will be broken and capped sif.

Jumper pipes will be installed between the existing Nuclear: Services River Water System (NSRIS) the existing Secondary Services River Water Sustem (SSRWS) to provide cooling water: to the tube side of the new heat exchanger. The safety elassification of the Nuclear Services giver ilater System will be naintained by oroviding touble isplation ralves. 
All piping connections will be welded. These modifications are expected to be completed and the system ready for operation by the middle of May.

\section{3) Systems Evaluations}

The system design as.proposed will meet the recessary secondary side requirements for decay heat removal with either forced or natural. circulation through the reactor core. All recuired modifications will be made to accomplish this purpose. This system is completely independent and separate.from steam generator "B" during all intended modes of operation with the exception that the Nuclear Services River Water. System and Secondary Services River Water System will be shared by both loops of steam generator cooling.

The system will not be provided with redundant active components. However, a single active failure within the system will not compromise natural circulation. of the primary system in that the secondary cooling loop through steam generator "B" will continue to operate (see staff evaluation of MM-2 natural circulation performance).

The fllowrates predicted through each of the heat exchangers. will provide adequate cooling based on an assumed heat load of $30 \times 10^{6} \mathrm{Btu} / \mathrm{hr}$ (RCP operating $+3 \mathrm{MWOH}$ ). Oderating performance and design parameters for the system are as follows: 


\subsection{STANDBY REACTOR COOLANT PRESSURE CONTROL SYSTEM}

\section{A. System Evaluation}

\section{1) Description}

A standby reactor coolant pressure control and makeup system has been proposed by the licensee. This system would serve as a backup to the CVCS and maintain reactor soolant system pressure ivith the pressurizer filles solid with water. Primary soolant system pressure will be maintained even with the loss of pressurizer instrumentation and inoperative pressurizer heaters. A!so, the pressure control system will be designed to provide adequate NPSH to the reactor coolant pumos if they are needed.

The stanby reactor coolant pressure control system will consists of passive components (a series of water storage tanks and a surgetank with nitrogen blanket for pressure control) and active components (charging pumps). The system will control reactor coolant pressure over the range of 100 psig to 750 p.sig.

The passive reactor coolant pressure system which would be operated initially with local control. Additional instrumentation and remote control will be incorporated to permit automatic operiation of the system. The active pressure control portion would resupply water to the surge tanks with added.capability of providing additional makeup water directly to the RCS if needed. 
Steam Generator A Modified System

System

Location

Doerating Conditions

Desion

Pressure (osio) Temp. (OF) Flow (apm) Pressure (psia)

New: Pump Discharge

670

100

$3000-5000$

800

New Pump Suction

500

100

$3000-5000$

600

(New Heat Exch.

Disch. Shell Side)

New Pump Recirc.

670

100

Pump min. flow

800

New Heat Exchanger

670

120

$3000-5200$

800

Supply (Shell Side)

NSRW Supoly to New

100

85

6000

150

Heat Exchanger

(Tube Side)

NSRW Return from New

100

95

6000

150

Heat Exchanger (Tube Side)

The system flow arrangement has been selected to minimize

fouling effects by maintaining Nuclear Services River Water

on the-tube side of the new heat exchanger. System operating

temperature indicated for NSRI, supply and return are design

4.4

values. 


\section{2) Modifications}

The standby reactor coolant system pressure control and makeup. system will involve installation of two 900 gallon capacity water tanks and one surge tank (all will be of the Westinghouse Boron Injection Tank design), nitrogen bottles, two $40 \mathrm{gpm}$ positive displacement oumps, a degassed borated water supoly tank, valves, and piping. This system will be connected between the discharge side of the high pressure makeup system downstream of valve $M U-V-144 C$ and upstream of valve MU-VI6C. All the components will be placed in the fuel handling building.

The above modification will establish a flowpath of makeup water and pressure control through the normal makeup lines that connect with the reactor coolant loop cold legs. Chemical control of the degassified borated water used in the pressure control system will be provided by the present chemical addition system. Connections will be provided to accommodate the addition of boric acid, $\mathrm{H}_{2}$, demineralized water and hydrazine, $\mathrm{LiOH}$ and $\mathrm{NaOH}$. The degassed water tank will be replenished via piping connection from borated water transfer pump and boric acid batching tank. The boron concentration will be maintained in the range of 2200 to $4000 \mathrm{ppm}$. Figure 1 depicts the proposed pressure control system and interface connections to the existing systems. 


\section{3) Evaluation}

If required, the passive portion of the standby pressure control and makeup system is designed to provide peak initial $500 \mathrm{gpm}$ injection rate to the reactor coolant system. The $500 \mathrm{gpm}$ injection rate will be adequate to provide primary system makeup for certain transient events that can cause considerable shrinkage in the RCS. Because of the finite inventory (1900-2000 gal) this injection will decrease as the discharge proceeds. Als.o, the passive portion of the system will be designed to provide continuous makeup of 4 gpm for 8 hours:

Sufficient makeup volume requirement can be met by the proposed RCS pressure control system for moderate system perturbations and for the following postulated transient event: loss of natural circulation cooling due to a loss of all secondary side cooling with restart of one secondary cooling loop following a hot leg temperature rise of $50^{\circ} \mathrm{F}$.

For this event the licensee has shown a total volume change of 1900 gallons which can be made up by the proposed system. However, the pressure control system is not designed for makeup requirements of more severe transients such as a sudden complete loss of natural circulation for a period of 2 hours, followed by an RC pump start. Procedures which permit reactor coolant pump restart following loss of natural circulation would require tis availability of other makeup systems such as the HPI in addition to the prooosed pressure control system. 
The reactor coolant pressure control and makeup system will not provide letdown capability of reactor coolant caused by overpressurization events. Reactor coolant fluid expansion will be relieved by one or a combination of the following current components and systcms: (1) normal letdowi line (through the letdown coolers): (2) maintaining letdown with concurren: termination of makeup/seal injection; (3) continued reactor coolant punp seal return flow; (4) opening or pressurizer vent valve; and (5) lifting of the pressurizer relief value.

Piping integrity of the reactor coolant pressure control and makeup system has been examined for postulated overpressurization events such as inadvertent startup of an HPI pump. This system will have a design pressure of 1000 psig except for the section from the HPI makeup line back through the second isolation check valve which will have a design pressure of 1500 psig. Overpressurization protestion of the latter pioing section when the HPI/makeup pump is started will be provided by installation of a relief value about the HPl/makeup pump set at 1000 psig. and a relief flowrate of $525 \mathrm{gpm}$. Check valves located downstream of the HPI/makeup pumps that are inside the Reactor Building will also provide protection to this system from inadvertent overpressurization of the RCS due to any other causes. The criteria and procedures for letdown and overpressure control of the RCS will be established priar to the operation of this system. 
The proposed reactor coolant pressure control and makeup system may not meet makeup demand following a depressurization event of the primary system such as inadvertent opening of the pressurizer PORV (with downstream isolation valve open). If not isolated in time, the system would be drained resulting in entrainment of nitrogen ints the reactor coolent system. To prevent such an sccurrence the systen will automatically issla:z on low level in the water tank. In. the event of loss of offsite power this valve will fail in the "as is" position. Since this position is the preferred position for normal operation and it would also be the preferred position in the event of loss of offsite power. Also, an alarm will be annunciated locally and in the control room when the isolation valve is not fully open.

We have examined for single failures that can disable the pressure control and makeup system. The discharge valve SPC-VS is a single failure point, however it will be a manually operated ball valve positioned to an open position, and then locked in that position. For simplicity of design and installation, we have not required redundant valves to meet single criterion to insure system isolation capability. A redundant charging pump will be available to fill the water tanks in response to tank level reduction. 


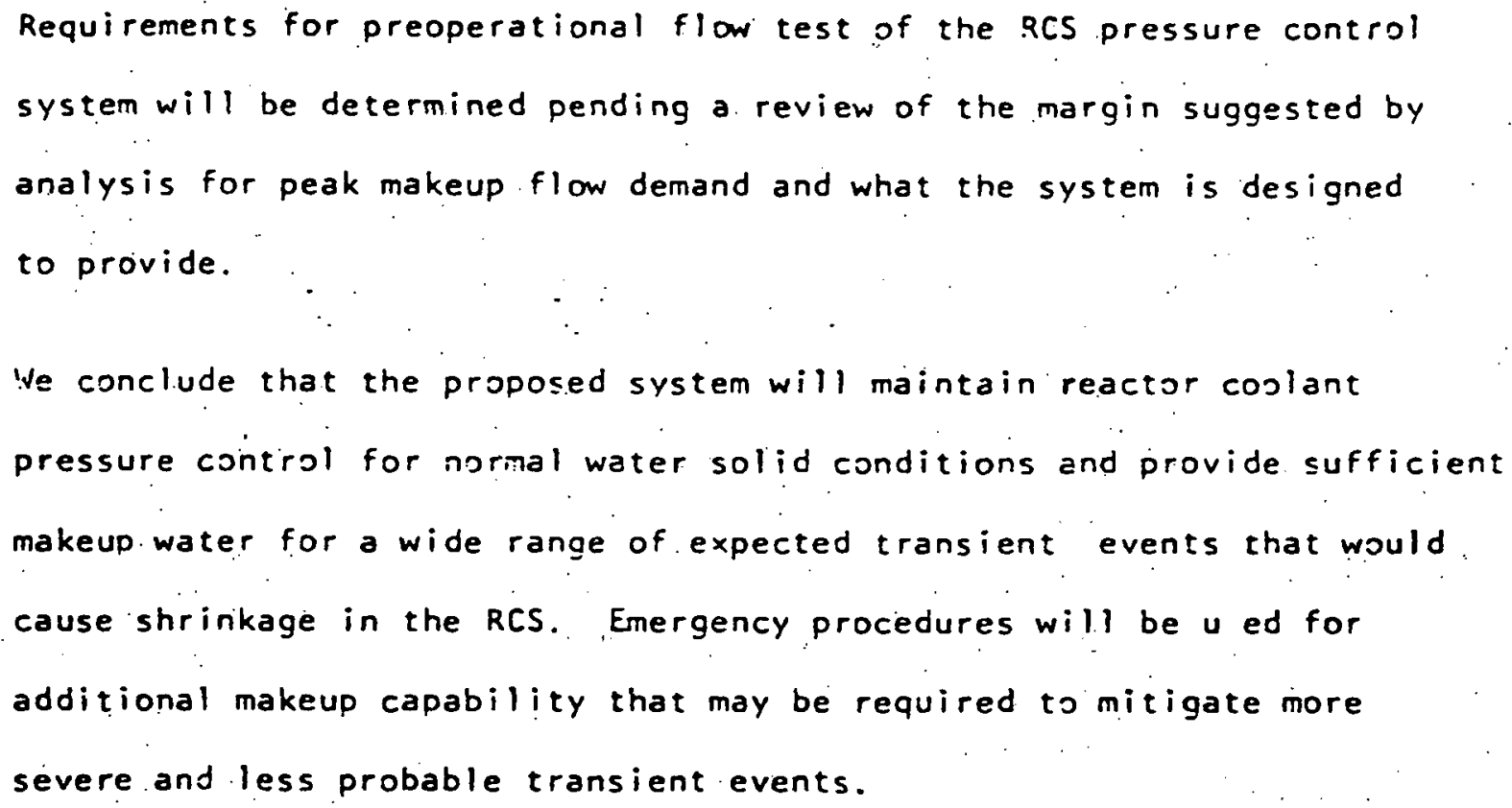

B. Mechanical Design

\section{1) Description}

The Reactor Coolant Pressure Control System is madeup of several water supply tanks, positive displacement pumps, valves, and piping. The applicable desian codes and standards used for the design of these components are provided in the Table 1. 


\section{Table 1}

\section{Applicable Desian Codes or Standards}

Water Supply Tank (Passive System)

ASME Section \|\|$C L .1$ - S.S.

Charging Pumps

ASME Section $1 \| \mathrm{CL} .2$

piping

ANSI B31.1 (minimum requirement)

Degassified Water Supplv Tank

ASME Section VIII Div. I

Component Supports

ANS1. B31.1 


\section{2) Design Loads.}

Pressure, pump vibration, component and fluid deadweight, and maximum anticipated pressure surge forces were considered in developing design loads for the RCS makeup systen. The staff considers these to be accedtable load considerations for this r.pplication. The staff has not required the RCS pressure control and makeup system be evaluated for seismic load capability.

\section{3) Other Considerations}

Welded construction will be used wherever possible to minimize the potential for system leakage. Components will be fabricated from stainless steel or carbon steel clad with stainless steel.

\section{4) Evaluation Conclusion}

We conclude that the licensee has specified components that will be designed and fabricated in accordance with acceptable industry codes or standards and will taken into account the loads associated with startup, testing, and expected system operation.

The use of components that are in conformance with these cirteria provides adequate assurance that structural integrity of the Reactor Coolant Pressure Control System will be maintained. 


\section{Structural. Design}

The system includes the following major equipment:

a) Three water tanks, 900 gal, capacity. Each weigh 20 ki.ps empty and 27.5 kips when full of water. Each tank will be supported. on four $12 \mathrm{in.}$ by $12 \mathrm{in}$. plates.

b Borated water tank weighing 60 kips supported on four 6 in. plates.

c) Two - $100 \mathrm{HP}$ pumps weighing $5.4 \mathrm{kips}$. each.

The enclosed figure 2 (2 sheets) show the conditions of the original structure. The area is located between columns AP and AT in south-north direction and columns $A 65$ and $A 67$ in east-west direction. The slab is three feet thick and the reinforsing steel is 4,3 at 9 in. top and bottom in north-south direction and $\# 8$ at 6 in. top and bottom in the east-west direction. The compressive strength of the concrete is 3000 psi and the yield stress of the reinforcing steel is $60 \mathrm{ksi}$. The licensee has analyzed the slab for the additional loads resulting from the new equipment and concluded that the stresses will be within the allowables using generally accepted codes. The analysis was performed for the static conditions only. We conclude that the licensee has performed his analys is in accordance with the methods and pracedures which are specified by the appropriate codes and standards. The use of these methods provide reasonable assurance that the structures. affected by this modification wil! continue to perforn their intended sunction. 


\section{Finding}

For reasons not yet understood, the low-pressure heat removal system was not placed into operation during the early (first 12 hours) stages of the accident. The operators attempted to reduce system pressure after approximately $71 / 2$ hours (see Figure 2); however, the pressure never was low enough to cut-in the residual heat removal (RHR) system (about $300 \mathrm{psig}$ ). Subsequent long-term heat removal by the RHR was not carried out because of the high levels of contamination in the reactor coolant system water and an apparent question of the leak tightness of the RHR system outside of the containment.

\section{Recomnendation}

The NRC, licensees, and designers should reexamine the design basis and adecuacy of the RHR system in the light of the TMI-2 experience in which the reactor coolant system became highly contaminated due to significant core damage. This should include access capability and location of equipment for the operator. 
NRR Lessons Learned Task Force

Short-Term Recommendations

TITLE: Automatic Initiation of the Auxiliary Feedwater System for PWRs (Section 2.7.7.a)

\section{INTRODUCTION}

In recent design reviews since the issuance of the Standard Review Plan, the auxiliary feedwater system (AFWS) is treated as a safety system in a pressurized water reactor (PWR) plant. It is required to satisfy the decay heat removal. requirements set forth-in General Design Criterion 34 of Appendix A in 10 CF. Part 50. It also plays a significant role in the mitigation of feedwater transients that are anticipated operational occurrences (A00s). In addition, General Design Criterion 20 sets forth requirements for protection systems, including the following: "The protection system shall be designed (1) to initiate automatically the operation of appropriate systems including the reactivity control system, to assure that specified acceptable fuel design limits are not exceeded as a result of anticipated operational occurrences...."

The need to automatically initiate the operation of the auxiliary feedwater system was not considered essential to safety in the past, and in some plants dependence was placed on the operator to put the system in service when required. Although this need was not emphasized, there are plants in which the initiation of the auxiliary feedwater system is automatic.

Recent analyses of primary system response to feedwater transients and reliability of installed auxiliary feedwater systems establish the need for automatically initiating the auxiliary feedwater system, consistent with satisfying the requirements of $\mathrm{GDC}-20$.

\section{DISCUSSION}

The auxiliary feedwater system is used to supply feedwater to the steam generators during emergency conditions involving loss of the normal feedwater as well as during normal startup, normal shutdown, and hot standby condition. The auxiliary feedwater system initiation time and capacity and the reactor scram time should be such that the water levels in the steam generators being supplied, following loss of main feedwater flow, remain high enough to provide sufficient heat transfer capability to remove stored and residual heat without causing opening of the primary coolant system relief and code safety valves.

Consistent with preventing the steam generators from drying out following loss of main feedwater and minimizing operator errors that could delay the timely initiation of the auxiliary feedwater system in a PWR plant, the auxiliary feedwater system should be automatically initiated in response to a loss of the main feedwater. Equivalent requirements for BWR plants need further evaluation. to be accomplished on a long-term basis.

In the short term, as a minimum, control-grade signals and circuits (as defined in Section 3 below) should be used to initiate the auxiliary feedwater system. The initiating circuits should be designed so that a single failure will not 
cause the auxiliary feedwater system to lose its capability to perform as intended. Furthermore, testability of the initiating signals and circuits should be a feature of the design. In the long term, the manual and automatic initiation signals and circuits should be upgraded in accordance with safetygrade requirements. The question of automatic versus manual isolation of the auxiliary feedwater system from the affected steam generator in the event of a steam or feedwater line break requires further evaluation to be accomplished on a long-term basis.

\section{POSITION}

Consistent with satisfying the requirements of General Design Criterion 20 of Appendix A to $10 \mathrm{CFR}$ Part 50 wi.th respect to the timely initiation of the auxiliary feedwater system, the following requirements shall be implemented in the short term:

1. The design shall provide for the automatic initiation of the auxiliary feedwater system.

2. The automatic initiation signals and circuits shall be designed so that a single failure will not result in the loss of auxiliary feedwater system function.

3. Testability of the initiating signals and circuits shall be a feature of the design.

4. The initiating signals and circuits shall be powered from the emergency buses.

5. Manual capability to initiate the auxiliary feedwater system from the control room shall be retained and shall be implemented so that a single failure in the manual circuits will not result in the loss of system function.

6. The a-c motor-driven pumps and valves in the auxiliary feedwater system shall be included in the automatic actuation (simultaneous and/or sequential) of the. loads to the emergency buses.

7. The automatic initiating signals and circuits shall be designed so that their failure will not result in the loss of manual capability to initiate the AFWS from the control room.

In the long term, the automatic initiation signals and circuits shall be upgraded in accordance with safety-grade requirements. 
NRR Lessons Learned Task Force

Short-Term Recommendations

TITLE: Containment Isolation Provisions for PWRs and BWRs (Section 2.1.4)

1. INTRODUCTION

General Design Criterion 54 of Appendix A to 10 CFR Part 50 requires that piping systems penetrating primary reactor containment be provided with leak detection, isolation, and containment capabilities having redundancy, reliability, and performance capabilities which reflect the importance to safety of isolating the piping systems. Standard Review Plan, Section 6.2.4, "Containment Isoletion System," requires that there be diversity in the parameters sensed for the initiation of containment isolation.

Some early plants, including TMI-2, provided automatic containment isolation demand on high containment pressure only (approximately 2 to $5 \mathrm{psig}$ ). For small rates of loss of coolant, there would be little pressure increase in the containment, and automatic containment isolation may be delayed or may possibly not be achieved. The loss of coolant at TMI-2, which produced a small pressure rise in the containment, was accompanied by substantial core damage and a large release of radionuclides into the containment building. Containment isolation was not achieved until approximately 4-1/2 hours after the start of the event. Although this apparently did not lead directly to release of fission products outside containment, it clearly indicated an unacceptable possibility that it could occur.

The purpose of this recommendation is to ensure that effective containment isolation is accomplished and maintained.

\section{DISCUSSION}

Since the purpose of the containment is to provide a final barrier to the release of radioactivity in the event of an accident, isolation of non-essential systems penetrating the containment boundary prior to significant releases from the building is imperative. The TMI-2 event has clearly illustrated the need for selecting diverse parameters to be used for initiation of containment isolation and has shown that a dependance solely on containment pressure rise is inadequate. Current staff requirements (SRP 6.2.4) call for automatic initiation of containment isolation by diverse parameters.

Many plants of earlier vintage have not used diverse parameters for initiation of automatic containment isolation. However, most plants of current design initiate automatic containment isolation upon either safety injection demand or containment high pressure. In some instances, high radiation level in the containment building or ventilation system ducting has been used as a diverse parameter for the initiation of automatic isolation of part or all of the non-essential systems penetrating the containment building.

All containments use a low positive containment pressure for the initiation of automatic containment isolation. Previous LOCA analyses have consistently 
shown that containment pressure will increase rapidly and will reach lowpressure levels that may be used to initiate containment isolation prior to the release of radionuclides resulting from fuel damage for the event being analyzed. For these events, minimum ECCS function has always been assumed. None of these analyses has assumed the failure of emergency core cooling and the subsequent release to containment through such a small vent area as a stuck-open power-operated relief valve as it occurred at TMI- 2 .

The most commonly used second parameter is safety injection demand. Safety injection demand is a safety-grade signal already available through the reactor protection system. Design analyses indicate that safety injection demand is also an early signal of loss of the reactor coolant system integrity and in most cases, when used as a diverse containment isolation signal, will result in earlier initiation of containment isolation than containment high pressure.

Another alternative is the use of high radiation level as a diverse parameter for initiation of containment isolation. Design of a dependable containment isolation signal using radiation detection involves a complex consideration of several factors; i.e., location of detectors versus postulated reactor coolant system (RCS) break locations, dilution factors, trip level set point, etc. Only two plants have adopted a high radiation level as a safety-grade parameter for the initiation of containment isolation. The use of either a safety injection signal or a properly designed high radiation level as a diverse containrent isolation initiator would have assured the early isolation of the containment building at TMI-2.

A second containment isolation problem highlighted by the accident at TMI- 2 is the lack of consistency among plants in the definition of essential and non-essential systems. Systems important to the removal of reactor heat (e.g., reactor coolant pump cooling and seal. water) are isolated by the containment isolation signal for some plants. Other plants isolate such systems on another signal, such as containment hi-hi pressure (usually 1/4 to $1 / 2$ of containment design pressure), whereas for others such systems are manualiy isolated by the operator.

The sequence of events at Three Mile Island has illustrated the necessity for careful consideration of those systems that should be immediately isolated (non-essential systems) and those that should be selectively isolated only after it is established that use of these systems (essential systems) will not be needed. We recommend that all plants reconsider their definition of essential and non-essential systems and provide the NRC with the results of this review. It is our long-term goal to use this information in the development of a consistent set of guidelines for the selection of essential and non-essential systems.

A third containment isolation problem was highlighted by the accident at Three Mile Island Unit 2 and by several of the responses to the Inspection and Enforcement Bulletins. For some plants, the design of containment isolation system controls is such that resetting the isolating signal may cause the containment isolation valves, which were in the open position at the time of automatic containment isolation, to automatically reopen. To prevent this, 
the operator must manualiy move the individual containment isolation valve controls, or in some cases a ganged control, to the closed position prior to resetting the isolation signal. This design introduces the unnecessary potential for operator error resulting in unexpected releases from the containment building and offsite dose consequences. Such designs should be modified to eliminate the possibility of inadvertent reopening containment isolation valves upon resetting of the isolating signal.

\section{POSITION}

1. All containment isolation system designs shall comply with the recommendations of SRP 6.2.4; i.e., that there be diversity in the parameters sensed for the initiation of containment isolation.

2. All plants shall give careful reconsideration to the definition of essential and non-essential systems, shall identify each system determined to be essential, shall identify each system determined to be non-essential, shall describe the basis for selection of each essential system, stiall modify their containment isolation designs accordingly, and shall report the results of the re-evaluation to the NRC.

3. All non-essential systems shall be automaticalily isolated by the containment isolation signal.

4. The design of control systems for automatic containment isolation valves shall be such that resetting the isolation signal will not result in the automatic reopening of containment isolation valves. Reopening of containment isolation valves shall require deliberate operator action. 
$\frac{\text { NRR Lessons Learned Task Force }}{\text { Short-Term Recommendations }}$

TITLE: Integrity of Systems Outside Containment Likely to Contain Radioactive Materials (Engineered Safety Systems and Auxiliary Systems) for PWRs and BWRs (Section 2.1.6.a)

\section{INTRODUCTION}

Parts 20 and 100 of the Commission regulations specify radiation imits and guidelines that must be met by licensed facilities to assure protection of public. health and safety. In a power reactor, many systems that will or may handle liquids or gases containing large radioactive inventories after a serious transient or accident are located outside containment. Some systems have technical specification leakage limits established in the plant's operating license, and others do not.

\section{DISCUSSION}

Several of the engineered safety features (ESF) and auxiliary systems (Aux), located outside reactor containment will or may have to function during a serious transient or accident with large radioactive inventories in the fluids they process. The leakage from these systems, when operated, must be minimized or eliminated to prevent the release of significant amounts of radioactive materials to the environment. Examples of such systems include residual heat removal (ESF), containment spray recirculation (ESF), high-pressure injection recirculation (ESF), sampling (Aux), makeup and letdown (Aux), and waste gas (Aux). These systems are checked out during pre-operational testing and startup testing but are not usually included in any periodic leak testing program. It is important that the plant operating staff know the leakage rates of these systems and maintain them at rates that are as low as practical.

Some of these systems were used during the TMI-2 accident with resulting releases of radioactive materials to the auxiliary building ventilation systems. These releases are believed to have resulted from leaking relief valves, waste gas compressor seals, valves, and open rupture discs. The residual heat removal system was not used in its design mode for several reasons, one of which was the uncertainty of the leakage characteristics of the system. Therefore, the lesson learned in this case was that more positive control and knowledge of the leakage rates of these systems is needed to provide the operating staff with the maximum usable equipment and to restrict or control the release of radioactive materials to the environment.

The recommended solution is to make every effort to eliminate or reduce the leakage from these systems, perform.periodic tests to assure that the leakage from these systems is maintained as low as practical, and provide the plant staff with current knowledge of the system leakage rates. 


\section{POSITION}

Applicants and licensees shall immediately implement a program to reduce leakage from systems outside containment that would or could contain highly radioactive fluids during a serious transient or accident to as-low-as-practical levels. This program shall include the following:

1. Immediate Leak Reduction

a. Implement all practical leak reduction measures for all systems that could carry radioactive fluid outside. of containment.

b. Measure actual leakage rates with system in.operation and report them to the NRC.

2. Continuing Leak Reduction

Establish and implement a program of preventive maintenance to reduce leakage to as-low-as-practical levels. This program shall include periodic integrated leak tests at a frequency not to exceed refueling cycle intervals. 
Technical Assessment of Disturbance Analysis Systems

prepared for publication in the Nuclear Safety Journal. by:

A. B. Long

Electric Power Research Institute April, 1979

Ex

AUG 151979

ABSTRACT

SAI = PITTSSURGH

In December of 1978, the Electric Power Research Institute sponsored an international. specialists' vorkshop on Disturbance Analysis Systems. Since the Three Mile Isiand incident, the utility has been evaluating the use of this type of system as a means to improve the operator-process interface during normal and abnormal modes of nuclear plant operation. The functional requirements, justification, technical descriptions and operation experience with such systems are summarized on the basis of the workshop presentations. Unresoived problems are idenftified and on-going research and develop activities in the U.S. and Europe are briefly reviewed.

\section{BIOGRAPHICAL SKETCH}

A. B. Long is currently a project manager in the Nuclear Safety \& Analys is Department of the Electric. Power Research Institute, Palo Alto, Califorria. His responsibilities include the formulation and management of researcis and oevelopment projects involving the application of advanced technologies (hardware and softivare) to the control and safety of nuclear power plants. Long holds a BA in physics from Williams College and a MS and PhD in nuclear engineering from the University of Illinois. He is a member of the Anerican Nuclear Society and the IEEE. 
Table 11. Example of DAS application Based Upon TMI-2 Incident

(Sequence of event times in hours, minutes, seconds fron start of transtent).

- Improved Process Computea

00:16:-- RCP FLOW VALIDITY IN OUESTION DUE YO VOIDING

00:32:30 Integration and Trending of core exit T.C.S.

01:13:00 MLARM PRINTER JaM. LOG RUNnING 85 min. bEMIND

01:13:40 EX-CORE SIGNAL VALIDITY IN OUESTION DUE TO DOHNCOMER VOIOS

01:50:- - TAVE YALID OVER hIDE RÁNGE

02:--:-- SUPPORT OFF-SITE EMERGENCY REVIEW

02:57:-- Remote stations to alleviate control roOM CONGESTION

- Surveillance monitoring for mode of operation

- $X$ AuX. feed valve alignment.

00:00:12 SECURING OF LETDOWM LINES AFTER TRIP

$\rightarrow \quad 00: 03: 26$ RCDT COOLING INITIATED ON HIGH TEMPERATURE

$\stackrel{1}{\infty} \quad 00: 07: 43$. SUMP PUMP ALIGMMENT

00:14:50 CONTAINMENT ISOLATION ON LOSS OF PRIMARY BOUNDARY

06:52:-- CONTROL ROOM INTEGRITY

\section{- Simplified analytical models}

- Primari coolant jiventory

- Margin to saturated conditions in primary systems

- Residual heat generation versus removal

- Gross fuel integritr

- Steam gemfhator mass \& energer bal.ance

- Core energu bal.ance

- Rorron concentration inventopi

\section{- Disturbance Recognition 8 Correction}

00:00:14 No AUX. FEED EVEN TIIOUGII PUMPS ARE ON

00:00:30 PRESSURIZER RELIEF VALVE NOT RESEATED

00:16:-- RCP FLOW DEGRADATION DUE TO VOIDS

02:38:00 FUEL INTEGRITY VIOLATED

- Procedural assistance for Off-Normal Condition 00:05:06 More than loss of feed

- - Primary coolant inventory

- Saturation conditions

00:14:50 DEGRADATION OF RADIATION BARRIERS - Evaluate contaimment isolation

OC:32:30 Inadequate heat removal from core - Synthesize exir T.C. Data

01:40:45 FeasibilltT \& EFFECTIVENESS OF matural RECIRCULATION

02:38:00 DEgaAded fuel INTEgaity -Evaluate containment isolation

03:23:23 GENERAL EMERGENCY DECLARED

011:30:45 CONTINUED USE OF SECONDARY SYSTEM - Evaluate integritr

07:30:00 FEASIBILITY \& EFFECTIVENESS OF RESIDUAL hEAT REMOVAL
- Simplified Plant Configuration Models

- Safety systems

- Flujo systems

- Ventilation systems

- Electrical systems

- Containment isolation

- Conthol moum immitiauilitir

- I S C sYstems 
$\frac{\text { NRR Lessons Learned Task Force }}{\text { Short-Term Recommendations }}$

TITLE: Analysis of Design and 'Off-Normal Transients and Accidents (Section 2.1.9)

\section{INTRODUCTION}

The design requirements for the Emergency Core Cooling System (ECCS) are stated in 10 CFR Part 50.46. Each applicant for a CP or OL must show compliance with these requirements through analyses that are prescribed in Appendix $K$ to 10 CFR Part 50. The design requirements for other important safety systems, such as the reactor coolant system pressure boundary and the reactor protection system, are stated in the General Design Criteria in Appendix A to 10 CFR Part 50. The required analyses to show compliance with the General Design Criteria are stated in Section 15 of Regulatory Guide 1.70 ("Standard Format and Content of Safety Analysis Reports for Nuclear Power Plants"). These are requirements for the analysis of the so-called "design basis events" which comprise various anticipated transients and postulated accidents.

Although the anaiyses listed above are primarily intended to show acceptable performance and design of various safety systems, they have also been used for developing emergency procedures and operator training. These other uses of analyses are not addressed in the NRC Standard Review Plans, and the analytical basis for emergency procedures has therefore not been generally reviewed by NRC. The emergency procedures are audited by the office of Inspection and Enforcement; however, NRC does not perform a formal technical review of all procedures, or evaluate which analyses were used to develop them.

The experience of the TMI-2 accident indicates that further analyses of transients and small LOCAs are needed. These conclusions, including the coordination of the results of analyses and emergency procedures, were discussed in NUREG-0560, "Staff Report on the Generic Assessment of Feedwater Transients in Pressurized Water Reactors Designed by the Babcock \& Wilcox Company."

In the Three Mile Island accident, a loss of feedwater transient led to a small break loss-of-coolant accident when the pilot-operated relief valve failed to close. The emergency procedure for a loss of feedwater did not alert the operators to this possibility; nor did it provide any indication that the opening of the PORV should have been expected. In addition, recent reviews of emergency procedures for the small break loss-of-coolant accident at B\&W plants clearly indicate that the procedures were inadequate to provide the operators with needed instructions on actions required to cope with various sizes and locations of small breaks. It is clear from the events at Three Mile Island that operator training and emergency procedures were not adequate for the operators to conclude from the information available that the reactor core was uncovered and inadequately cooled for a long period of time.

The purpose of the recommended action is to provide a substantial increase in safety by improving the performance of reactor operators during transient and accident conditions. Substantive short-term improvement can be made through a combination of analyses, improved procedures, and improved training. 


\section{DISCUSSION}

The Three Mile Island event is an example of an accident in which the performance of important safety systems was degraded due to human errors. This is an indication that human errors are a significant factor in the unavailability of needed safety systems. This appears to result from inadequate coordination between the organizations providing the system design and analysis and the organizations developing the emergency procedures and providing the operator training. The staff has looked broadly at this problem since the accident. In some cases, the NSSS vendor does not supply any guidelines on the development of emergency procedures. Even for those cases in which guidelines are supplied, the guidelines are usually based on the transient and accident analyses from Section 15 of the Final Safety Analysis Report úsed in the licensing design review. This is not satisfactory since the Section 15 FSAR analyses are performed to demonstrate the acceptability of various system designs pursuant to specific and prescriptive design basis events derived from the Commission regulations. More and a different kind of analysis is needed for use in developing emergency procedures and operator training. For example, the FSAR design analysis of the loss of feedwater transient for Three Mile Island assumed that the PORV did not open. This assumption led to the highest calculated pressure and was therefore appropriate for a design calculation. However, as a result of not analyzing the expected response of the PORV, the emergency procedure for a loss of feedwater did not acknowledge that the PORV would open. Moreover, it did not indicate when PORV closure should have been expected or that it was important to verify PORV closure. Prior to TMI-2, the NRC staff had never reviewed plant operating procedures or emergency procedures for conformance to expected plant response in transient or accident situations. On the basis of our review of this area since the accident, we find several important kinds of deficiencies that require correction.

A substantial improvement in safety can be obtained by improving operator performance during transients and accidents. The following steps are required in order to accomplish this objective: (a) analyze to predict plant response during abnormal occurrences and to identify proper and improper operator actions associated with important safety considerations (such as prevention of core uncovery, establishing natural circulation, and prevention of more serious accidents); (b) prepare guidelines for emergency procedures; (c) implement improvements in emergency procedures; and (d) retrain operators.

We have established the following priorities for the short term:

1. Analysis of small break loss-of-coolant accidents;

2. Analysis of the symptoms of inadequate core cooling and required actions to restore core cooling; and

3. Analysis of transient and accident scenarios including operator actions not previously analyzed.

The efforts related to small breaks have been completed for B\&W plants and are well under way for other plants. This effort is being accomplished by the Bulletins and Orders Task Force and does not require additional input from the 
Lessons Learned Task Force. The analysis of inddequate core cooling will provide information in an area in which the operators presently may have no procedures or training. This effort will provide defense in depth because it will inform the operators and call for appropriate corrective action if system failures or operator errors lead to a situation of inadequate core cooling. Specific analysis to be performed are addressed in the next section. The third priority short-term effort is related to analysis of transients and accidents to identify operator actions (to be required or to be prohibited) associated with important safety considerations (such as natural circulation, prevention of more serious accidents, and prevention of core uncovery). Each of the short-term efforts is related to improving emergency procedures and improving operator training. Additional analyses will be required in the long term.

Additional small break calculations are being performed in the near term following the Three Mile Island accident. These calculations will support changes in emergency procedures to cover the full spectrum of small breaks. The question of compliance with 10 CFR Part 50 Appendix $K$ requirements for the full spectrum of small breaks has not been addressed in the short term, but should be addressed in the long term. In addition, reconsideration of the appropriateness of the single-failure criterion may lead to the need for more analyses in the long term.

\section{POSITION}

Analyses, procedures, and training addressing the following are required:
1. Small break loss-of-coolant accidents;
2. Inadequate core cooling; and
3. Transients and accidents.

Some analysis requirements for small breaks have already been specified by the Bulletins and Orders Task Force. These should be completed. In addition, pretest calculations of some of the Loss of Fluid Test (LOFT) small break tests (scheduled to start in September 1979) shall be performed as means to verify the analyses performed in support of the small break emergency procedures and in support of an eventual long term verification of compliance with Appendix $K$ of 10 CFR Part 50 .

In the analysis of inadequate core cooling, the following conditions shall be analyzed using realistic (best-estimate) methods:

1. Low reactor coolant system inventory (two examples will be required LOCA with forced flow, LOCA without forced flow).

2. Loss of natural circulation (due to loss of heat sink).

These calculations shall include the period of time during which inadequate core cooling is approached as well as the period of time during which inadequate core cooling exists. The calculations shall be carried out in real time far 
enough that all important phenomena and instrument indications are included. Each case should then be repeated taking credit for correct operator action. These additional cases will provide the basis for developing appropriate emergency procedures. These calculations should also provide the analytical basis for the design of any additional instrumentation needed to provide operators with an unambiguous indication of vessel water level and core cooling adequacy (see Section 2.1.3.b in this appendix).

The analyses of transients and accidents shall include the design basis events specified in Section 15 of each FSAR. The analyses shall include a single active failure for each system called upon to function for a particular event. Consequential failures shall also be considered. Failures of the operators to perform required control manipulations shall be given consideration for permutations of the analyses. Operator actions that could cause the complete loss of function of a safety system shall also be considered. At present, these analyses need not address passive failures or multiple system failures in the short term. In the recent analysis of small break LOCAs, complete loss of auxiliary feedwater was considered. The complete loss of auxiliary feedwater may be added to the failures being considered in the analys is of transients and accidents if it is concluded that more is needed in operator training beyond the short-term actions to upgrade auxiliary feedwater system reliability. Similarly, in the long term, multiple failures and passive failures may be considered depending in part on staff review of the results of the short-term analyses.

The transient and accident analyses shall include event tree analyses, which are supplemented by computer calculations for those cases in which the system response to operator actions is unclear or these calculations could be used to provide important quantitative information not available from an event tree. For example, failure to initiate high-pressure injection could lead to core uncovery for some transients, and a computer calculation could provide information on the amount of time available for corrective action. Reactor simulators may provide some information in defining the event trees and would be useful in studying the information available to the operators. The transient and accident analyses are to be performed for the purpose of identifying appropriate and inappropriate operator actions relating to important safety considerations such as natural circulation, prevention of core uncovery, and prevention of more serious accidents.

The information derived from the preceding analyses shall be included in the plant emergency procedures and operator training. It is expected that anaiyses performed by the NSSS vendors will be put in the form of emergency procedure guidelines and that the changes in the procedures will be implemented by each licensee or applicant.

In addition to the analyses performed by the reactor vendors, analyses of selected transients should be performed by the NRC Office of Research, using the best available computer codes, to provide the basis for comparisons with the analytical methods being used by the reactor vendors. These comparisons together with comparisons to data, including LOFT small break test data, will constitute the short-term verification effort to assure the adequacy of the analytical methods being used to generate emergency procedures. 


\subsubsection{Human Factors}

\section{Findings}

The operator has been trained to rely on his instrumentation. He will continue to do so until he suspects an erroneous reading; however, he must be trained not to rely solely on a single indication since it may be erroneous or misleading under certain conditions.

If the operator has too many additional manual functions to' perform, he may reduce. his observations on other system parameters, which may lead him to have "tunnel vision." Subject to further understanding, it appears at this time that in the TMI-2 accident the operator apparently kept relying only on the high pressurizer level.

Human factors engineering has not been sufficiently emphasized in the design and layout of the control rooms. The location of instruments and controls in many power plants often increases the likelihood of operator error or, at the least, impedes the operator in efficiently carrying out the normal, abnormal, and emergency actions required of him.

\section{Recommendations}

Operator and technical staff training should be revised as necessary to improve the operator's understanding of his responsibilities during abnormal and emergency conditions. The design basis for the plant has provided that, in the event of emergencies, suitable actions will be automatically initiated by the safety systems. The operator's initial responsibility is to monitor the parameters of interest and verify that appropriate safety systems actuations have taken place. If the appropriate actuations have not occurred, the operator must intercede and perform whatever action is necessary to effect them. The entire control board should be monitored and all parameters of concern evaluated. In conjunction with the evaluation, it is recognized that the operator has been trained to believe his instrumentation, but he must not do so blindly. Almost every parameter of interest that is monitored can be validated by appropriate checking of other instrumentation. He must perform this cross-check to verify instrument display and must not develop "tunnel vision" in which one display is relied on exclusively. 
Other automatic means of recording events during emergencies must be used. A voice tape recorder should be used to provide a record for the events.

Critiques should be made immediately after any major events have occurred. This should include all recorder charts and alarm printouts. The individuals involved should prepare their reports before leaving the station.

More emphasis on human factors engineering should be placed on the design and layout of control rooms. System identification and location of instruments should be analyzed to improve operator response during an abnormal or emergency operation. 
TMI - 2: TECHNICAL INSIGHTS AFTER THE FACT

\author{
Presentation By \\ Dr. Shepard Bartnoff \\ President, Jersey Central Power \& Light Co. \\ (A Subsidiary of General Public Utilities Corp.)
}

at

Atomic Industrial Forum Workshop

On Reactor Licensing and Safety

New York, New York

May 15, 1979

4-51 
Introduction

The accident at Three Mile Island Unit 2 on March 28, 1979 was an event of singular significance, not only for GPU and the residents of central Pennsylvania, but also for utilities, their customers, and the nuclear industry throughout the entire nation. The accident was a result of a complex combination of equipment malfunctions and human factors, and if it is viewed simply as a matter of operator, equipment, or management failure, its full significance will be lost. We at GPU strongly believe that it is important to understand all of the factors that contributed to this accident, and to the ability of our company, our industry, the government agencies, and the affected population to cope with it, as they did. After experiencing the first accident of this magnitude in the history of the U.S. commercial nuclear power program, we can, with hindsight, identify many areas that should be reviewed in depth, ranging from emergency planning to operator training to reactor plant design philosophy to financial risk diversification. While the list of specific areas is already large and growing, it is probably still too soon after the incident to define and implement specific actions to be taken on a more or less generic basis. The lessons of TMI-2 should be identified and applied after objective review of the accident and its aftermath, with due deliberation, and we should resist pressures to act precipitously.

Consequently, I shall not attempt to present complete answers to the host of questions raised by the TMI-2 accident or detailed recommendations for changes in nuclear plant design, operations, or regulations. I will attempt to present a general perspective on some things that the nuclear utilities and various government agencies should be looking at. These are areas in which, in retrospect, any added available strength or capability would have been very welcome indeed at TMI.

\section{Industry Emergency Support Team}

The TMI-2 accident differed from the popular perception of common accidents because of the extended time it took to achieve a full realization of its scope. In retrospect, this should not be surprising; accidents by definition tend to happen as a result of unforeseen chains of events. One of the lessons of TMI-2 is that no matter how diligently we research potential accident causes and chains of events, some prospect of unpleasant surprises will always remain. Coping with a major emergency at a nuclear power plant requires that resources far beyond those normally available at any plant site be assembled and placed into effective action as quickly as possible. Technical and management support are needed:

a. to assess and understand the status of the plant and how this status came about.

b. to identify and evaluate alternative courses of action to improve the plant status and minimize public risk.

c. to control radioactivity releases and monitor accurately those that are unavoidable. 
d. to control damage to the plant and equipment so that vital components remain available for plant status improvement. and ultimately for plant recovery:

e. to reinforce plant systems and equipment to assure safety on a long term basis.

One of the bright spots in this TMI-2 experience has been the support provided by the entire utility and nuclear industries. A wealth of technical and management talent, as well as vitally needed items of equipment, was provided to GPU voluntarily and quickly. This type of support is vital for rapidly gaining control over emergency situations and for maintaining credibility with the public and confidence that the best talent in the world is on the job to ensure its protection. Consideration should therefore be given to establishing on an industry-wide basis one or more emergency support teams to provide the needed talent in an even shorter time than it took to assemble the TMI team, and to prearrange the organizational and logistical emplacement and direction of such a team at each nuclear plant. This concept would involve:

a. review and, if necessary, extension of each nuclear utility's emergency planning to include an emergency organizational structure into which the support team could be plugged.

b. development of criteria for calling the emergency support team into action.

c. participation by NRC representatives, not only for their technical contributions, but also to ensure complete and thorough communication and expeditious approval for "off-normal" actions and procedures.

d. composition and organization of the team itself. Functional areas that should be represented include plant operations, existing plant systems design including instrumentation and control systems, emergency modifications engineering and construction, plant operations analys is under abnormal conditions, radioactivity contamination and release control, health physics, site logistics, and public information. A separate advisory group may also be desirable. My thought here is that the teams would be assembled with utility and vendor personnel who would undergo periodic training exercises as a team and who would be available on a quick reaction basis in emergencies.

The public information aspect of emergency planning merits careful consideration. A fine balance must be struck between giving out too little information, thereby giving an impression of secrecy, and giving out too much 
Industry Evergency Support Team (Cont inued)

information or giving it out prematurely, and convejing an inage of confusion anc uncertainty. Procedures to disseminate credible and objective information to the public through a single authoritative source, wino is identified at the onset of the emergency, should be developed. The need to dissecinate information sioul $c$ not be allowed to interfere with first priority demancs to maintain the damagec plant in a controlled and safe state.

Development of this Industry Evergency Support Team concept should include consideration of sources of funding for developing and maintaining one or more teams in a more or less standby wode, funding such a team in the event of an actual emergency, and the legal and insurance implications of the use of such teams.

Let me also note that the logistics of assembling and maintaining a large emergency support operation at a relatively remote plant site merit advance consideration by each inoividual nuclear utility. These logistics include temporary working and living accomodations for on-site and off-site personnel, food, transportation, sanitation facilities, and communications (telephones including "hot lines", telecopiers, remote terminals for computers, etc.)

Emergency Eouipment Pool

Any future nuclear plant emergencies will undoubtedly call for rapid on-site availability of equipment that is not normally available or needed on a quick reaction basis. Consideration should be given to developing and maintaining, on an industry-wide basis, a pool of such equipwent that would be useful in a nuclear plant accident to control radioactivity releases, reduce reliance on existing plant equipwent whose reliability may be questionable because of exposure to stressful environmental conditions (heat, humidity, radiation), or substitute for permanent plant equipment to minimize contamination of such equipment. The emergency equipment pool wight include:

a. filters, demineralizers, etc. needed to control radioactivity releases or contamination.

b. pumps, piping, heat exchangers, etc. or packaged emergency cooling systems.

c. Tespirators, air compressors and other equipment needed to support operations in highly contaminated areas.

d. tanks for interim storage. of large volumes of radioactive liquids.

e. containers for radwaste and contaminated material, including used filters, resin, tools and equipment, etc. Both short-term on-site storage followed by off-site disposal and long term on-site storage should be considered in establishing criteria for these containers. 
Emergancy Equipment Pool (Continued)

This equipment should be available in air and truck transportable packages. In addition to determining what kinds of equipment should be available, consideration should be given to how these equipment items might easily be plugged into existing plants. This might mean development of standardized interfacing components at individual plants as well as for the pool equipment.

\section{Operator Training}

The performance of the TMI-2 plant operators has been the subject of much speculation and "Monday morning quarterbacking". Their performance must be viewed in the context of:

1. Ambiguous and contradictory information in the control room relating to pressurizer level and relief valve closure.

2. The experience and training underlying the operators' emphasis on maintaining pressurizer level.

3. The operators' awareness of equipment limitations.

4. The time and opportunity to assimilate large quantities of data.

The operators on duty at the time of the accident are a qualified and competent group. They performed their functions professionally in a period of extreme stress. Our own investigation and the many governmental investigations will ultimately attempt to determine the role of operator performance in this accident, and to provide insight into improvements in operator training. Already suggested possibilities range from enhanced simulator training, particularly involving transients and other "off-normal" events, to greater industry wide sharing of highly experienced operators.

Perhaps greater attention should be paid to ranking the objectives of operator action in order of priority (i.e., accepting minor equipment damage to reduce risk of major damage, accepting major damage to reduce risk of radiation releases, etc.) and ensuring that operators are fully aware of the desired priorities. Training that enhances operator knowledge of plant behavior under abnormal conditions and how the plant will respond to his actions should be particularly valuable. Operator qualifications should include such knowledge and the development of the capability of almost instinctive proper reactions. Advanced simulator training would clearly be valuable here. Each operator should also know enough about the current status of equipment in all portions of the plant with all its interfacing systems so that he can anticipate problem areas and appropriate responses, and understand the full impact of actions that he might take. 
Design Philosophy

Among other things, the TMI-2 incident control and recovery activities will produce lists of things (instruments, plant equipment, alternative syster designs) that we wished we had but didn't, and records of equipment malfunctions and their probable causes. These should be carefully considered in the evaluation of design philosophy to be applied to both existing and new plants. Specific areas that merit attention include:

1. The ability to place a stricken plant into a relatively passive and stable mode with minimal reliance on active components (i.e., pumps, instruments, power supplies, etc.) whose reliability may be seriously degraded by the accident and its aftermath. An example is reliance on natural circulation in.the primary coolant system. An envelope of conditions (decay heat levels, pressures, temperatures, equipment integrity, etc.) under which each particular plant may be safely placed in a natural circulation state might be developed, along with operating procedures and operator training in such procedures. Design modifications to enchance natural circulation capability might also be considered.

2. The ability of electrical components (motors, controls, pressurizer heaters, instruments), pump seals, and other equipment to survive under post accident conditions potentially involving abnormally high temperatures, humidity levels, radiation levels, actual flooding, and emergency usage. In many cases, this ability could be enhanced by relocation to places outside of areas that might be prone to flooding or collection of highly radioactive liquids or gases, or by hermetic sealing. In other cases, additional redundancy may be desirable.

3. Control room improvements to assist operators in understanding what's really happening during a transient. This might include displays that call attention to or resolve apparent conflicts between what different instruments are telling the operator, and signal a priority on where the operator's attention should be directed.

4. Improved ability to assess equipment status and environmental conditions in areas of the plant where post accident access may be prohibited by high radiation levels. Examples include ability to extract primary coolant samples including pressurized samples for dissolved gas analysis, measurement of radiation levels within containment and in other areas where primary coolant dispersal could occur, and measurement of water level within containment. Improved methods of ascertaining hydrogen gas concentration and explosion potential in. the containment atmosphere would also be very helpful. 
Design Philosophy (Continued)

5. Facilitation of emergency modifications, such as special interface provisions for emergency closed loop cooling systems or other pieces of equipment whose temporary installation could reduce the risk of radiation releases and contamination of permanent plant equipment.

Conclusions

The term "learning experience" doesn't begin to describe the TMI-2 accident from GPU's prospective. Nobody can afford such expensive "lessons", and this may be the most important lesson of all. Insights gained from comprehensive review of this accident and its aftermath will need to be implemented in order to reduce the risk and consequences of a future accident of this magnitude. However, these insights must be applied reflectively, not reflexively. Wholesale plant modifications, hardware additions, changes in operational procedures, etc. may not provide improvement in real safety. We need to remember that every new piece of hardware brings with it new failure modes that must be analyzed for protection adequacy. Existing designs and design philosophies should not be discarded until we are sure that the changes offer real improvements.

Finally, the question arises, under what conditions of financial risk should any utility undertake or continue to operate a nuclear plant. If our society is to reap the very real benefits of nuclear power, mechanisms for ameliorating financial risk through regulatory actions or methods for diversifying risk through industry action will be necessary. The latter area might include mutual insurance pools that cover replacement energy costs as well as physical damage costs, or joint ownership of many nuclear plants by many utilities, perhaps through formation and joint ownership of nuclear generating companies. This concept would not only spread the risk of a major accident over multiple companies and a large assets base, but would also facilitate economical assembly of the technical and material resources needed to support safer operation of these nuclear plants.

Two things are needed if nuclear power is to recover successfully from TMI-2; a willingness on the part of our. industry to seek out and apply the lessons of this incident, and a recognition on the part of the public and the regulatory authorities that it is in everyone's best interest to maintain a viable nuclear program and viable utilities to implement this program. Let us hope that both of these will be forthcoming. 
NRR Lessons Learned Task Forcè

Short-Term Recommendations

TITLE: Capability to Install Hydrogen Recombiner at Each Light Water Nuclear Power Plant (Section 2. i.5.c)

\section{1.. INTRODUCTION}

The current design basis for combustible gas control. in the containment building is given in 10 CFR Part 50.44, Regulatory Guide 1.7, Revision 1, and Standard Review Plan Section 6.2.5. Provisions are required to deal with quantities of hydrogen that may be generated during a LOCA accident from (a) clad metal-water reaction, (b) corrosion of materials inside containment, and (c) radiolytic decomposition of water. The current regulations in 10 CFR 50.44 require that a plant be inerted unless it can accommodate hydrogen that may be released during a LOCA. Furthermore, the provisions of 10 CFR $50.44(d)(2),(e),(f)$, and $(g)$ require that light water reactor plants, whose notice of hearing for construction permit applications occurred on or after November 5, 1970, install a recombiner system for long-term post-accident combustible gas control (i.e., hydrogen). For plants whose notice of hearing on applications for construction permits occurred prior to November 5, 1970, combustible gas control measures include a purge and/or repressurization system. In this case, the design basis for the control system would lead to a release of the containment atmosphere for long-term hydrogen control in a matter of weeks to several months, depending upon the containment design. The purpose of the hydrogen recombiner or purge and/or repressurization systems is to deal with the long-term post-accident generation of hydrogen from all sources.

The experience at TMI-2 emphasized the benefit of having a recombiner to cope with the hydrogen generated during the initial core uncovery period as well as that generated during the subsequent post-accident radiolysis of water or corrosion in the reactor vessel and containment. Recombiners of the type currently provided are not capable of preventing the 28 psi (pounds per square inch) containment pressure spike attributed to combustion of hydrogen in the containment building at TMI-2. However, had there not been provisions to use a recombiner at TMI-2, it is possible that for a slightly different accident scenario the containment atmosphere would have required venting for hydrogen control in the week following the accident. It is also possible that the containment may have had to be pressurized with nitrogen over the long term to reduce the hydrogen concentration. Thus, a question. for early resolution is whether there should be, in all operating plants, an ability for post-accident hydrogen control other than venting. As previously stated, older plants are not required to have recombiners; thus, if the accjent had occurred at another plant, it is possible that venting would have been necessary.

The plants that are not required to have recombiners because of the November 5 , 1970, cutoff date include some presently operating:plants and some plants that will soon begin operation that experienced delays in construction. Table A-1 lists about 60 plants without recombiners. Some older plants have provided recombiners on their own, e.g., Ginna and Calvert Cliffs Units 1 and 2.

$$
4-58
$$


It is recommended by a minority of the Task Force that all plants should incorporate the capabijity to install a hydrogen recombiner. The majority. view is that imposition of an immediate requirement for the use of recombiners at every plant is premature and deserves further evaluation in light of more general questions involving the degraded core consequences experienced at TMI-2.

\section{DISCUSSION}

\section{Minority View}

The safety significance of this recommendation is that a recombiner system can control hydrogen buildup in the containment without venting of the containment. atmosphere to the environment. A decision was made at TMI-2 to not release the containment atmosphere to the environment." A number of factors lead to this decision; i.e., the availability of recombiners, the apparent low concertration of hydrogen after the 28 psi pressure spike, and the desire to keep releases to the environment at a minimum. This last factor contradicts the basis for previous NRC rulemaking decisions to not require recombiners at older plants.

The use of a recombiner in the event of a LOCA may not always be required. In some cases (such as a remote site), a purge and repressurization system may be adequate; i.e., purposeful offsite releases do not affect large populations. However, because recombiner technology is well established and is not very costly, the added capability to augment the defense-in-depth principle by providing options to venting for hydrogen control is a prudent public safety measure.

It is the minority viewpoint of the Lessons Learned Task Force that it would be prudent to require that the capability to install a recombiner be backfit to provide means other than venting for control of hydrogen in the containment. This recommendation derives from the premise that the short-term actions of NRC should assure that safety features are available to mitigate the consequences of events similar to TMI-2 that could have the potential for appreciable offsite releases.

Majority View

The hydrogen problem at TMI-2 was a short-term situation and fortunately was safely relieved by the apparent combustion of hydrogen in the containment building. The source of this hydrogen was the metal-water reaction of a sizeable fraction of the zircalloy in the core. This amount of hydrogen generation was well in excess of the amount required by the Commission regulations as a design basis for any type of post-accident combustible gas control system.

The basic parameters that establish the capacity of post-accident combustible gas control systems are the long-term decomposition of water due to fission product energy and the corrosion of metals exposed to the chemical action of - containment atmosphere and containment sprays. As a resuit, post-accident combustible gas control systems are designed to process containment air at the 
typical rate of 50 to 100 SCFM and are not required to operate until about a week (minimum) to several months (maximum) after the design basis accident. The usual parameter used to initiate recombiner operation is a measured containment hydrogen concentration of'about 3 to 3.5 volumetric percent hydrogen. The hydrogen recombiner at TMI-2 was put into operation at a time when the measured hydrogen concentration was approximately 2 percent. Current estimates of the maximum hydrogen remaining in solution in the reactor coolant indicate that, even if it were all released to the containment, the hydrogen concentration would not have exceeded 3 percent and would more probably have been less than 2.5 percent. However, site personnel wanted to empty the two waste gas decay tanks back into the containment to try to stop a suspected leak in the waste gas compressor suction line. Because the hydrogen content of the waste gas decay tanks was unknown, site operations personnel wanted the recombiner in operation prior to the slow discharge of the waste gas tanks into the containment. After the recombiners were placed in service, the waste gas decay tanks were only partially emptied into the containment and the repair of the compressor suction line was not attempted.

Information from the work performed by Knolls Atomic Power Laboratory (KAPL) for NRR in the days following the accident indicated that radiolysis should not be adding free hydrogen to the containment. This was attributed to gamma-induced recombinaton of any oxygen formed due to radiolysis of water in a water system rich in dissolved hydrogen, as was the case at TMI- 2 . In addition, due to the low containment temperatures and the negligible amount of caustic containment sprays the containment spray was operated for only 6 minutes. There should not have been any appreciable generation of hydrogen due to the corrosion of zinc and aluminum. Thus, information was available to indicate that the overall hydrogen concentration in the containment was well below and not likely to approach the design set point for recombiner operation for some appreciable period of time unless the decay tanks were emptied into the containment. An increase in hydrogen over the long term could have been attributed to radiolysis effects; however, actuation of the recombiner to remove the hydrogen prevented a quantitative determination of that hydrogen source.

The course of events at TMI- 2 with respect to hydrogen production and control in containment has indicated a need for thorough reconsideration of the Commission's design basis for combustible gas control systems. This should include both a re-examination of the reactor system effects (i.e., coupling the ECCS evaluation and the assumption of hydrogen produced by metal-water reaction) and the acceptability of 10 CFR Part 100 guidelines for evaluation of offsite doses from purposeful. releases from the containment. In general, the accident at TMI-2 raises the question of whether the short-term design basis for post-accident combustible gas control systems (metal-water reaction) is underestimated and the long-term design basis (radiolysis and corrosion) is overestimated, resulting in a hydrogen recombiner design that is not capable of providing short-term protection and may not have been needed in the long term.

Because of these considerations, it is the conclusion of the majority of the Lessons Learned Task. Force that provisions for the post-accident installation of recombiners should not be required as a short-term action. Such consideration should be part of the long-term reconsideration of the design basis for combustible gas control systems. 
3. POSITION (Minority View)

1. All licensees of light water reactor plants shall have the capability to obtain and install recombiners in their. plants within a few days following an accident if containment access is impaired and if such a system is needed for long-term post-accident combustible gas control.

2. . The procedures and bases upon which the recombiners would be used on all plants. should be the subject of a review by the licensees in considering sheilding requirements and personnel exposure limitations as demonstrated to be necessary in the case of TMI-2. 
Appendix A Synopsis of Studies in Progress Relative to TMI

Considerable time and effort was initially expended attempting to establish "who's doing what" in relation to TMI. An early attempt at synopsizing this information was in fact presented to Sandia during the course of the work. However, it became increasingly apparent that given the multitide of entities involved in review, each with multiple objectives and task forces, additional effort along these lines would not be productive. This effort did accomplish two objectives, however.

1. Provided an overview of which entities were concentrating effort and the magnitude of that effort, and

2. Idenfitied where documentation, findings and study results could be obtained or were scheduled for issuance.

Table A-1 presents a compilitation of organizations and entities related to TMI. This information has been pieced together from many separate sources, many of which are probably inaccurate or outdated. However; if reviewed and utilized with this limitation in mind, it may be useful to the reader. 
Table A-l

TMI-Related tasks and Activities in Progress

\section{Nuclear Regulatory Commission}

Discussion: The NRC office of the Executive Director for Operations prepared a catalog of over 130 TMI-related NRC activities under way in June. The following synopsizes the purpose of these tasks by major NRC offices engaged in the work.

\section{Office of Inspection and Enforcement}

Nine activities including NUREG-0600.preparation, IE Bulletin issuance and evaluation, TMI on-site support, NRC operations center design and modification, telephone and other communications, rad assistance and emergency response and resident inspection program activities.

Office of Material Safety and Safeguards

Seven activities including TMI-2 criticality calculations, TMI-2 rad waste, fuel cycle meterial safety contingency plans, emergency planning, physical security and vital fuel cycle safety system modeling.

\section{Office of Nuclear Reactor Regulation}

Four activities including TMI site support, licensing and operation of reactors, NUREG-0578 and financial protection. 


\section{Office of Nuclear Regulatory Research}

Thirty-two activities including NUREG-0557, core status analysis, containment venting, conceptual design, hydrogen content in water and environment, interpretation of instrumentation, review of relief valve testing facilities, simulation of initial transient, radioiodine analysis, probabilistic analysis, social-economic analysis, charcoal filter performance evaluation, LOFT small break tests, TRAC calculations, define requalification requirements, alternate relief valve operation, gas venting from coolant system vessel level, instrumentation, water availability during accident, semi-scale tests, TMI site assistance, $\mathrm{H}_{2}$ source terms and problems.

Office of Standards Development

Four activities including NUREG-0558, occupational health study, state and federal study assistance, and reordering of standards priorities.

Office of Administration

Approximately 40 activities, not segregated.

Office of Executive Legal Director

Ten activities related to legal aspects

Office of State Programs

Twelve activities, principally focused upon emergency planning, preparedness and radiation monitoring. 
Other

Approximately 14 miscellaneous programs and activities involving international programs, management and program analysis, general council policy evaluation and the Commissioners' special study group.

ACRS

Ongoing subcommittee and full committee activities.

\section{Federal Legislative Studies and Investigations}

Sources indicate that approximately 18 distinct House and Senate committees are investigating or reviewing TMI-2 accident-related material. Some of the more pertinent are:

1. House Subcommittee on Environment, Energy and Natural Resources

2. Senate Nuclear Regulatory Subcommittee

3. House Subcommittee on Energy and the Environment

4. House Subcommittee on Energy, Nuclear Proliferation and Federal Services

5. House Energy Research \& Production Subcommittee

6. Senate Subcomittee on. Health

7. Senate Energy Subcommittee of Government Affairs Committee

8. Energy Subcommittee of the Joint Economic Committee

\section{Presidential Inquiry Commission}

Report due October 25, 1979 - Investigation is one of largest in progress. 
Industry

Industry organizations involved in TMI activities:

1. NSAC (EPRI, includes many tasks per Section 2.2)

2. NSSS Vendors (GE, CE, B\&W, Westinghouse)

3. Individual Utility task forces

4. Metropolitan Edison

5. TVA

6. ERRI - Nuclear Operations Institute

7. EEI - Scientific Review Board

State Investigations

1. Pennsylvania - many, including rate hearings

2. California

3. Oregon

4. Many other states involved in emergency planning

International

1. IAEA

2. France

3. Germany

4. Sweden

5. United Kingdom

6. Canada 
Other Federal Governmental Agencies

i. $\mathrm{GAO}$

2. $\mathrm{HEW}$

3. Interior

4. Department of Energy 
DISTRIBUTION :

TID-4500 - UC-78 (197 copies)

J. H. Carlson

Safety \& Quality Assurance Branch

U. S. Department of Energy

Division of Nuclear Power Development

Mail Station B-107

Washington; DC 20545

R. Disalvo

Probabilistic Analysis Branch

Mail stop 3100

U. S. Nuclear Regulatory Commission

Washington, DC 20555

M. P. Norin, Chief (5)

Quality Assurance, Standards \&

Operational Safety Branch

Mail Station B-107, Room E459

U. S. Department of Energy

Germantown, MD 20767

A. J. Pressesky

Division of Nuclear Power Development

ET -760

U. S. Department of Energy

Washington, DC 20545

T. E. Murley, Director

Division of Reactor Safety Research Mail stop 1130ss

U. S. Nuclear Regulatory Commission

Washington, DC 20555

J. A. Morley

Special Programs Division

Albuquerque Operations office

U. S. Department of Energy

Albuquerque, NM 37185

G. R. Burdick

Idaho National Engineering Laboratory EG\&G Idaho, Inc.

550 Second Street

Idaho Falls, ID 83501

D. M. Rasmuson

Idaho National Engineering Laboratory

EG\&G Idaho, Inc.

550 Second street

Idaho Falls, ID 83501 
Distribution (cont'd):

D. Okrent

University of California

405 Hilgard Avenue

Los Angeles, CA 90024

W. B. Lowenstein, Director

Nuclear Safety \& Analysis

Electric Power Research Institute

3412 Hillview Avenue

Palo Alto, CA 94303

L. L. Conradi

Energy Incorporated

Suite 220

515 West Harrison

Kent, WA 98031

J. E. Ward, Vice President

Sargent \& Lundy Inc.

Suite 920

6151 West Century Blvd.

Los Angeles, CA 90045

2165 J. E. Gover

4400 A. W. Snyder

4440 G. R. Otey

4442. W. A. Von Riesemann

4443 A. R. DuCharme

4443 H. G. Jones (45).

4443 B. J. Roscoe

4443 J. I. Sprung

4443 P. O. Strom

4443 P. Yarrington

8266 E. A. Aas

3141 T. L. Werner

3151

W. L. Garner

For DOE/TIC (Unlimited Release) 